\title{
Geologia, petrografia e geoquímica dos granitoides arqueanos de alto magnésio da região de Água Azul do Norte, porção sul do Domínio Carajás, Pará Geology, petrography and geochemistry of Archaean high-magnesium granitoids of the Agua Azul do Norte area, southern Carajás Domain, Pará
}

\author{
Eleilson Oliveira Gabriel', Davis Carvalho de Oliveiral \\ Universidade Federal do Pará. Belém, Pará, Brasil
}

\begin{abstract}
Resumo: Os granitoides mesoarqueanos de alto Mg que afloram a nordeste de Água Azul do Norte ocorrem como dois corpos alongados na direção E-W. Correspondem a intrusões compostas por granodioritos e tonalitos porfiríticos miloníticos, com anfibólio, biotita e epidoto como principais minerais máficos. Geoquimicamente são caracterizados pelo fracionamento de $\mathrm{CaO}, \mathrm{Fe}_{2} \mathrm{O}_{3}, \mathrm{MgO}, \mathrm{TiO}_{2}$ e $\mathrm{Al}_{2} \mathrm{O}_{3}$, e aumento de $\mathrm{K}_{2} \mathrm{O}$ e da razão $\mathrm{K}_{2} \mathrm{O} / \mathrm{Na}_{2} \mathrm{O}$ da fácies menos evoluída, com anfibólio, em direção à fácies mais evoluída, com biotita. Sr, Y, Zr, \#Mg, Ni, Cr e Sr/Ba decrescem, enquanto que Rb, Ba e Rb/Sr aumentam no sentido das rochas mais diferenciadas. Os padrões de elementos terras raras (ETR) mostram importante fracionamento de elementos terras raras pesados (ETRP) com moderada razão $\mathrm{La}_{N} / \mathrm{Yb}_{N}$ e anomalia de Eu ausente ou pouco expressiva. As rochas estudadas são predominantemente metaluminosas, com altos valores de \#Mg, $\mathrm{Cr}$ e Ni, distintas geoquimicamente das séries cálcio-alcalinas de margens continentais ativas e de associações tonalito-trondhjemitogranodioritos (TTG) e leucogranodioritos arqueanos. As afinidades petrográficas e geoquímicas existentes entre as rochas estudadas e as principais ocorrências de granitoides de alto-Mg da Província Carajás sugerem que estas podem fazer parte de uma suíte magmática análoga, até então não identificada nesta parte da Província.
\end{abstract}

Palavras-chave: Granitoides. Sanukitoides. Arqueano. Carajás. Cráton Amazônico.

Abstract: The Mesoarchaean high-Mg granitoids that outcrop in the Água Azul do Norte area occur as two elongated and deformed bodies in the E-W direction. They are bodies composed of mylonitic porphyritic granodiorites and tonalites, with amphibole, biotite, and epidote as the main mafic minerals. Their evolution is marked by fractionation of $\mathrm{CaO}$, $\mathrm{Fe}_{2} \mathrm{O}_{3}, \mathrm{MgO}, \mathrm{TiO}_{2}$, and $\mathrm{Al}_{2} \mathrm{O}_{3}$, an increase of $\mathrm{K}_{2} \mathrm{O}$ and $\mathrm{K}, \mathrm{O} / \mathrm{Na}_{2} \mathrm{O}$ ratio from the amphibole-rich facies toward the more evolved facies with biotite. Sr, Y, Zr, \#Mg, Ni, Cr, and $\mathrm{Sr} / \mathrm{Ba}$ decrease, whereas Rb, Ba, and Rb/Sr increase towards the more differentiated facies. The rare earth elements (REE) patterns show a significant fractionation of heavy rare earth elements (HREE) with moderate $\mathrm{La}_{N} / \mathrm{Yb}_{N}$ ratio and discrete anomalies of Eu. The studied rocks are predominantly metaluminous, with high values of $\mathrm{AMg}, \mathrm{Cr}$, and $\mathrm{Ni}$, distinct geochemically from calc-alkaline series of active continental margins and Archaean TTG suites and leucogranodiorites. The petrographic and geochemical affinity between the studied rocks and classical occurrences of high-Mg granitoids suggest that they can be part of a similar magmatic suite, identified for the first time in this part of the Carajás Province.

Keywords: Granitoids. Sanukitoids. Archaean. Carajás. Amazonian craton.

GABRIEL, E. O. \& D. C. OLIVEIRA, 2014. Geologia, petrografia e geoquímica dos granitoides arqueanos de alto magnésio da região de Água Azul do Norte, porção sul do Domínio Carajás, Pará. Boletim do Museu Paraense Emílio Goeldi. Ciências Naturais 9(3): $533-564$. Autor para correspondência: Eleilson Oliveira Gabriel. Universidade Federal do Pará. Instituto de Geociências. Av. Augusto Corrêa, 1 - Guamá. Belém, PA, Brasil. CEP 66075-100 (eleilson@ufpa.br).

Recebido em 03/05/2013

Aprovado em 13/05/2014

Responsabilidade editorial: Fernando Jacques Althoff

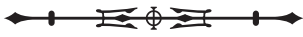




\section{INTRODUÇÃO}

A porção nordeste do município de Água Azul do Norte está inserida na Província Amazônia Central (Figura 1A; Tassinari \& Macambira, 1999) ou Carajás (Santos et al., 2000), mais precisamente no segmento sul do Domínio Carajás, borda sudeste do Cráton Amazônico (Almeida et al., 1981). Segundo D. C. Oliveira et al. (2010), essa região é marcada pela ocorrência expressiva de granitoides variavelmente deformados e recristalizados, gerados no Mesoarqueano ( 2,88 Ga) e Neoarqueano ( 2,75 Ga), e inseridos até então no Complexo Xingu (Vasquez et al., 2008), o qual agrupa granitoides indiferenciados, de natureza e idades ainda indefinidas. Embora diversos trabalhos tenham sido realizados nessa parte do cráton ao longo dos últimos 30 anos, esse complexo continua sendo a unidade de maior expressão areal. Trabalhos recentes de mapeamento geológico das rochas do Complexo Xingu que afloram entre a cidade de Água Azul do Norte e a Vila Nova Canadá permitiram individualizar grande variedade de granodioritos e tonalitos, e a ocorrência expressiva de granitoides porfiríticos enriquecidos em anfibólio (Gabriel et al., 2010; Sousa et al., 2010; D. C. Oliveira et al., 2010).

A área de interesse do presente estudo é delimitada a sul pela faixa de greenstone belt de Sapucaia e a nordeste pelas rochas máficas do Diopsídio-Norito Pium e das associadas à Suíte Plaquê. Nesta região, são descritas expressivas ocorrências de granodioritos com anfibólio, não se sabendo, porém, se os mesmos eram ou não equivalentes aos sanukitoides registrados no Domínio Rio Maria ou em outros crátons, porque não se dispunha da caracterização petrográfica e geoquímica detalhada dessas rochas. Até o presente momento, ainda não haviam sido reconhecidas ocorrências de sanukitoides no Domínio Carajás, embora sejam relativamente abundantes no Domínio Rio Maria (M. A. Oliveira et al., 2009, 2010). Apesar do avanço do conhecimento na área estudada, ainda se fazem necessários estudos aprofundados para individualização mais precisa desses litotipos. Sendo assim, o presente trabalho objetiva a caracterização geológica, petrográfica e geoquímica dos granitoides com anfibólio da porção nordeste de Água Azul do Norte. Definindose sua natureza e comparando-os com rochas similares estudadas em outros crátons e nos demais domínios da Província Carajás, pretende-se ainda contribuir para o melhor entendimento do quadro geológico da região.

\section{GEOLOGIA REGIONAL}

A região NE de Água Azul do Norte está inserida no segmento situado entre o Terreno Granito-Greenstone de Rio Maria e a Bacia Carajás (Figura 1B), definido informalmente como Domínio de Transição por Dall'Agnol et al. (1997). Vasquez et al. (2008), ao revisarem a geologia do estado do Pará, dividiram a Província Carajás em Domínio Carajás e Domínio Rio Maria. Isso levou Feio et al. (2012) a redefinir o Domínio de Transição como Subdomínio de Transição, correspondente à porção sul do Domínio Carajás. Ele se estende desde a borda sul da Bacia Carajás até o norte de Xinguara, prolongando-se lateralmente por Água Azul do Norte, Tucumã e São Félix do Xingu. É limitado a leste pelas sequências supracrustais do Cinturão Araguaia e a oeste pelas vulcânicas do Supergrupo Uatumã.

O conhecimento sobre a geologia do Subdomínio de Transição é ainda limitado, uma vez que o mesmo somente veio a ganhar a devida atenção a partir da última década (ver Dall'Agnol et al., 2013). A área de Canaã dos Carajás, situada a NE da área estudada, vem recebendo uma série de estudos petrológicos, geocronológicos, metalogenéticos e tectono-estruturais, que contribuíram para o melhor entendimento desse segmento. Em um cenário geológico atualizado, a porção sul do Domínio Carajás é formada principalmente por: 1) metavulcânicas máficas afins dos greenstone belts; 2) rochas de alto grau metamórfico do Ortogranulito Chicrim-Cateté (Vasquez et al., 2008) juntamente com as rochas gabroicas da série charnockítica do Diopsídio-Norito Pium (Hirata et al., 1982; Ricci \& Carvalho, 2006; R. D. Santos et al., 2013), que representam, de acordo com as idades obtidas por 


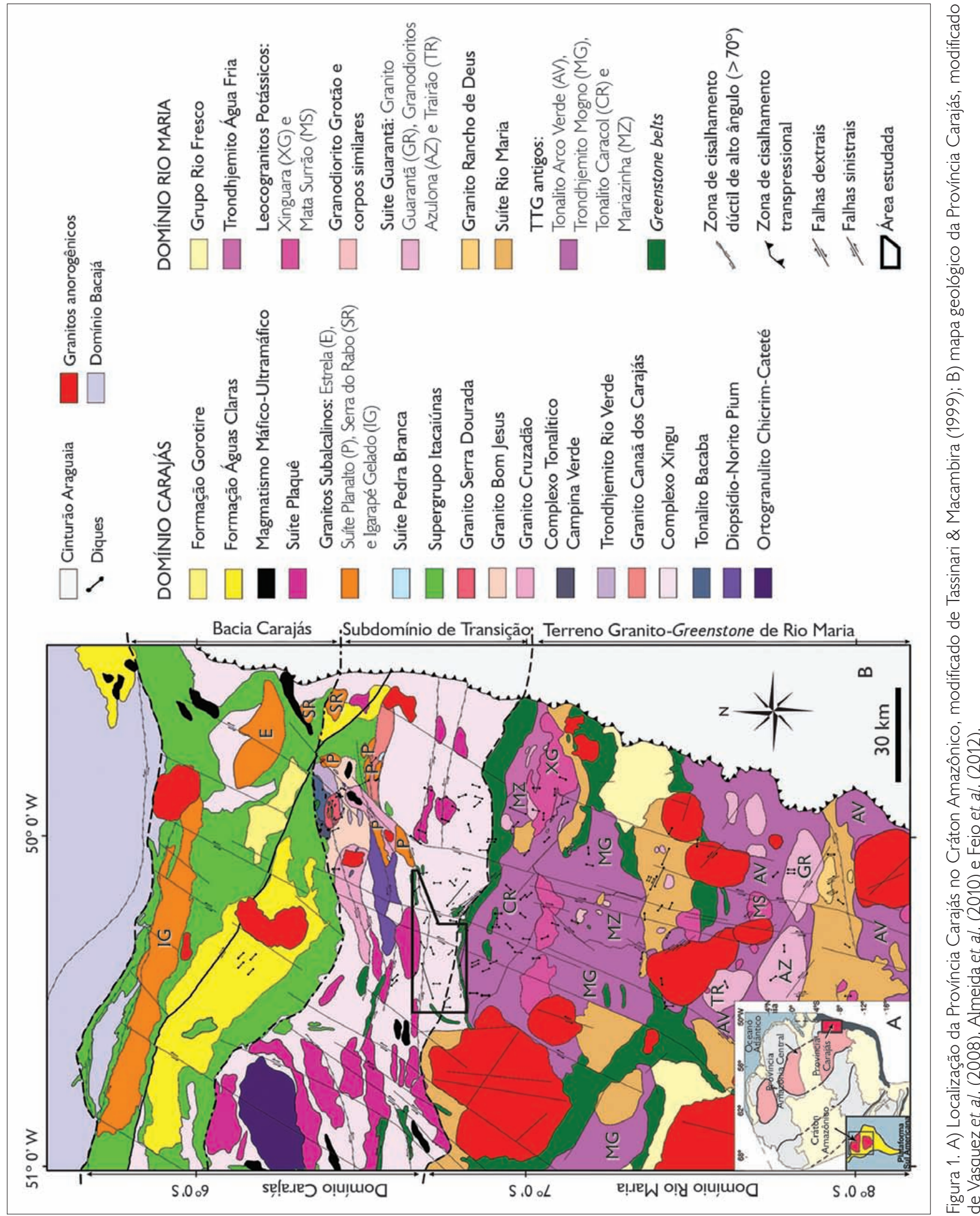


Pidgeon et al. (2000), o embasamento mesoarqueano de 3,0 Ga metamorfizado em 2,8 Ga. No entanto, P. A. Santos et al. (2013) obtiveram idade Pb-Pb em zircão de 2746 $\pm 1 \mathrm{Ma}$, que foi considerada como de cristalização das rochas do Diopsídio-Norito Pium, sugerindo a formação simultânea dessas rochas com as suítes magmáticas neoarqueanas do Domínio Carajás; 3) associações de granitoides mesoarqueanos cujas idades variam entre 2,96 e 2,83 Ga, que, por ordem de formação, são representados pelo Tonalito Bacaba (Moreto et al., 2011), Granito Canaã dos Carajás, Trondhjemito Rio Verde, Complexo Tonalítico Campina Verde e granitos Cruzadão, Bom Jesus e Serra Dourada (Feio et al., 2013), além dos ortognaisses e granitoides do Complexo Xingu, de 2,97 a 2,85 Ga (Silva et al., 1974; DOCEGEO, 1988; Machado et al., 1991; Avelar et al., 1999); 4) granitoides neoarqueanos de 2,75 a 2,73 Ga das suítes Plaquê (Araújo et al., 1988; Avelar et al., 1999), Planalto (Huhn et al., 1999; D. C. Oliveira et al., 2010; Feio et al., 2013) e Pedra Branca (Sardinha et al., 2004; Gomes \& Dall'Agnol, 2007; Feio et al., 2012); 5) magmatismo máfico-ultramáfico da Suíte Cateté (Macambira \& Vale, 1997; Lafon et al., 2000); 6) granito anorogênico paleoproterozoico Rio Branco (Dall'Agnol et al., 2005; P. A. Santos et al., 2013) e enxame de diques de composição predominantemente máfica.

\section{GRANITOIDES ARQUEANOS DE ALTO MAGNÉSIO (SUÍTES SANUKITOIDES)}

Granitoides com alto magnésio acham-se expostos em vários crátons do mundo, sendo muito comuns no final do Arqueano. Shirey \& Hanson (1984) sugeriram a expressão 'suíte sanukitoide' para denominar todas as variedades de rochas ígneas arqueanas, plutônicas ou vulcânicas, que apresentam características geoquímicas similares a andesitos com altos teores de magnésio (sanukitos) do Mioceno, ocorrentes no cinturão vulcânico Setouchi do Japão (Tatsumi \& Ishizaka, 1982). Koto (1916) originalmente introduziu o termo 'sanukitoide' para se referir a todas as modificações texturais de magmas do tipo sanukito. Sanukitoides arqueanos apresentam características geoquímicas contraditórias, ora similares às das rochas magmáticas de origem mantélica, ora daquelas derivadas da fusão de crosta. São enriquecidos nos elementos compatíveis $\mathrm{Mg}$, $\mathrm{Ni}$ e $\mathrm{Cr}$, assim como nos elementos incompatíveis $\mathrm{Ba}, \mathrm{Sr}, \mathrm{K}$ (LILE) e $\mathrm{P}$ e elementos terras raras leves (ETRL). Stern et al. (1989) definiram sanukitoides como rochas ígneas primitivas de composição intermediária, com $\mathrm{SiO}_{2}$ entre 55-60\%, \#Mg > 0.6, Ni e Cr > 100 ppm, $\mathrm{K}_{2} \mathrm{O}>1 \%$, Sr e Ba $>600$ ppm e grande enriquecimento de ETRL, com inexpressiva anomalia de Eu. Mais recentemente, os sanukitoides arqueanos foram definidos simplesmente como uma série de granitoides com alto conteúdo de elementos compatíveis e incompatíveis a dado conteúdo de $\mathrm{SiO}_{2}$ (Halla, 2005).

As suítes ou séries sanukitoides são classicamente compostas por dioritos, monzodioritos, monzonitos, quartzo-dioritos e quartzo-monzodioritos, com granodioritos e monzogranitos relacionados como membros derivados e mais evoluídos que não possuem a mesma composição geoquímica, mas apresentam comportamentos geoquímicos similares. Sanukitoides ocorrem como intrusões tardi- a pós-tectônicas (Stern et al., 1989), seccionando associações TTG em terrenos granito-greenstone arqueanos, em geral não se associando temporalmente com as primeiras (Heilimo et al., 2010). Sanukitoides foram reconhecidos em vários crátons, como na Província Superior (Shirey \& Hanson, 1984; Stern et al., 1989; Stern \& Hanson, 1991; Stevenson et al., 1999), Província Karelian do Escudo Báltico (Lobach-Zhuchenko et al., 2000; Kovalenko et al., 2005; Halla, 2005; Heilimo et al., 2010), Cráton Dharwar (Sarvothaman, 2001; Moyen et al., 2003), Domínio Rio Maria da Província Carajás (M. A. Oliveira et al., 2009, 2010, 2011), Cráton Zimbábue (Kampunzu et al., 2003), Groenlândia (Steenfelt et al., 2005), Cráton Pilbara (Smithies \& Champion, 2000) e Cráton Yilgarn (Cassidy et al., 1991; Wiedenbeck \& Watkins, 1993).

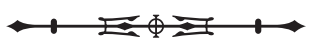


A origem dos sanukitoides é ainda assunto de debate, sendo o modelo mais disseminado o do processo de geração em dois estágios. No primeiro estágio, fluidos e/ou magmas do tipo TTG (Evans \& Hanson, 1997; Smithies \& Champion, 2000), oriundos de crosta oceânica subductante e possivelmente sedimentos (Halla, 2005), contaminam/metassomatizam e enriquecem a cunha do manto sobrejacente. No segundo estágio, a cunha do manto metassomatizado é fundida em um evento termal no final da subducção (Stern \& Hanson, 1991; Kovalenko et al., 2005; Oliveira et al., 2011).

\section{CARACTERIZAÇÃO DOS GRANITOIDES DE ALTO MAGNÉSIO DE ÁGUA AZUL DO NORTE}

\section{GEOLOGIA}

Existem pelo menos dois períodos distintos de geração de rochas na porção nordeste do município de Água Azul do Norte (D. C. Oliveira et al., 2010): 1) granitoides mesoarqueanos de 2,88 a 2,85 Ga, que são biotitaanfibólio-granodioritos porfiríticos, associações tonalíticotrondhjemíticas, biotita-granitos e leucogranitos; e 2) granitoides neoarqueanos de 2,75 a 2,73 Ga, que são biotita-granodioritos heterogranulares e hiperstêniotrondhjemitos pertencentes à série charnockítica. Essas rochas foram desmembradas do Complexo Xingu, e a atual pesquisa conseguiu avançar no conhecimento dos biotita-anfibólio-granodioritos porfiríticos, caracterizados inicialmente por Gabriel et al. (2010) e Sousa et al. (2010), utilizando-se, para isso, novos dados de campo, petrográficos e geoquímicos. Como resultado, foram individualizados, nas proximidades dos rios homônimos, os plútons dos granodioritos Água Azul (GAA) e Água Limpa (GAL), foco do presente trabalho, além de ocorrências significativas de trondhjemitos e leucogranodioritos-granitos ainda pouco estudados (Figura 2).

Essas unidades formam corpos dispostos ao longo de duas faixas E-W, localizadas nos extremos sul e norte da área e que se estendem por pouco mais de 20 e 40 km, respectivamente (Figura 2). O GAA ocorre ao sul e corta o greenstone belt Sapucaia (Figura 3B), enquanto o GAL é seccionado ao norte pelo batólito leucogranítico Boa Sorte (Figura 2; Rodrigues et al., 2010). Esses granitoides são separados por um corpo trondhjemítico ainda não estudado e que ocupa toda a parte central da área, seccionados ainda por stocks de leucogranodioritosgranitos e diques máficos de pequenas dimensões. Idades Pb-Pb em zircão de $2884 \pm$ 1,7 Ma e $2879 \pm$ 1,3 Ma para - GAA e GAL, respectivamente, foram obtidas por Gabriel et al. (2010) e Sousa et al. (2010).

O GAA e o GAL afloram em grandes lajeiros (Figura 3A) ou em blocos rolados, compostos por rochas de coloração cinza-escuro, com foliação pronunciada. A foliação geral segue o trend regional E-W, com mergulhos moderados a fortes $\left(40^{\circ}\right.$ a $\left.89^{\circ}\right)$ e caimentos para norte, que evoluem localmente, onde as taxas de recristalização foram mais intensas, para bandamento composicional/xistosidade difuso. Lineações de estiramento mineral (quartzo) podem ocorrer junto à foliação. Sua obliquidade varia de inclinada a perpendicular à direção da foliação. A presença de enclaves máficos, orientados ou não segundo o plano da foliação e que podem estar rotacionados em cinemática sinistral, é uma feição marcante nos dois corpos (Figuras 3C e 3D).

Esses granitoides mostram-se variavelmente deformados e afetados por extensas zonas de cisalhamento de cinemática sinistral e direção geral E-W. O caimento da lineação mineral sugere que ocorreu transpressão. Imagens por sensores remotos, aliadas às anomalias gamaespectrométricas do canal do tório e magnéticas da área estudada, indicam a presença de pelo menos uma zona de cisalhamento cortando cada um dos sanukitoides estudados, que chegam a atingir extensões de aproximadamente $25 \mathrm{~km}$ (Figura 2). Não foi possível obter em campo informações nítidas quanto à largura dessas zonas, uma vez que todos os pontos observados exibem deformação generalizada. No entanto, levando em consideração os dados de campo, aliados às imagens dos sensores, estima-se que essas zonas de cisalhamento 


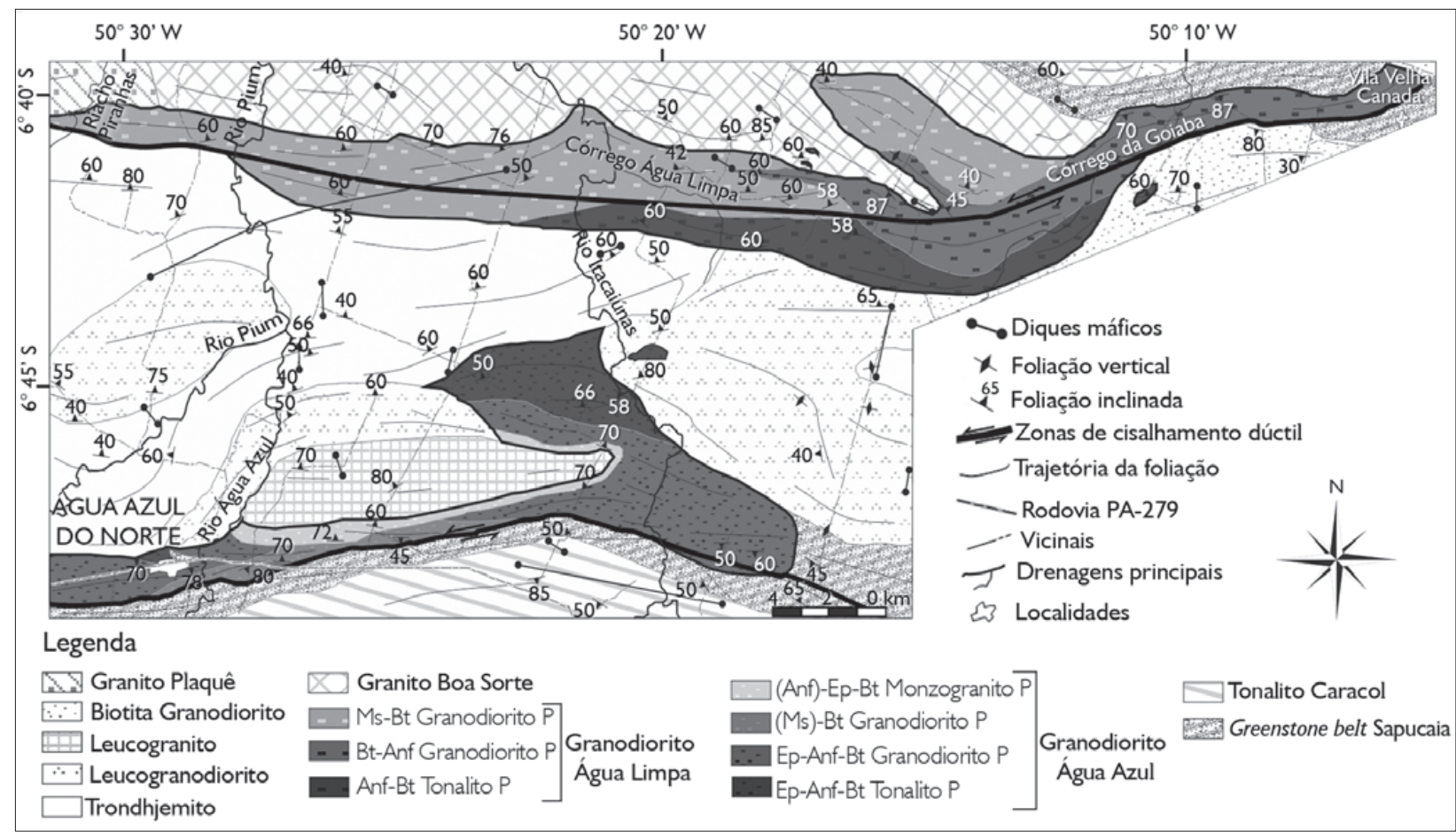

Figura 2. Mapa geológico detalhado da porção nordeste de Água Azul do Norte, distinguindo ainda as diversas variedades faciológicas de cada corpo mapeado. Legendas: Ms = muscovita; Bt = biotita; Anf = anfibólio; Ep = epidoto; P = porfirítico.

possam ter uma área de atuação lateral em torno de $1 \mathrm{~km}$ de cada lado da linha traçada no mapa para o GAL, e pouco menos de 300 m para o GAA, ao longo de toda a sua extensão. Raramente podem ser encontradas amostras que ainda preservam texturas interpretadas como de origem magmática. A foliação milonítica nessas rochas é delineada pela orientação dos minerais máficos dispostos em níveis preferenciais, realçados nos termos mais deformados. No GAL, são observadas estruturas planares localmente transpostas para a direção N-S em cinemática dextral, com desenvolvimento de dobras apertadas. Além disso, registram-se ainda dobras de arrasto localizadas e dobras ptigmáticas em veios de quartzo próximas às zonas de contato com os leucogranodioritos-granitos intrusivos. Tais estruturas ainda são truncadas por bandas de cisalhamento de direção NNW-SSE, de cinemática dextral. Por outro lado, o GAA comumente apresenta uma foliação proeminente, chegando a ser xistosa e sofrer crenulação nas proximidades da zona de cisalhamento que o separa do greenstone Sapucaia, além de estruturas do tipo boudins em veios de quartzo. Esses corpos são cortados por fraturas e localmente por falhas de rejeito centimétrico de direções N-S, NW-SE e NE-SW, direções que coincidem com aquelas mostradas pelos diques máficos que seccionam as rochas da região.

\section{PETROGRAFIA}

\section{COMPOSIÇÃO MODAL E CLASSIFICAÇÃO}

O GAA e o GAL apresentam características petrográficas ligeiramente distintas, com variações significativas nas concentrações de seus minerais (Tabelas 1 e 2). Para o estudo petrográfico, foram efetuadas análises modais de vinte e sete amostras do GAL e dezoito amostras do GAA. Os cristais de epidoto e de muscovita, interpretados como primários, foram contados separadamente dos secundários.

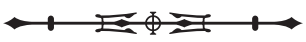



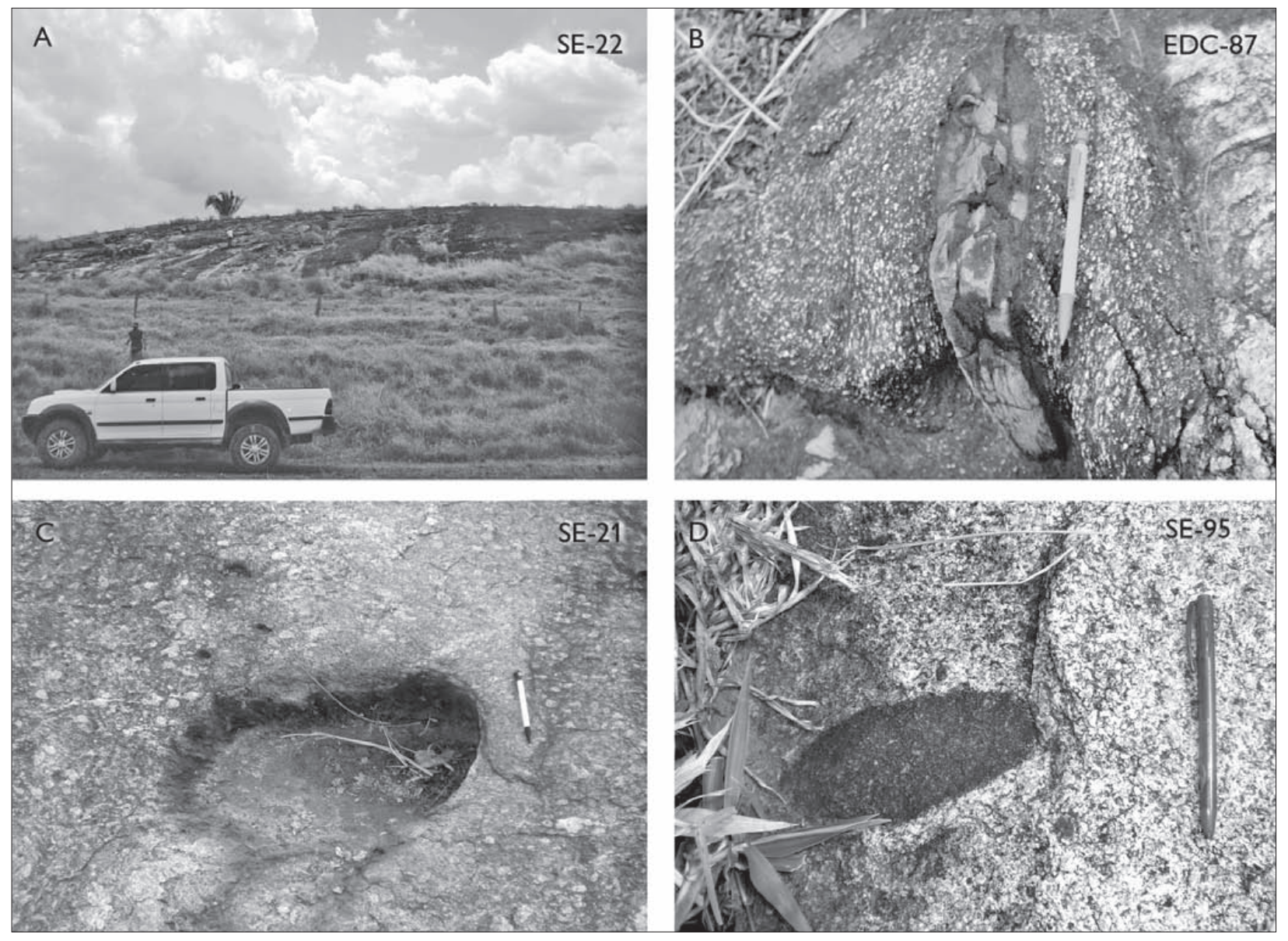

Figura 3. A) Afloramento do GAL em grandes lajeiros; B) xenólito xistoso de metabasalto pertencente ao Grupo Sapucaia englobado por GAA foliado; C) cavidade devido à remoção de enclave no GAL; D) enclave máfico no GAA. Dimensão das canetas (escalas): 15 cm. Fotos: E. O. Gabriel \& D. C. Oliveira.

Os resultados foram lançados nos diagramas Q-A-P e Q-(A+P)-M' (Figura 4, conforme Le Maitre, 2002) e as variedades petrográficas reunidas em grupos faciológicos, determinados principalmente pela razão plagioclásio/ K-feldspato e pela presença de anfibólio. A distribuição espacial dos grupos faciológicos identificados está delineada no mapa da Figura 2. As duas unidades contêm mais de $31 \%$ de plagioclásio, 34 a 16\% de quartzo, e o conteúdo de álcali feldspato pode chegar a até 24\%. Biotita e anfibólio são os principais minerais ferromagnesianos. Os minerais acessórios primários são epidoto, opacos, titanita, allanita, zircão, apatita, muscovita e rara turmalina; os acessórios secundários são clorita, escapolita, sericita, carbonato e epidoto. A muscovita somente é encontrada nas amostras desprovidas de anfibólio, chegando a constituir fase varietal, em proporções modais significativas (até 2,5\%) dentro desses corpos. Nos monzogranitos do GAA, ocorrem restritamente microcristais de turmalina.

O GAL exibe dominância de granodioritos, com tonalitos restritos à porção sudeste do corpo (Figura 2). Os principais grupos faciológicos identificados nessa unidade são biotita-anfibólio-granodiorito porfirítico (Bt-Anf-GrdP), muscovita-biotita-granodiorito porfirítico (Ms-Bt-GrdP) e anfibólio-biotita-tonalito porfiŕtico (Anf-Bt-TnlP).

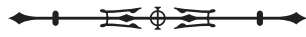




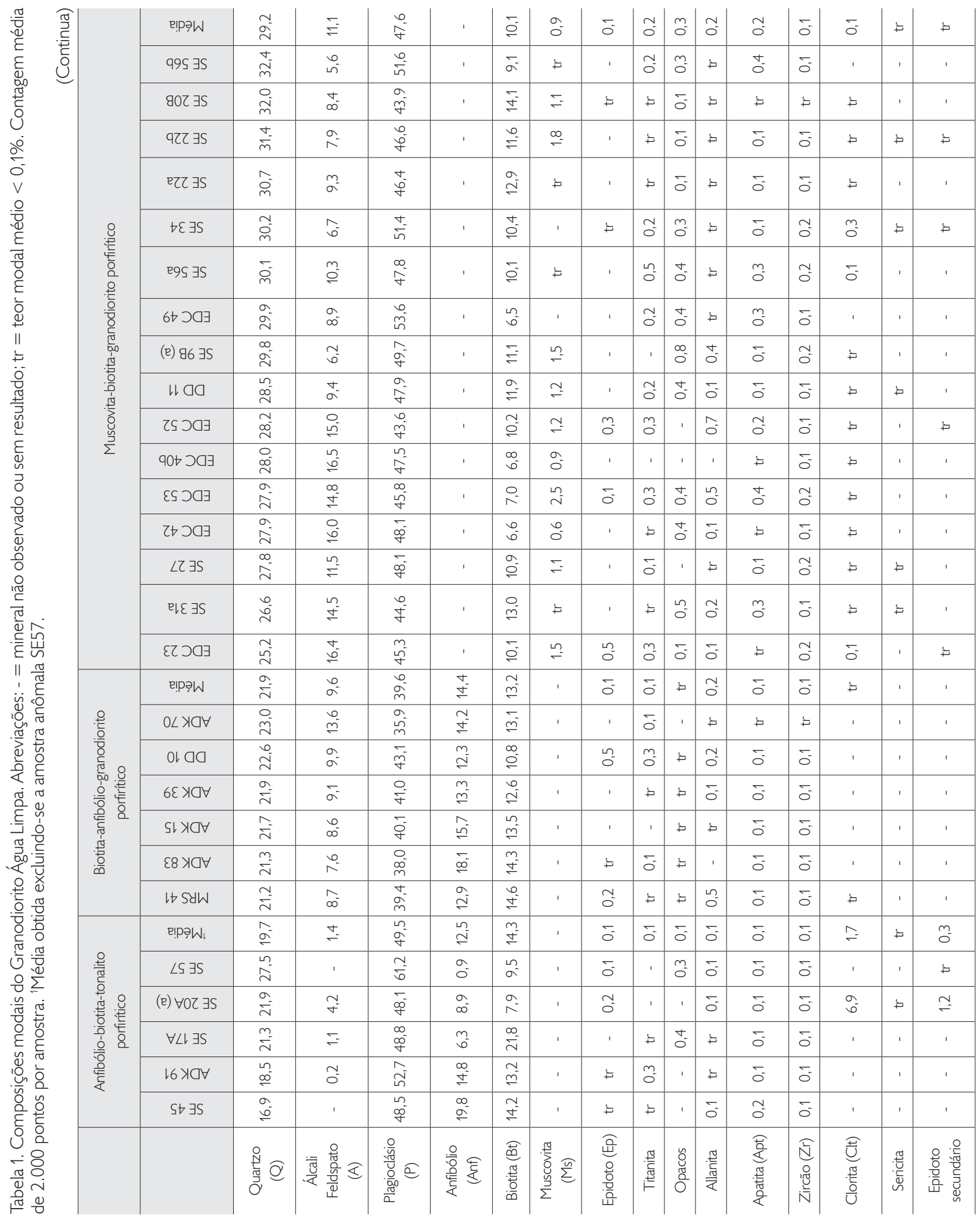




\begin{tabular}{|c|c|c|c|c|c|c|c|c|c|c|c|c|c|c|c|c|c|}
\hline \multirow{17}{*}{ 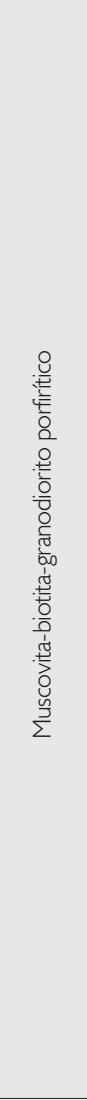 } & Е!pə̧W & $\overline{0}$ & ó & $=$ & & $\begin{array}{l}\hat{\sigma} \\
\hat{0}\end{array}$ & $m_{0}^{m}$ & r̃ & 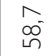 & ô & $\stackrel{?}{0}$ & & $\bar{o}$ & & $\stackrel{\sim}{m}$ & $\stackrel{0}{I}$ & 弪 \\
\hline & ৭9ऽ ヨऽ & $\bar{o}$ & $\bar{o}$ & 1 & ' & $\sigma^{-}$ & $\stackrel{n}{0}$ & ชี & $\stackrel{2}{n}$ & $\begin{array}{l}\circ \\
\infty \\
m\end{array}$ & $\bar{\sigma}$ & ' & $\bar{\delta}$ & & $\begin{array}{l}\tilde{N} \\
\tilde{n} \\
\tilde{n}\end{array}$ & ర్ & in \\
\hline & go乙 $\exists S$ & $\mp$ & $\Rightarrow$ & 1 & & $\stackrel{+}{\dot{I}}$ & $\bar{\sigma}$ & ô & Mi & $\begin{array}{l}t \\
\stackrel{g}{q}\end{array}$ & $\stackrel{\text { I }}{\leftarrow}$ & I & $\overline{0}$ & & $\begin{array}{l}0 \\
\infty^{-} \\
m^{-}\end{array}$ & 응 & กิ \\
\hline & ৭८Z ヨS & $=$ & $=$ & $\overline{0}$ & & $\stackrel{\sigma}{\xi}$ & ָ̃ & $\stackrel{t}{0}$ & 号 & $\stackrel{m}{m}_{m}^{2}$ & $\stackrel{\digamma}{E}$ & ' & こ̃ & & $\begin{array}{l}0 \\
\dot{0} \\
m\end{array}$ & $\tilde{\sigma}$ & $\stackrel{\sim}{\stackrel{+}{*}}$ \\
\hline & eZZ ヨS & $=$ & $=$ & $\overline{0}$ & & $\stackrel{\sim}{m}$ & $\stackrel{\text { an }}{0}$ & m & ผ & ○ & $\stackrel{\circ}{\stackrel{m}{2}}$ & ' & $\begin{array}{l}\delta \\
\delta \\
v \\
v\end{array}$ & & $\stackrel{\stackrel{n}{n}}{\stackrel{m}{m}}$ & $\begin{array}{l}\infty \\
\stackrel{0}{\circ}\end{array}$ & $\hat{n^{-}}$ \\
\hline & $\forall \varepsilon \exists S$ & $=$ & $\Rightarrow$ & 1 & 1 & $\stackrel{m}{=}$ & $\stackrel{m}{0}$ & $\stackrel{\text { 응 }}{0}$ & $\bar{\infty}$ & $\begin{array}{l}\sigma \\
\text { pे }\end{array}$ & $\hat{O}$ & ' & . & & $\stackrel{\sim}{\stackrel{f}{m}}$ & $\stackrel{0}{\wedge}$ & $\stackrel{\sim}{\infty}$ \\
\hline & ए9ৎ $\exists S$ & $\bar{o}$ & $=$ & 1 & ' & 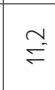 & $\stackrel{\sim n}{0}$ & $m_{0}^{m}$ & $\bar{\infty}_{n \rightarrow}^{\circ}$ & $\stackrel{q}{g}$ & $\stackrel{?}{0}$ & ' & $\begin{array}{l} \\
\delta \\
\bar{\sigma} \\
v\end{array}$ & & $\bar{F}$ & $\stackrel{-}{\risingdotseq}$ & 苟 \\
\hline & $6+\supset 0 \exists$ & $=$ & $=$ & . & ' & $\stackrel{2}{\pi}$ & $\stackrel{t}{0}$ & $\bar{\sigma}$ & 望 & $\begin{array}{l}\infty \\
\infty \\
\infty^{\infty}\end{array}$ & ก & ' & ' & & 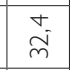 & $\sigma^{\circ}$ & $\begin{array}{l}\circ \\
\infty \\
\stackrel{\infty}{n}\end{array}$ \\
\hline & (e) $96 \exists S$ & $\Rightarrow$ & $=$ & $\overline{0}$ & ' & 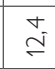 & $\stackrel{m}{0}$ & $\stackrel{m}{o}$ & 命 & $\begin{array}{l}\circ \\
\text { pे }\end{array}$ & $\stackrel{\cong}{=}$ & ' & $\bar{\sigma}$ & & $\begin{array}{l}\stackrel{\infty}{0}^{\infty} \\
\stackrel{5}{m}\end{array}$ & $\stackrel{2}{N}$ & $\stackrel{\circ}{\circ} \stackrel{\infty}{n}^{-}$ \\
\hline & ॥०० & $\mp$ & $\bar{o}$ & . & ' & 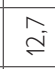 & ָ̃ & $\stackrel{m}{0}$ & $\stackrel{m}{n}_{n}^{-}$ & $\begin{array}{l}\stackrel{\sigma}{-} \\
\hat{m}\end{array}$ & $\stackrel{\text { i }}{i}$ & ' & $\overline{0}$ & & $\stackrel{\sim}{m}$ & $\stackrel{\circ}{=}$ & 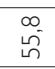 \\
\hline & 乙૬ Ј૦ヨ & $=$ & $=$ & 1 & , & $\stackrel{\circ}{=}$ & m. & $\tilde{O}_{0}^{2}$ & $\begin{array}{l} \\
\infty \\
\infty \\
\infty\end{array}$ & $\tilde{r}$ & $\stackrel{m}{\rho}$ & . & $\overline{0}$ & & $\begin{array}{l}\tilde{n} \\
\stackrel{n}{m}\end{array}$ & $\stackrel{m}{\stackrel{m}{f}}$ & $\begin{array}{l}n \\
\text { ñ } \\
\text { ñ }\end{array}$ \\
\hline & $90+\supset 0 \exists$ & $=$ & $=$ & . & ' & $\sigma_{\bar{\sigma}}$ & ָे & ๙̃ & \begin{tabular}{l} 
\\
\multirow{8}{*}{} \\
\end{tabular} & $\begin{array}{l}\stackrel{\sim}{*} \\
\forall\end{array}$ & $\begin{array}{l}\sigma \\
\sigma \\
\end{array}$ & ' & $\overline{0}$ & & $\underline{\tilde{n}}$ & $\stackrel{\curvearrowright}{\curvearrowright}$ & $\stackrel{0}{i=}$ \\
\hline & દ૬ ગ૦ヨ & $\mp$ & \pm & . & ' & $\begin{array}{l}\sigma \\
\infty \\
\infty\end{array}$ & $\stackrel{0}{0}$ & กै & $\begin{array}{l}0 \\
0 \\
0\end{array}$ & $\hat{\bar{q}}$ & $\bar{N}$ & ' & $\begin{array}{l}t \\
0\end{array}$ & & $\stackrel{\stackrel{n}{m}}{m}$ & $\stackrel{\hat{\imath}}{\underline{0}}$ & $\stackrel{\infty}{i=-}$ \\
\hline & て৮つOヨ & $=$ & $=$ & 1 & ' & $\stackrel{2}{\curvearrowright}$ & $\tilde{\sigma}$ & ๙̃ & 守 & $\begin{array}{l}\hat{\gamma}^{2} \\
\bar{\gamma}\end{array}$ & ڤ. & ' & $\overline{0}$ & & $\begin{array}{l}m \\
\stackrel{m}{m} \\
m\end{array}$ & 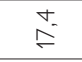 & స్n \\
\hline & $\angle Z \exists S$ & $=$ & $=$ & . & ' & 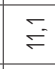 & $\stackrel{m}{0}$ & กै & $\begin{array}{l}0 \\
\text { aे } \\
\text { ñ }\end{array}$ & $\frac{m}{\sigma^{2}}$ & $\stackrel{\circ}{\risingdotseq}$ & ' & $\overline{0}$ & & $\stackrel{\infty}{\grave{m}}$ & $\stackrel{\sim}{m}$ & 号 \\
\hline & $E \vee \varepsilon \exists S$ & $\Rightarrow$ & $=$ & . & ' & $\stackrel{\infty}{m}$ & $\stackrel{0}{0}$ & ?ָ- & $\bar{\sigma}$ & $\bar{F}$ & $\bar{m}$ & ' & $\begin{array}{l}\bar{\delta} \\
\bar{\sigma} \\
v\end{array}$ & & $\stackrel{\circ}{m}$ & $\begin{array}{l}\sigma \\
\text { oे }\end{array}$ & $\overline{\tilde{n}}$ \\
\hline & દૃગ૦ヨ & + & $\Rightarrow$ & . & ' & 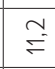 & m & $\stackrel{m}{o^{2}}$ & $\frac{1}{6}$ & $\begin{array}{l}\stackrel{0}{\sigma} \\
\stackrel{F}{*}\end{array}$ & ำ & ' & $\tilde{\sigma}$ & & ㅇ. & $\begin{array}{l}\stackrel{\circ}{\circ} \\
\stackrel{\infty}{\infty}\end{array}$ & $\overline{\tilde{N}}$ \\
\hline \multirow{7}{*}{ 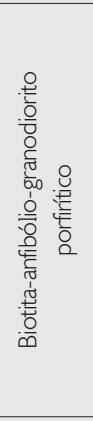 } & е!pə̧W & $=$ & $=$ & $=$ & ○' & $\begin{array}{l}0 \\
\stackrel{0}{0}^{\circ} \\
\text { N }\end{array}$ & ก̃ & $\hat{\circ}$ & $\begin{array}{c}\frac{1}{d} \\
\frac{a}{d}\end{array}$ & $\stackrel{\stackrel{n}{m}}{m}$ & $\stackrel{n}{m}$ & $=$ & 1 & & $\begin{array}{l}\hat{\sigma} \\
\hat{m}\end{array}$ & $\stackrel{+}{m}$ & 氙 \\
\hline & $0 \angle \lambda \square \forall$ & ' & ' & . & ' & $\stackrel{+}{\stackrel{\sim}{~}}$ & $\overline{0}$ & : & $\begin{array}{l}n \\
\sigma \\
\sigma \\
\sigma\end{array}$ & $\begin{array}{l}\dot{0} \\
\dot{m} \\
m\end{array}$ & $\stackrel{\bar{m}}{\underline{m}}$ & 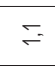 & 1 & & $\stackrel{\hat{m}}{\bar{m}}$ & $\begin{array}{l}\infty \\
\infty^{\infty} \\
\end{array}$ & $\begin{array}{l}\stackrel{\tilde{n}}{\sigma} \\
\stackrel{\sigma}{\sigma}\end{array}$ \\
\hline & ০ ০০ & $=$ & $=$ & 1 & ' & $\overline{\dot{J}}$ & ó & $\overline{0}$ & กั & $\stackrel{\stackrel{n}{n}}{m}$ & $\begin{array}{l}\infty \\
0 \\
0\end{array}$ & 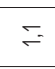 & 1 & & $\begin{array}{l}\sigma \\
\text { సे }\end{array}$ & $\bar{m}$ & in \\
\hline & $6 \varepsilon \times \gg \forall$ & , & ' & . & 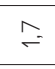 & $\overline{\text { s. }}$ & ป̂ & 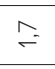 & $\overline{\text { ó }}$ & $\stackrel{\circ}{m}$ & I & 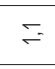 & ' & & $\stackrel{n}{\tilde{m}}$ & $\stackrel{0}{1}$ & $\begin{array}{l}\sigma \\
\text { மे } \\
\tilde{n}^{-}\end{array}$ \\
\hline & 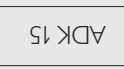 & $=$ & \pm & 1 & ' & m & ô & $\overline{0}$ & $\begin{array}{c}\hat{N} \\
\stackrel{\alpha}{+} \\
\end{array}$ & $\stackrel{m}{m}_{m}^{n}$ & $\stackrel{\stackrel{n}{m}}{\stackrel{m}{r}}$ & $\cong$ & 1 & & \begin{tabular}{|l|}
$\infty$ \\
$0^{-}$ \\
$m$
\end{tabular} & 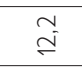 & in \\
\hline & $\varepsilon 8 \times \gg \forall$ & ' & ' & $\begin{array}{l}m \\
0 \\
0\end{array}$ & ' & $\begin{array}{l}\text { in } \\
\tilde{m}\end{array}$ & $\tilde{0}$ & $\stackrel{m}{0}$ & 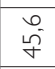 & $\begin{array}{l}\stackrel{\sigma}{\circ} \\
\text { ๙े }\end{array}$ & $\stackrel{m}{\underset{*}{t}}$ & $\stackrel{m}{=}$ & 1 & & $\stackrel{\infty}{m}$ & $\stackrel{t}{F}$ & 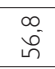 \\
\hline & lt syw & $=$ & . & . & $\bar{i}$ & $\stackrel{+}{\infty} \underset{\sim}{\sim}$ & व̃ & $\stackrel{\sim}{i}$ & $\stackrel{\bar{o}}{\stackrel{\sigma}{\sigma}}$ & $\begin{array}{l}\text { ते } \\
\text { ते }\end{array}$ & $\begin{array}{l}\text { f } \\
\dot{+}\end{array}$ & ó & 1 & & $\begin{array}{l}\dot{0} \\
\dot{m}\end{array}$ & $\stackrel{0}{1}$ & $\begin{array}{l}\infty \\
\infty^{-} \\
\left\llcorner^{-}\right.\end{array}$ \\
\hline \multirow{6}{*}{ 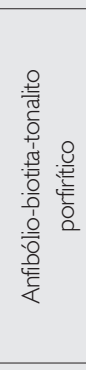 } & Ł!p’̧W & $\overline{0}$ & $=$ & $=$ & 1 & $\begin{array}{l}\infty \\
\stackrel{\infty}{\infty} \\
\sim\end{array}$ & ô & $\stackrel{\sim}{i}$ & $\begin{array}{l}\sigma \\
\text { oे }\end{array}$ & $\stackrel{i}{i}$ & $\begin{array}{l}0 \\
0 \\
0\end{array}$ & $\stackrel{\circ}{\circ}$ & 1 & & $\stackrel{\infty}{\stackrel{\infty}{\sim}}$ & 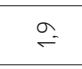 & $\stackrel{m}{2}$ \\
\hline & $\angle S \exists S$ & $\overline{0}$ & ' & $=$ & 1 & ڤे & ô & กै & $\frac{1}{5}$ & $\stackrel{\stackrel{n}{\sim}}{\stackrel{\sim}{\sim}}$ & $\stackrel{n}{\sigma}$ & $\overline{0}$ & . & & $\stackrel{\circ}{m}$ & ○ & $\begin{array}{l}\circ \\
0 \\
0\end{array}$ \\
\hline & (e) $\forall 0 Z \exists S$ & $\bar{o}$ & $\overline{0}$ & $\overline{0}$ & . & $\bar{d}$ & ô. & $\begin{array}{l}n \\
\infty \\
\infty\end{array}$ & $\tilde{n}_{n}^{n}$ & $\bar{\sigma}$ & $\begin{array}{l}\sigma \\
\dot{J} \\
\dot{y}\end{array}$ & 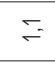 & 1 & & $\stackrel{\sim}{\tilde{N}}$ & in & 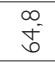 \\
\hline & $\forall \angle L \exists S$ & ' & ' & 1 & I & $\begin{array}{l}0 \\
\stackrel{\infty}{\infty} \\
\sim\end{array}$ & ô & :- & $\begin{array}{l}\sigma \\
\sigma \\
\sigma\end{array}$ & $\stackrel{a}{a}$ & $\stackrel{\infty}{i}$ & m & . & & $\begin{array}{l}\sigma \\
\text { ते }\end{array}$ & $\stackrel{n}{\sim}$ & 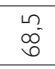 \\
\hline & $16 \times 0 \forall$ & $\mp$ & ' & 1 & , & $\underset{\substack{\sigma \\
\sim}}{\stackrel{\sigma}{*}}$ & ô & $\begin{array}{l}\text { Ln } \\
\stackrel{0}{0}\end{array}$ & ते & $\stackrel{\curvearrowright}{\stackrel{\infty}{\circ}}$ & $\stackrel{\stackrel{m}{m}}{\stackrel{n}{m}}$ & $=$ & . & & 岕 & m. & $\stackrel{\infty}{n}_{\substack{n \\
N}}$ \\
\hline & $S t \exists S$ & $=$ & $=$ & $=$ & ' & $\stackrel{\sim}{\sim}$ & $\stackrel{m}{0}$ & ช้ & $\begin{array}{l}\stackrel{n}{2} \\
\stackrel{\infty}{+} \\
\end{array}$ & $\begin{array}{l}\sigma \\
\stackrel{\sigma}{\sigma}\end{array}$ & İ & $\stackrel{t}{-}$ & 1 & & 岂 & O- & $\overline{ \pm}$ \\
\hline & & 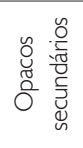 & 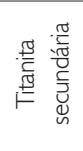 & 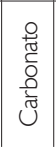 & 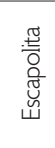 & 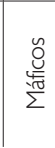 & $\begin{array}{l}\text { N } \\
+ \\
+ \\
+ \\
\end{array}$ & 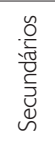 & $\begin{array}{l}a \\
+ \\
<\end{array}$ & $\begin{array}{l}\varangle \\
+ \\
0\end{array}$ & 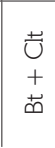 & 䓬 & 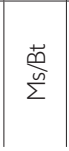 & $\frac{\circ}{8}$ & 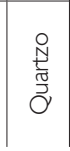 & 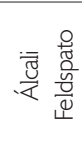 & 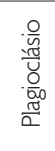 \\
\hline
\end{tabular}




\begin{tabular}{|c|c|c|c|c|c|c|c|c|c|c|c|c|c|c|c|c|c|c|c|}
\hline \multirow{3}{*}{ 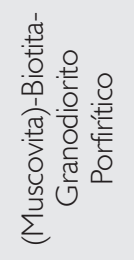 } & छ!p?,W & 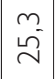 & $\stackrel{n}{N}$ & $\begin{array}{l}t \\
t_{0}^{-}\end{array}$ & & $\stackrel{2}{\sigma}$ & $\hat{0}$ & $\begin{array}{l}t \\
0\end{array}$ & $\mp$ & $\risingdotseq$ & $\tilde{0}$ & $=$ & $\tilde{c}^{2}$ & ' & $\bar{\sigma}$ & $\doteq$ & $\doteq$ & $=$ & $\mp$ \\
\hline & $98 \supset 0 \exists$ & 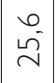 & $\stackrel{\circ}{\circ}$ & $\begin{array}{l}\hat{y} \\
\sigma^{-}\end{array}$ & I & $\check{E}$ & $\tilde{O}^{2}$ & $\mp$ & ' & 1 & & ' & $\bar{o}$ & ' & $\tilde{o}^{2}$ & 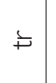 & & ' & \\
\hline & $69 \supset 0 \exists$ & $\begin{array}{l}\sigma \\
\dot{\nu} \\
\end{array}$ & 요 & $\begin{array}{l}2 \\
\sigma \\
f\end{array}$ & 1 & $\stackrel{\sim}{\bar{N}}$ & $\stackrel{\simeq}{=}$ & $\hat{0}$ & $\mp$ & $\doteqdot$ & $\begin{array}{l}m \\
0\end{array}$ & $\mp$ & $\stackrel{2}{0}$ & ' & $\mp$ & ' & $=$ & $=$ & $\doteqdot$ \\
\hline \multirow{7}{*}{ 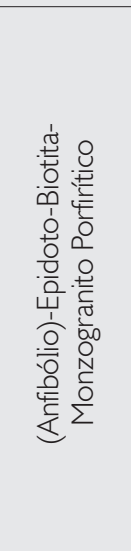 } & छ!pə,W & $\begin{array}{l}\sigma \\
\tilde{\nu}^{-}\end{array}$ & స̃ & $\begin{array}{l}a \\
\vec{m} \\
m\end{array}$ & $\tilde{c}$ & $\begin{array}{l}m \\
\alpha^{2}\end{array}$ & $\begin{array}{ll}\sim \\
0\end{array}$ & $\stackrel{\simeq}{=}$ & $\overline{0}$ & $\bar{o}$ & m & $=$ & $\bar{\sigma}$ & $\overline{0}$ & $\stackrel{m}{o}$ & $\bar{o}$ & $\bar{o}$ & $\doteq$ & $\mp$ \\
\hline & $\angle \angle \supset O \exists$ & \begin{tabular}{|l|}
$\stackrel{\sim}{2}$ \\
$\stackrel{\sim}{\sim}$ \\
\end{tabular} & $\hat{\infty}^{-}$ & $\begin{array}{l}\hat{a} \\
m\end{array}$ & ' & $\begin{array}{l}\hat{\sigma} \\
\sigma\end{array}$ & $\mathfrak{m}^{m}$ & $\stackrel{a}{=}$ & ' & $=$ & ֻ̊ & ' & $\overline{0}$ & $\mp$ & ô & $\tilde{O}$ & $\tilde{o}^{2}$ & ' & \\
\hline & $(\mathrm{e}) t \angle \supset \triangle \exists$ & $\begin{array}{l}m \\
\stackrel{m}{\sim}\end{array}$ & $\stackrel{n}{\circ}$ & $\begin{array}{l}m \\
m \\
m\end{array}$ & ' & $\check{\infty}^{\circ}$ & 1 & $\stackrel{\sigma}{=}$ & $\mp$ & $\mathfrak{m}^{m}$ & थٌ & ' & $\tilde{\sigma}$ & $\begin{array}{l}\infty \\
0_{-}^{-} \\
\end{array}$ & $\overline{0}$ & 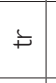 & $=$ & ' & 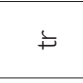 \\
\hline & $9 t \exists S$ & 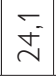 & $\stackrel{m}{\sigma}$ & \begin{tabular}{|l|}
$a$ \\
$m$ \\
$m$
\end{tabular} & ' & $\stackrel{m}{\stackrel{m}{\leftarrow}}$ & 1 & $\begin{array}{l}2 \\
0 \\
-\end{array}$ & ' & ֻ̃ & ֵ & $\mp$ & $\overline{0}$ & ' & $\stackrel{\circ}{\circ}$ & ' & ¿ & $\overline{0}$ & $\doteq$ \\
\hline & LつOヨ & $\begin{array}{l}\sigma \\
\tilde{\nu}^{-}\end{array}$ & $\hat{\sigma}$ & $\bar{i}$ & $\begin{array}{l}\sigma \\
\dot{0}\end{array}$ & $\begin{array}{l}\stackrel{\sim}{\alpha} \\
\sigma^{\prime}\end{array}$ & ' & $\begin{array}{l}0 \\
\text { i }\end{array}$ & ma & $\mp$ & $\begin{array}{l}m \\
0\end{array}$ & $\mp$ & $\stackrel{n}{0}$ & ' & $\mp$ & $\mp$ & $=$ & ' & \\
\hline & $10 \forall O S$ & $\begin{array}{l}\vec{r} \\
\stackrel{n}{z}\end{array}$ & $\stackrel{m}{\stackrel{m}{\sim}}$ & $\begin{array}{l}n \\
\text { m } \\
m\end{array}$ & ' & \begin{tabular}{|l|}
$\sigma^{\prime}$ \\
$\infty$ \\
$\propto$
\end{tabular} & \begin{tabular}{ll|}
$\infty$ & \\
0 & \\
0
\end{tabular} & ' & ' & 1 & 1 & $=$ & $\bar{o}$ & 1 & $\bar{\sigma}$ & $\doteq$ & $\mp$ & ' & \\
\hline & 乙Lつดヨ & $\overline{\tilde{v}}$ & $\stackrel{\sigma}{\sigma}$ & $\begin{array}{l}\stackrel{\sim}{m} \\
\stackrel{m}{n}\end{array}$ & ' & $\overline{\tilde{\lambda}}$ & $=$ & $\begin{array}{l}+ \\
0\end{array}$ & $\mp$ & $\mp$ & m & ' & $\overline{0}$ & ' & $\begin{array}{l}2 \\
0\end{array}$ & 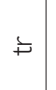 & 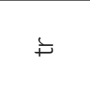 & $=$ & $\mp$ \\
\hline \multirow{6}{*}{ 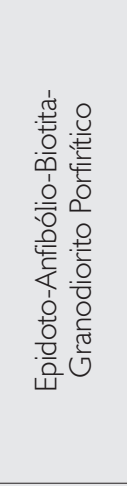 } & е!рә,W & $\hat{\tilde{v}^{-}}$ & $\stackrel{m}{m}$ & $=$ & $a^{m}$ & $\overline{\check{I}}$ & . & $\begin{array}{l}\sigma \\
\hat{o}\end{array}$ & $\widetilde{N}$ & $\mp$ & $\widetilde{\sigma}$ & $\mp$ & $\bar{o}$ & , & $\stackrel{\circ}{\circ}$ & $\mp$ & $\stackrel{\circ}{=}$ & $=$ & $\mp$ \\
\hline & ऽ6 $\exists S$ & 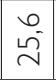 & $\stackrel{1}{\simeq}$ & 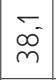 & $\stackrel{m}{=}$ & O & ' & $\begin{array}{l}n \\
0 \\
0\end{array}$ & $\tilde{\sigma}$ & $\mp$ & $\overline{0}$ & $\neq$ & $\tilde{c}$ & ' & $\mp$ & $\mp$ & $\stackrel{t}{0}$ & $=$ & $\doteq$ \\
\hline & $80 \exists S$ & i⿱丶万⿰冫欠 & $\stackrel{\mathscr{\sim}}{\mp}$ & \begin{tabular}{|l}
$\hat{n}$ \\
$n^{-}$
\end{tabular} & $\begin{array}{l}\infty \\
0 \\
0\end{array}$ & 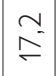 & ' & $a^{m}$ & ' & $\mp$ & $\bar{\sigma}$ & $\bar{\sigma}$ & $\overline{0}$ & ' & $\overline{0}$ & ' & $\bar{\sigma}$ & $=$ & \\
\hline & IS $\exists S$ & 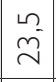 & $\begin{array}{l}\stackrel{\circ}{+} \\
+\end{array}$ & $\begin{array}{l}\bar{\sigma} \\
m\end{array}$ & $=$ & $\begin{array}{l}2 \\
\stackrel{2}{0} \\
\end{array}$ & ' & $\bar{i}$ & mo & $\mp$ & $\stackrel{2}{0}$ & 1 & . & ' & \begin{tabular}{l|}
0 \\
$\sigma^{-}$
\end{tabular} & ' & $\stackrel{\infty}{0}^{\infty}$ & $=$ & $\overline{0}$ \\
\hline & $\downarrow 6 \exists S$ & $\stackrel{+}{\vec{z}}$ & $\bar{m}$ & $\begin{array}{l}a \\
\hat{m}\end{array}$ & $\bar{m}$ & $\stackrel{\circ}{=}$ & 1 & $\stackrel{m}{=}$ & ma & $\mp$ & $\overline{0}$ & $\mp$ & $\overline{0}$ & ' & $=$ & ' & $\stackrel{+}{\circ}$ & $=$ & $\mp$ \\
\hline & SL כOت & $\bar{z}$ & $\underset{\simeq}{\stackrel{2}{Z}}$ & \begin{tabular}{|l|}
$\infty$ \\
$n$ \\
$m$
\end{tabular} & $\stackrel{\sim}{ \pm}$ & $\stackrel{m}{\sim}$ & ' & $\begin{array}{l}n \\
0 \\
0\end{array}$ & mo & 1 & $\widetilde{\sigma}$ & $\mp$ & $\tilde{O}^{n}$ & ' & 1 & 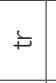 & $=$ & ' & \\
\hline \multirow{7}{*}{ 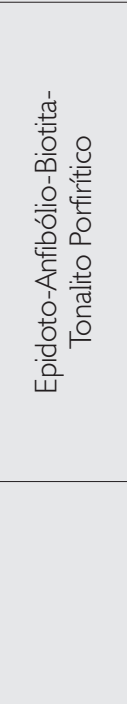 } & в!рә̧ & $\begin{array}{l}\sigma \\
\stackrel{\sim}{\sim}\end{array}$ & $\hat{0}$ & $\overline{\sigma o}^{-}$ & $\begin{array}{l}\dot{H}^{\prime} \\
\text { ஸ́ }\end{array}$ & $\check{\infty}^{\infty}$ & ' & $\stackrel{\circ}{\circ}$ & \pm & $\overline{0}$ & $\tilde{0}$ & $\mp$ & $\overline{0}$ & ' & $\overline{0}^{\circ}$ & ' & $=$ & $\bar{\sigma}$ & $=$ \\
\hline & †9 $\exists S$ & $\begin{array}{l}\sim \\
\stackrel{2}{2}\end{array}$ & $\stackrel{n}{\sim}$ & $\begin{array}{l}\sim^{n} \\
\infty^{\infty} \\
\end{array}$ & $\stackrel{\sim}{\sim}$ & $\stackrel{\stackrel{n}{=}}{=}$ & 1 & $\begin{array}{c}m \\
o \\
o\end{array}$ & $\mp$ & ' & $\overline{0}$ & $\overline{0}$ & $\bar{o}$ & ' & $\mp$ & ' & ' & $=$ & $\mp$ \\
\hline & ৎ৪ $\exists S$ & $\begin{array}{l}\hat{\alpha} \\
\stackrel{\sim}{-}^{-}\end{array}$ & ' & $\bar{c}_{\dot{\alpha}}^{-}$ & $\dot{\sigma}_{0}$ & $\stackrel{\sim}{\sim}$ & ' & $\cong$ & ' & ' & $\overline{0}$ & $\neq$ & $\overline{0}$ & ' & $\mp$ & ' & $=$ & ' & \\
\hline & $98 \exists S$ & 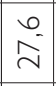 & ' & $\begin{array}{c}\stackrel{N}{f} \\
\stackrel{f}{*}\end{array}$ & $\begin{array}{l}\hat{m} \\
\hat{m}^{2}\end{array}$ & $\stackrel{\circ}{\circ}$ & ' & $\stackrel{\infty}{=}$ & $\bar{o}$ & ' & 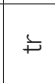 & $\doteqdot$ & $\overline{0}$ & ' & $=$ & ' & $=$ & $=$ & $=$ \\
\hline & $9\llcorner\supset 0 \exists$ & $\begin{array}{l}m \\
\stackrel{m}{\sim}\end{array}$ & $\Xi$ & $\begin{array}{l} \\
\infty \\
\infty^{-} \\
\end{array}$ & $\stackrel{2}{\wedge}$ & $\begin{array}{l}\sim \\
0 \\
\end{array}$ & 1 & $\begin{array}{l}\infty \\
0^{-}\end{array}$ & ' & 1 & $\sigma_{0}$ & 1 & $\tilde{O}^{n}$ & ' & $m^{m}$ & ' & $=$ & $=$ & \\
\hline & ع9 כ૦ヨ & $\begin{array}{l}\sim \\
\sigma \\
\sigma\end{array}$ & & $\begin{array}{l}\sigma \\
\hat{f}\end{array}$ & $\stackrel{\Omega}{\sim}$ & $\begin{array}{l}\infty \\
\tilde{N}\end{array}$ & 1 & $\stackrel{\circ}{\circ}$ & $\doteqdot$ & $a^{m}$ & $\widetilde{N}$ & $\mp$ & $\overline{0}$ & ' & $\mp$ & ' & & $\tilde{0}$ & \\
\hline & & 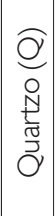 & 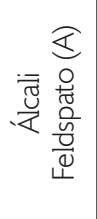 & 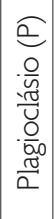 & 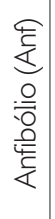 & 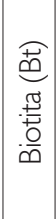 & 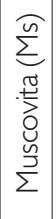 & 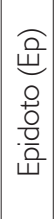 & 蔦 & $\begin{array}{l}\tilde{0} \\
\tilde{\tilde{O}} \\
0\end{array}$ & $\begin{array}{l}\frac{\pi}{\frac{\pi}{c}} \\
\frac{\pi}{z} \\
\frac{\pi}{z}\end{array}$ & 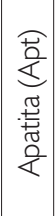 & 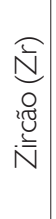 & 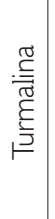 & 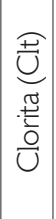 & 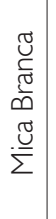 & 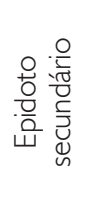 & 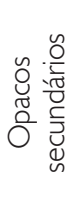 & 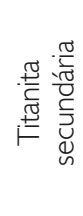 \\
\hline
\end{tabular}




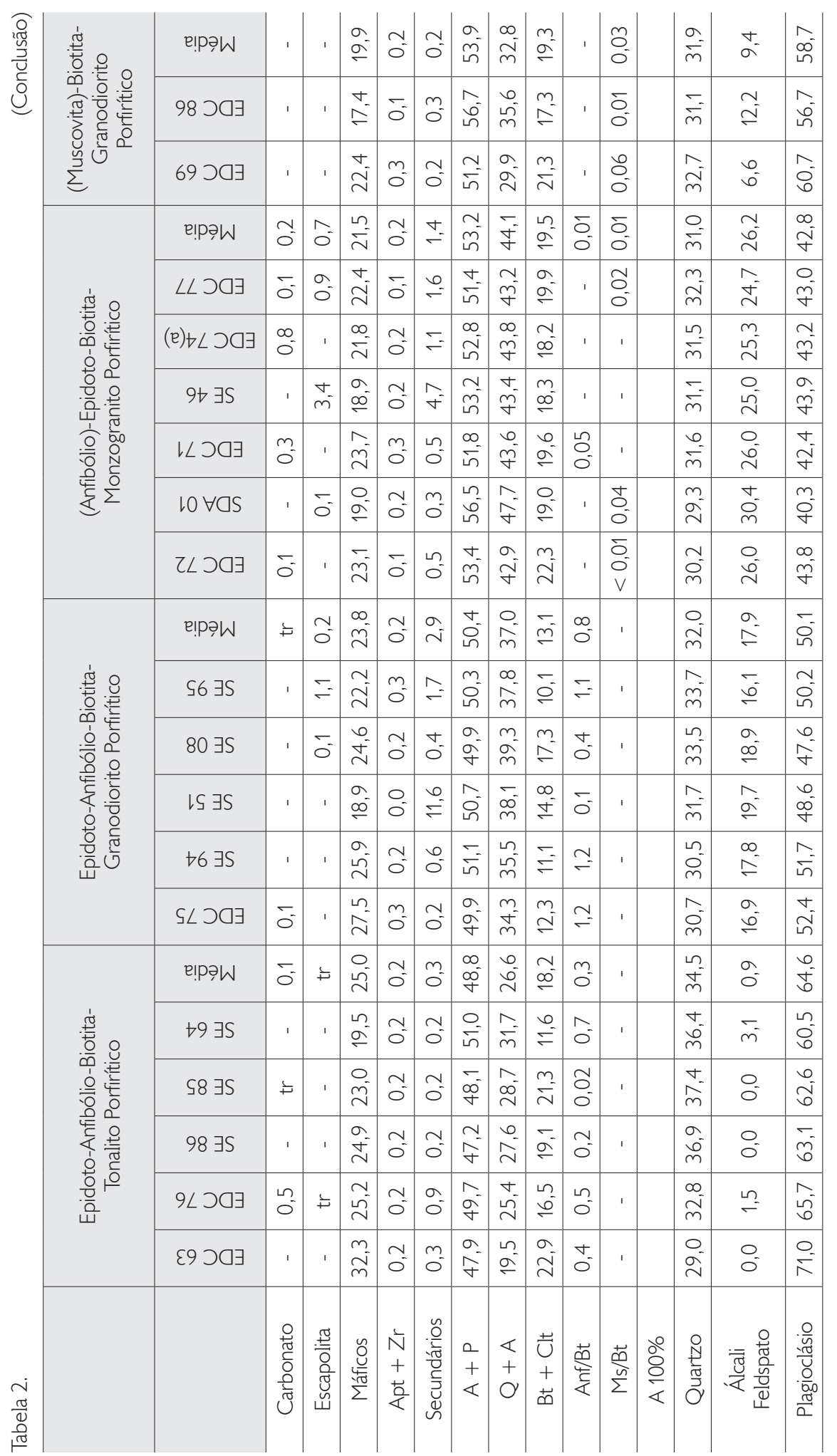


Os tonalitos e granodioritos com anfibólio possuem teor médio de máficos superior ao do Ms-Bt-GrdP (Tabela 1). No diagrama $\mathrm{Q}-(\mathrm{A}+\mathrm{P})-\mathrm{M}^{\prime}$ (Figura 4), nota-se que os conteúdos modais de minerais máficos dos granodioritos com anfibólio (24-28\%) e tonalitos com anfibólio (24-34\%) se sobrepõem, distinguindo-se nitidamente dos granodioritos com muscovita (7-14\% de minerais máficos), que são mais enriquecidos em quartzo.

Por sua vez, o GAA apresenta amplo espectro composicional, com predominância de granodioritos, além de tonalitos e monzogranitos subordinados. Vale notar que, no diagrama Q-A-P (Figura 4), os monzogranitos plotam próximo ao campo dos granodioritos, o que pode revelar possíveis afinidades petrográficas entre essas variedades. Os grupos faciológicos desse corpo são epidotoanfibólio-biotita-granodiorito porfirítico (Ep-Anf-Bt-GrdP), epidoto-anfibólio-biotita-tonalito porfirítico (Ep-Anf-Bt-TnlP), (anfibólio)-epidoto-biotita-monzogranito porfirítico [(Anf)-Ep-Bt-MzGP] e restritamente (muscovita)-biotita granodiorito porfirítico [(Ms)-Bt-GrdP]. Os conteúdos de minerais máficos dessas rochas tendem a se sobrepor no diagrama Q-(A+P)-M' (Figura 4). No entanto, o teor médio de máficos dos tonalitos (24,9\%) e granodioritos (22,9\%) com anfibólio é ligeiramente mais elevado do que nas demais variedades, entre 21,1\% e 19,7\% (Tabela 2).

\section{ASPECTOS TEXTURAIS}

Todas as variedades petrográficas identificadas nesses corpos foram afetadas por processos de deformação dúctil, sendo raras as amostras onde é possível identificar a textura ígnea original. Levando-se em consideração as afinidades mineralógicas e texturais entre as duas unidades, será realizada uma descrição conjunta das diversas variedades identificadas nesses corpos, sempre apontando, quando necessário, as principais diferenças existentes entre as mesmas.

O principal aspecto textural observado é a textura porfirítica (Figuras 5A-5B), muitas vezes obliterada e/ou realçada pela atuação de processos deformacionais, dando lugar a aspectos heterogranulares e equigranulares nas variedades mais recristalizadas. A textura porfirítica é caracterizada pela ocorrência de porfiroclastos prismáticos e grossos de feldspatos em meio a uma matriz média a fina, moderadamente recristalizada, enriquecida em máficos e fortemente orientada.

O plagioclásio ocorre em dois tipos texturalmente distintos. O plagioclásio 1, como cristais prismáticos subautomórficos e inequigranulares de até $6 \mathrm{~mm}$ (Figura 5C), que exibem localmente bordas albíticas estreitas, pode desenvolver mirmequitas nos contatos com microclina e, nos cristais maiores, desenvolve maclas do tipo Carlsbad. Quando há alterações, estas afetam os núcleos dos cristais, que são substituídos parcialmente por sericita, carbonatos e epidoto. O plagioclásio 2 ocorre como novos grãos xenomórficos de granulação fina (até 0,9 mm), formando agregados poligonais e podendo desenvolver ainda agregados mirmequíticos bulbosos.

O quartzo distribui-se em quatro tipos morfológicos: (i) quartzo 1 - são cristais inequigranulares (variam entre 4,0 e 0,4 mm), xenomórficos a subautomórficos, que apresentam formas granulares de contatos reentrantes, serrilhados a curvos; (ii) quartzo 2 - forma novos grãos subautomórficos variando entre 0,5 e 0,1 mm, com contatos sub-retilíneos em agregados poligonais; (iii) quartzo 3 restringe-se às fácies portadoras de anfibólio, apresentando granulação muito fina e formas subarredondadas, é tipicamente xenomórfico e associa-se com o anfibólio, com suas relações texturais sugerindo que seja oriundo da transformação de minerais ferromagnesianos precoces, devendo representar o excesso de sílica liberado durante a transformação do anfibólio para biotita; (iv) quartzo 4 - é encontrado nas variedades mais evoluídas, como microcristais vermiculares ou em formas de gotas em intercrescimento com bordas sódicas do plagioclásio nos pequenos bulbos de mirmequitas.

A microclina é comum nas rochas mais evoluídas e encontra-se em dois tipos morfológicos distintos: (i) microclina 1, de granulação variando de 11,0 a 1,0 mm,

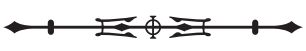




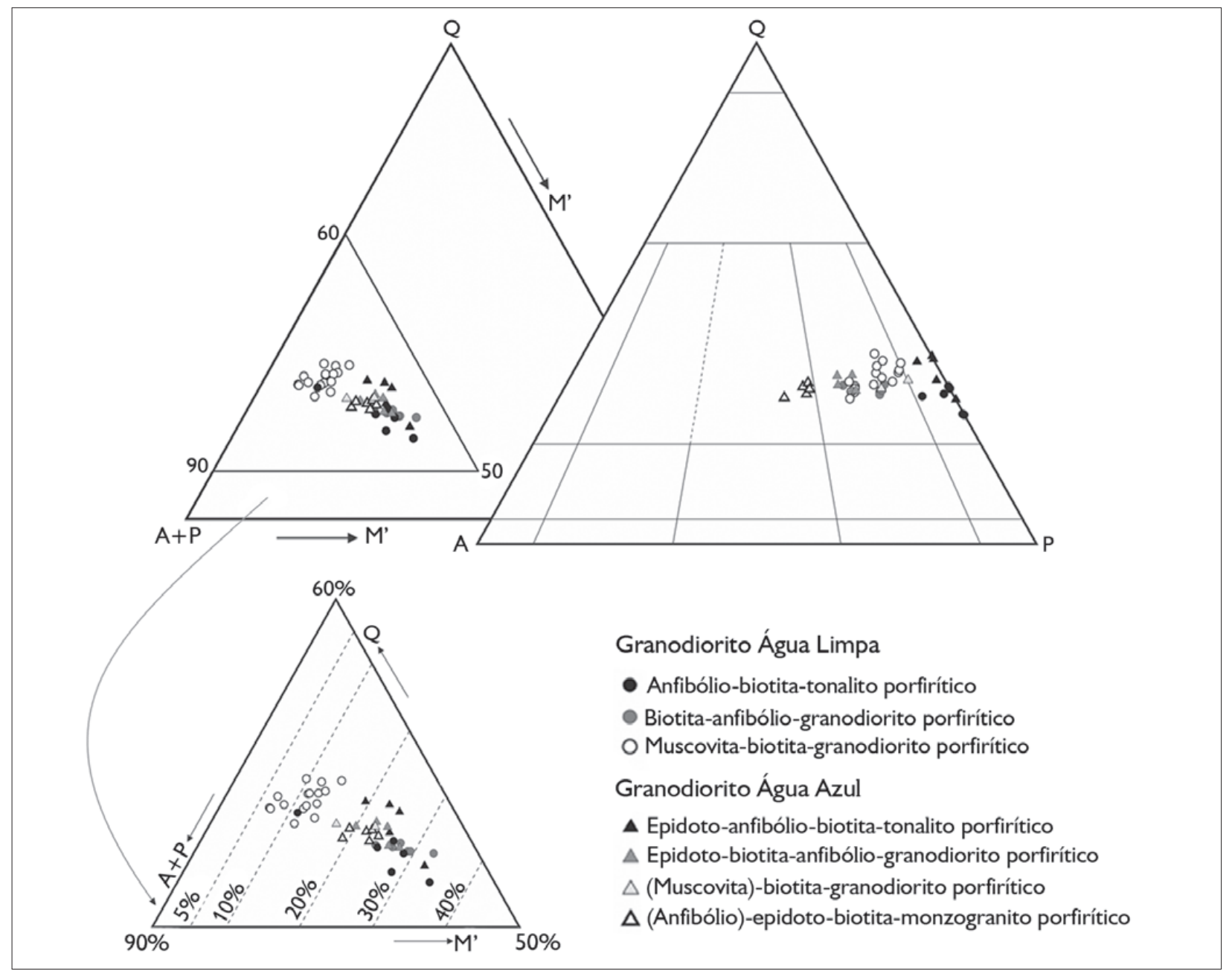

Figura 4. Diagramas modais Q-A-P e Q-(A+P)-M' (Le Maitre, 2002) para os granodioritos Água Azul e Água Limpa.

é subautomórfica, com maclas Carlsbad e albita-periclina, bem desenvolvidas, localmente exibindo micropertitas (Figura 5D). Em alguns casos, possuem textura poiquilítica, englobando plagioclásio, quartzo, biotita e anfibólio finos; (ii) microclina 2, que forma cristais subautomórficos e equigranulares finos (até 1,0 mm), exibindo contornos regulares em agregados poligonais. Seu maclamento albita-periclina é difuso e pode exibir micropertitas.

A biotita ocorre em dois tipos texturais: (i) biotita 1, a mais abundante, que forma cristais equigranulares finos (geralmente com $1 \mathrm{~mm}$, podendo localmente atingir 3 $\mathrm{mm}$ ), é subautomórfica, de contato reto com anfibólio e epidoto magmático, e pode estar parcialmente alterada para clorita, assim como, localmente, para titanita e hematita ao longo de suas clivagens; (ii) biotita 2, que ocorre como finos cristais subautomórficos e lamelares, relacionados à recristalização tardi-magmática do anfibólio e biotita 1.

Onfibólio é inequigranular, variando entre 4,0 e 0,3 mm, xenomórfico a subautomórfico de contatos irregulares. Pode desenvolver prismas curtos, muitas vezes maclados (Figura 5C). Pode conter inclusões de opacos, zircão e quartzo 3. Localmente, pode ser encontrada transformação do anfibólio para biotita

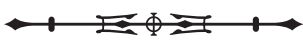



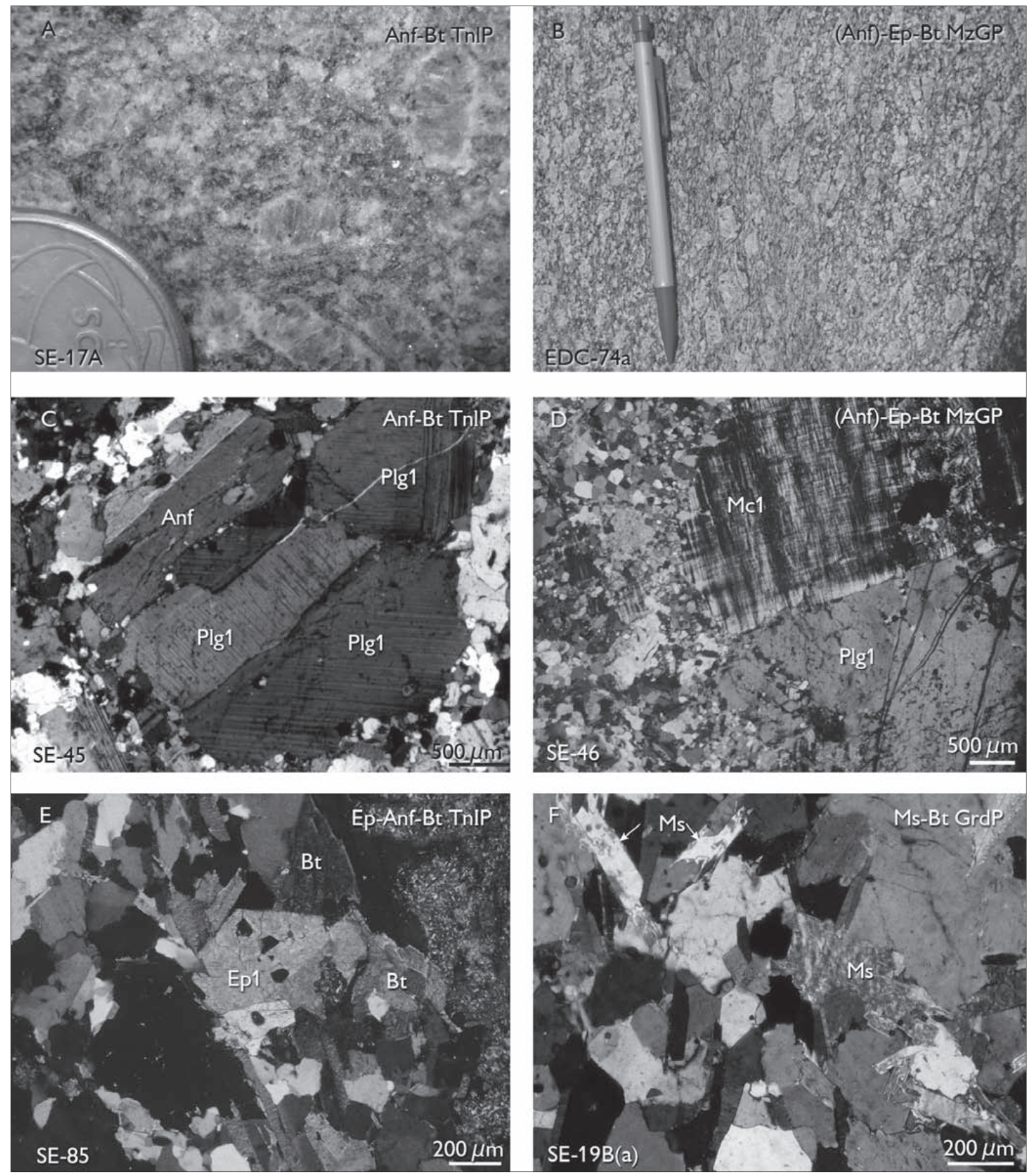

Figura 5. Aspectos texturais das rochas estudadas. Aspectos macroscópicos da textura porfirítica no GAL (A) e GAA (B). Fotos: E. O. Gabriel \&D. C. Oliveira. Fotomicrografias a nicóis cruzados: C) cristais de anfibólio (Anf) e de plagioclásio (Plg1) maclados, GAL; D) contato retilíneo entre microclina (Mc1) e plagioclásio (Plg1), GAA; E) epidoto magmático, automórfico (Ep1), maclado e em contato reto com biotita (Bt), GAA; F) forma de ocorrência da biotita e muscovita (Ms), GAL.

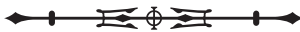


e, subordinadamente, titanita e opacos, afetando principalmente suas bordas, planos de clivagem e fraturas.

O epidoto é mais comum no GAA do que no $\mathrm{GAL}$, atingindo, no primeiro, concentração varietal (> 1,0\%). Com base em suas características texturais, foram identificadas duas gerações distintas: (i) epidoto 1 , de origem magmática, incolor, subautomórfico, prismático, localmente zonado e/ou maclado (Figura 5E), possui contatos retos com biotita preservando suas faces, sugerindo equilíbrio entre ambos, e contatos irregulares com as demais fases. É comum nesses cristais a preservação de núcleos de allanita automórfica, muitas vezes zonada e que podem ainda ser encontrados como pequenos pontos acastanhados; (ii) epidoto 2, de origem secundária, que forma cristais xenomórficos muito finos, geralmente de cor amarelo esverdeado claro, os quais preenchem veios e/ou fraturas, associam-se à clorita e à escapolita e podem ocorrer no interior ou nas bordas de plagioclásio alterado.

A muscovita é encontrada como cristais lamelares subautomórficos e equigranulares finos (com até 0,5 mm), os quais se associam à biotita, mostrando contatos retos, ao passo que exibem contatos irregulares, reentrantes a interdigitados com as demais fases (Figura 5F). São mais comuns no GAL do que no GAA e, via de regra, só estão presentes nas rochas mais evoluídas e sem anfibólio. Não há certeza quanto à sua natureza, mas suas feições sugerem que seja de origem primária e contemporânea à formação da biotita 1.

As fases acessórias primárias são minerais opacos, allanita, zircão, apatita, titanita e, restritamente, turmalina (apenas no GAA), que, de forma geral, são automórficos, ocorrem inclusos e/ou associados aos minerais ferromagnesianos precoces. Clorita, escapolita, sericita e carbonatos compõem as principais fases minerais secundárias, que são produtos de alteração pós-magmática de feldspatos, biotita e anfibólio, sendo formados por microcristais que podem substituir parcial ou completamente estes minerais, ocupando suas partes centrais, bordas, clivagens ou fraturas.

\section{ASPECTOS DEFORMACIONAIS}

As principais feições microestruturais foram caracterizadas com base no estudo de lâminas delgadas de amostras pertencentes aos dois corpos estudados. De maneira geral, tanto as amostras do GAA quanto as do GAL exibem forte anisotropia, manifestada por uma foliação pervasiva, definida por níveis enriquecidos em minerais ferromagnesianos e outros essencialmente quartzo-feldspáticos fortemente orientados. Dependendo do grau de deformação, os cristais podem estar recristalizados (neoblastos) e, localmente, formar agregados poligonais (Figura 6B). Nas variedades com anfibólio, são comumente encontrados agregados de minerais máficos orientados (clusters), nucleados por cristais de anfibólio e bordejados por biotita (Figura 6C).

Em decorrência das microestruturas observadas, torna-se apropriado o uso do termo 'milonito' (Passchier \& Trouw, 1996; Trouw et al., 2010) para as rochas que foram afetadas por zonas de cisalhamento dúcteis, proporcionando a recristalização de suas principais fases minerais, resultando em uma matriz mais fina, que engloba porfiroclastos de feldspatos. Esses cristais resistentes ainda podem conter evidências indicativas da atuação de mecanismos frágeis. A deformação atuou nessas rochas de forma heterogênea e pode ser descrita observando-se as principais fases minerais: (i) os feldspatos (plagioclásio 1 e microclina 1) preservam comumente porfiroclastos subautomórficos orientados, sendo que termos mais deformados apresentam-se como porfiroclastos do tipo sigma (Figura 6A), bordas recristalizadas e comumente envolvidas por neoblastos finos, que em alguns casos podem configurar sombras de pressão. Localmente, a recristalização inicial das bordas dos porfiroclastos de plagioclásio gera novos grãos, que desenham feições do tipo 'manto-núcleo', melhor desenvolvida na microclina (Figura 6D). Nos feldspatos, ainda foi possível identificar extinções ondulantes, encurvamento das maclas (Figura 6E), microkinks, fraturas preenchidas por neoblastos e micropertitas tectônicas na microclina 1 perpendiculares à foliação da rocha; (ii) quartzo 1 é comumente encontrado formando aglomerados 

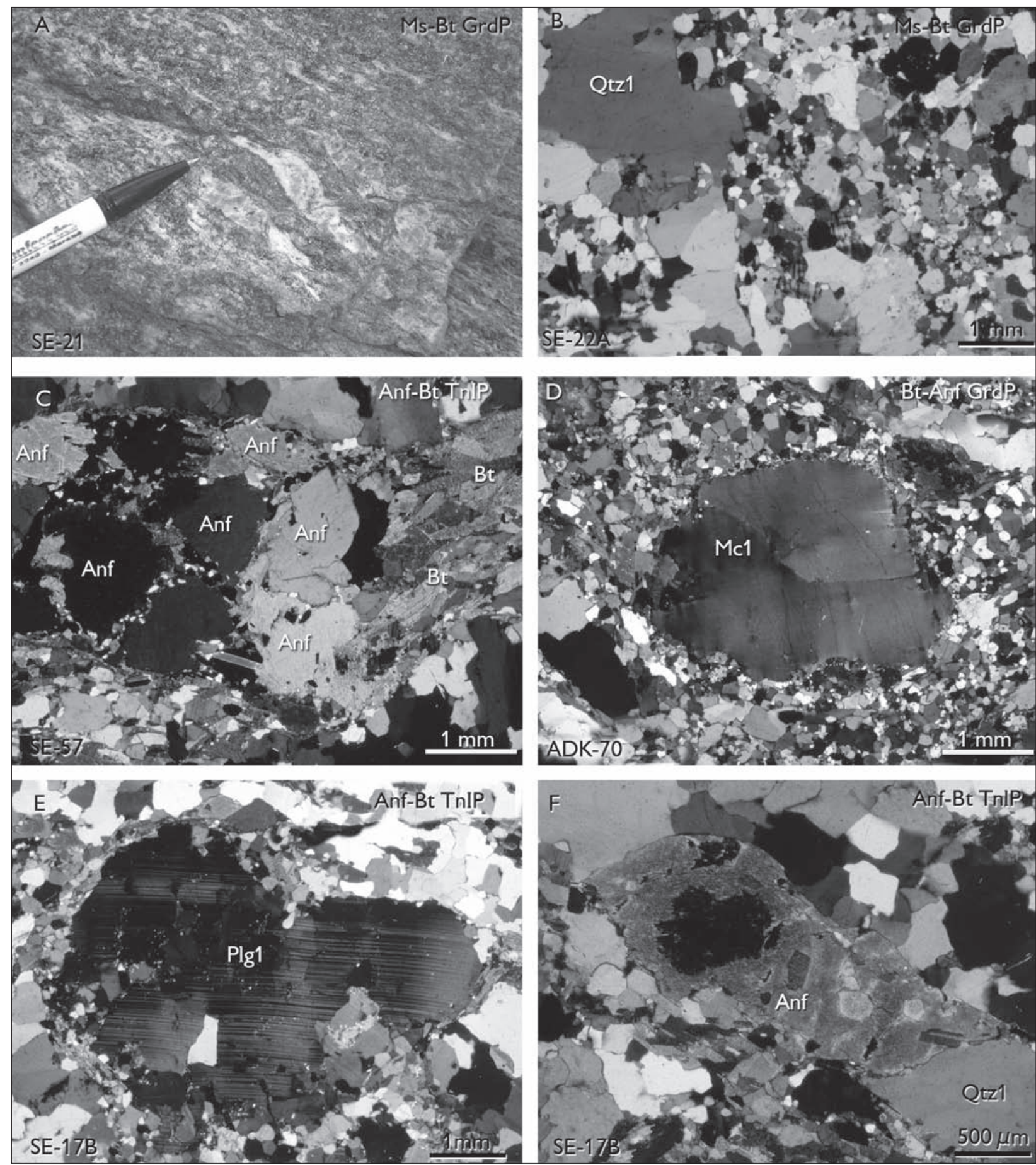

Figura 6. Aspectos deformacionais e microestruturais das rochas estudadas: A) granodiorito com porfiroclastos de K-feldspato do tipo sigma, GAL. Foto: E. O. Gabriel \& D. C. Oliveira. Fotomicrografias com nicóis cruzados: B) cristal de quartzo com extinção ondulante em meio a agregado de neoblastos poligonizados, GAL; C) agregado de minerais máficos (clusters) fortemente orientado, GAL; D) porfiroclasto de microclina com textura 'manto-núcleo', GAL; E) porfiroclasto de plagioclásio exibindo microfraturas, extinção ondulante e encurvamento das maclas, GAL; F) porfiroclasto de anfibólio em forma ocelar do tipo fish, GAL. Legendas: Qtz1 = Quartzo; Anf = anfibólio; Bt = biotita; Mc1 = microclima; Plg1 = plagioclásio. 
policristalinos entre os feldspatos, muitas vezes bordejado por novos grãos (Figura 6B). Com o aumento do grau de deformação, esse mineral desenvolve extinção ondulante, bandas de deformação, e forma subgrãos, cristais orientados e estirados como ribbons. O aumento gradual da recristalização leva ao surgimento de neoblastos finos (quartzo 2), que, em casos extremos, chegam a formar agregados orientados, muitos destes poligonais, de fraca extinção ondulante; (iii) biotita 1 forma pequenos agregados, dispostos em finos níveis descontínuos e ondulados, fortemente orientados, que, em alguns casos, bordejam os porfiroclastos de feldspatos. É possível encontrar localmente cristais com incipiente extinção ondulante e microkinks. Nas rochas mais recristalizadas, ocorrem neoblastos lamelares finos (biotita 2), orientados; (iv) o anfibólio pode ser encontrado fortemente orientado em agregados de minerais máficos, geralmente como cristais porfiroclásticos, que tendem a ter redução na granulação em resposta à recristalização, muitas vezes dando lugar à biotita 2. Em alguns casos, clastos de anfibólio têm formas ocelares do tipo fish (Figura 6F).

\section{GEOQUÍMICA}

Foram realizadas análises químicas de elementos maiores, menores e traço em 15 amostras representativas do GAL e 12 do GAA (Tabela 3). As análises foram realizadas no ACME Analytical Laboratories Ltd., sendo utilizados os pacotes analíticos 4A e 4B. Os métodos empregados e os limites de detecção podem ser encontrados em AcmeLabs (s.d.). Os elementos maiores e menores foram analisados por Inductively Coupled Plasma - Emission Spectrometry (ICP-ES), enquanto que os elementos-traço e terras raras foram analisados por Inductively Coupled Plasma - Mass Spectrometry (ICP-MS).

\section{ELEMENTOS MAIORES E MENORES}

O GAL apresenta variação de $\mathrm{SiO}_{2}(58,5$ a $72,6 \%)$ mais ampla quando comparado ao GAA (62,0 a 69,1\%; Tabela 3). Em ambos, os teores mais baixos de sílica estão associados às variedades portadoras de anfibólio (menos evoluídas), enquanto que os teores mais elevados associam-se às fácies sem anfibólio e com a biotita como principal mineral ferromagnesiano (mais evoluídas). As fácies do GAL mostram variações importantes nos teores de sílica, aumentando suas médias a partir dos Anf-Bt-TnlP (62,6\%), passando pelos Bt-Anf-GrdP $(65,9 \%)$ até os Ms-Bt-GrdP (71,6\%). Comportamento análogo, porém com variação menos acentuada, é observado no GAA, cujos teores médios de sílica aumentam a partir dos Ep-Anf-Bt-TnlP (64,4\%), passando pelos Ep-Anf-Bt-GrdP (65,3\%) até os (Anf)-Ep-Bt-MzGP (67,8\%) e (Ms)-Bt-GrdP (68,9\%).

$\mathrm{O}_{2} \mathrm{O}$ mostra correlação positiva com a sílica (Figura 7A), com aumento acentuado em direção às variedades mais evoluídas, tanto no GAA (2,9 a 4,3\%) quanto no $\operatorname{GAL}(2,1$ e $4,3 \%)$, porém com ligeiro decréscimo da fácies Bt-Anf-GrdP (3,5\%) para o Ms-Bt-GrdP (3,2\%). A razão $\mathrm{K}_{2} \mathrm{O} / \mathrm{Na}_{2} \mathrm{O}$ apresenta comportamento similar ao discutido para $\circ \mathrm{K}_{2} \mathrm{O}$ (Figura 7B). Os conteúdos de $\mathrm{Al}_{2} \mathrm{O}_{3}$ (Figura 7C) são moderados, com valores médios de 15,2\% para o GAL e 15,1\% para o GAA, ligeiramente inferiores aos observados em típicas séries cálcio-alcalinas em rochas de teores similares de sílica, assim como observado para o $\mathrm{Na}_{2} \mathrm{O}$ (Figura 7D; 4,1\% e 3,9\% para os GAL e GAA, respectivamente). Além disso, o $\mathrm{Al}_{2} \mathrm{O}_{3}$ exibe leve correlação negativa com $\mathrm{SiO}_{2}$ entre as variedades petrográficas, enquanto $\circ \mathrm{Na}_{2} \mathrm{O}$ não exibe variações significativas. Ressalte-se que esses valores são inferiores aos das típicas séries cálcio-alcalinas (Irvine \& Baragar, 1971).

Diagramas de Harker (1965) (Figuras 7E-7H) revelam decréscimo acentuado dos teores de $\mathrm{CaO}, \mathrm{Fe}_{2} \mathrm{O}_{3 t^{\prime}} \mathrm{MgO}$ e $\mathrm{TiO}_{2}$ com o incremento da sílica para as amostras dos corpos estudados. Os conteúdos de MgO são elevados e pouco divergentes entre as duas unidades, porém o valor médio deste óxido é mais alto no GAA (2,5\%; Tabela 3), enquanto que no GAL esse valor fica em torno de 2,3\%. Essa diferença ocorre devido à variação significativa de $\mathrm{MgO}$ entre as fácies do GAL, onde os teores médios diminuem linearmente com o aumento de $\mathrm{SiO}_{2}$ a partir dos Anf-Bt-TnlP $(3,4 \%)$ e Bt-Anf-GrdP (2,5\%) até os Ms-Bt-GrdP (0,9\%). 
Tabela 3. Composições químicas dos granodioritos Água Azul e Água Limpa. Legendas: Eu/Eu* $\left.\left.=\mathrm{Eu}_{N} /\left(\mathrm{Sm}_{N}+\mathrm{Gd}_{N}\right) * 0,5\right)\right]$; \#Mg $=$ razão molecular $\mathrm{Mg} /(\mathrm{Mg}+\mathrm{Fe}) ; \mathrm{A} / \mathrm{CNK}=\mathrm{Al}_{2} \mathrm{O}_{3 \mathrm{~mol}} /\left(\mathrm{CaO}_{\mathrm{mol}}+\mathrm{Na}_{2} \mathrm{O}_{\text {mol }}+\mathrm{K}_{2} \mathrm{O}_{\text {mol }}\right) ; \mathrm{Anf}=$ anfibólio; $\mathrm{Bt}=$ biotita; $\mathrm{Ep}=$ epidoto; $\mathrm{Ms}=$ muscovita; $\mathrm{Grd}$ = granodiorito; $\mathrm{MzG}=$ monzogranito; Tnl = tonalito; $\mathrm{P}=$ porfirítico; (1)Compilado do Trabalho de Conclusão de Curso de D. S. Rodrigues, de 2010, intitulado "Petrografia, geoquímica e geocronologia do granito Boa Sorte, município de Água Azul do Norte, Província Carajás".

(Continua)

\begin{tabular}{|c|c|c|c|c|c|c|c|c|c|c|c|c|c|c|c|c|c|c|}
\hline & \multicolumn{18}{|c|}{ Granodiorito Água Limpa } \\
\hline & \multicolumn{6}{|c|}{ Anf-Bt-TnlP } & \multicolumn{6}{|c|}{ Bt-Anf-GrdP } & \multicolumn{6}{|c|}{ Ms-Bt-GrdP } \\
\hline & $\begin{array}{c}\text { ADK } \\
91\end{array}$ & $\begin{array}{l}\text { SE } \\
45\end{array}$ & $\begin{array}{c}\text { SE } \\
20 \mathrm{~A}(\mathrm{a})\end{array}$ & $\begin{array}{l}\text { ADK } \\
75\end{array}$ & $\begin{array}{c}\text { SE } \\
17 A\end{array}$ & Média & $\begin{array}{c}\text { ADK } \\
83\end{array}$ & $\begin{array}{c}\text { ADK } \\
70\end{array}$ & $\begin{array}{c}\text { MRS } \\
41\end{array}$ & $\begin{array}{c}\text { DD } \\
10\end{array}$ & $\begin{array}{c}\text { ADK } \\
39\end{array}$ & Média & $\begin{array}{l}\text { (1) } S E \\
22 a\end{array}$ & $\begin{array}{l}\text { SE } \\
34\end{array}$ & $\begin{array}{c}\text { EDC } \\
52\end{array}$ & $\begin{array}{l}\text { SE } \\
56 a\end{array}$ & $\begin{array}{l}\text { SE } \\
27\end{array}$ & Média \\
\hline $\begin{array}{l}\mathrm{SiO}_{2} \\
(\%)\end{array}$ & 58,45 & 58,59 & 63,14 & 66,12 & 66,69 & 62,60 & 62,64 & 66,14 & 66,44 & 67,03 & 67,43 & 65,94 & 70,76 & 71,46 & 71,71 & 71,74 & 72,58 & 71,65 \\
\hline $\mathrm{TiO}_{2}$ & 0,63 & 0,61 & 0,47 & 0,40 & 0,35 & 0,49 & 0,47 & 0,38 & 0,35 & 0,34 & 0,32 & 0,37 & 0,25 & 0,30 & 0,22 & 0,26 & 0,15 & 0,24 \\
\hline $\mathrm{Al}_{2} \mathrm{O}_{3}$ & 15,93 & 16,68 & 15,96 & 15,37 & 15,49 & 15,89 & 15,53 & 15,08 & 14,72 & 15,10 & 14,76 & 15,04 & 14,55 & 15,03 & 14,39 & 14,71 & 14,75 & 14,69 \\
\hline $\mathrm{Fe}_{2} \mathrm{O}_{3 \mathrm{t}}$ & 6,70 & 6,37 & 4,66 & 3,88 & 3,58 & 5,04 & 4,99 & 3,85 & 4,18 & 3,32 & 3,56 & 3,98 & 2,41 & 2,28 & 2,09 & 2,09 & 1,37 & 2,05 \\
\hline $\mathrm{MnO}$ & 0,09 & 0,09 & 0,08 & 0,05 & 0,05 & 0,07 & 0,07 & 0,06 & 0,03 & 0,05 & 0,05 & 0,05 & 0,03 & 0,03 & 0,02 & 0,02 & 0,01 & 0,02 \\
\hline $\mathrm{MgO}$ & 4,80 & 4,42 & 3,02 & 2,50 & 2,18 & 3,38 & 3,39 & 2,51 & 2,51 & 2,06 & 2,15 & 2,52 & 1,06 & 0,90 & 1,08 & 0,90 & 0,50 & 0,89 \\
\hline $\mathrm{CaO}$ & 5,23 & 5,25 & 3,77 & 3,38 & 2,97 & 4,12 & 4,10 & 3,36 & 3,18 & 3,00 & 2,87 & 3,30 & 2,04 & 2,86 & 2,12 & 2,10 & 1,66 & 2,16 \\
\hline $\mathrm{Na}_{2} \mathrm{O}$ & 3,78 & 4,51 & 4,00 & 4,07 & 4,04 & 4,08 & 4,18 & 3,91 & 3,58 & 4,09 & 3,86 & 3,92 & 4,20 & 4,36 & 4,16 & 4,15 & 4,04 & 4,18 \\
\hline $\mathrm{K}_{2} \mathrm{O}$ & 2,86 & 2,20 & 3,22 & 3,00 & 3,67 & 2,99 & 2,91 & 3,51 & 3,98 & 3,42 & 3,84 & 3,53 & 3,17 & 2,10 & 3,05 & 3,38 & 4,28 & 3,20 \\
\hline $\mathrm{P}_{2} \mathrm{O}_{5}$ & 0,24 & 0,24 & 0,19 & 0,15 & 0,16 & 0,20 & 0,18 & 0,14 & 0,14 & 0,12 & 0,12 & 0,14 & 0,09 & 0,07 & 0,06 & 0,08 & 0,07 & 0,07 \\
\hline PF & 0,90 & 0,60 & 1,10 & 0,60 & 0,40 & 0,72 & 1,20 & 0,70 & 0,60 & 1,10 & 0,70 & 0,86 & 1,10 & 0,40 & 0,80 & 0,30 & 0,30 & 0,58 \\
\hline Total & 99,61 & 99,56 & 99,61 & 99,52 & 99,58 & 99,58 & 99,66 & 99,64 & 99,71 & 99,63 & 99,66 & 99,66 & 99,66 & 99,79 & 99,70 & 99,73 & 99,71 & 99,72 \\
\hline $\begin{array}{c}\mathrm{Ba} \\
(\mathrm{ppm})\end{array}$ & 1.196 & 1.121 & 1.671 & 1.966 & 1.760 & 1.543 & 1.029 & 1.286 & 925 & 1.193 & 950 & 1.077 & 935 & 519 & 1.331 & 1.108 & 1.237 & 1.026 \\
\hline $\mathrm{Sr}$ & 833 & 912,1 & 644,3 & 710,7 & 773,5 & 775 & 696 & 684,5 & 483,7 & 687,9 & 618,6 & 634 & 481,7 & 310,5 & 550,7 & 483,2 & 519,1 & 469,0 \\
\hline $\mathrm{Rb}$ & 102,1 & 76,0 & 89,0 & 85,8 & 97,3 & 90,0 & 127,1 & 115,3 & 152,2 & 148,2 & 140,8 & 137,0 & 111,5 & 75,6 & 89,8 & 98,7 & 113,8 & 97,9 \\
\hline $\mathrm{Zr}$ & 164,6 & 171,9 & 140,2 & 139,9 & 132,1 & 150,0 & 148,8 & 122,4 & 118,4 & 112,4 & 112,6 & 123,0 & 121,8 & 143,4 & 101,3 & 97,9 & 179,6 & 129,0 \\
\hline$Y$ & 12,2 & 11,2 & 13,5 & 10,7 & 5,8 & 10,7 & 13,3 & 8,5 & 11,1 & 6,7 & 7,2 & 9,4 & 2,8 & 2,8 & 1,9 & 2,0 & 2,3 & 2,4 \\
\hline $\mathrm{Nb}$ & 6,5 & 7,2 & 5,7 & 3,9 & 2,9 & 5,2 & 5,7 & 3,8 & 6,1 & 4,4 & 5,4 & 5,1 & 4,3 & 4,1 & 2,7 & 3,0 & 2,1 & 3,2 \\
\hline $\mathrm{Ga}$ & 19,9 & 21,1 & 18,6 & 17,9 & 17,3 & 19,0 & 19,5 & 16,6 & 16,5 & \begin{tabular}{|l|}
17,7 \\
\end{tabular} & 16,2 & 17,3 & 16,3 & 18,0 & 16,2 & 17,8 & 16,3 & 16,9 \\
\hline Th & 5,0 & 2,8 & 3,9 & 5,4 & 6,1 & 4,6 & 4,9 & 13,6 & 23,1 & \begin{tabular}{|l|}
13,3 \\
\end{tabular} & 19,8 & 14,9 & 15,0 & 4,0 & 6,9 & 14,8 & 37,6 & 15,7 \\
\hline $\mathrm{Ni}$ & 56,7 & 59,9 & 42,0 & 33,6 & 32,7 & 45,0 & 42,5 & 32,6 & 41,1 & 28,1 & 28,2 & 34,5 & 20,2 & 12,1 & 18,1 & 15,4 & 7,6 & 14,7 \\
\hline $\mathrm{Cr}$ & 260,0 & 239,5 & 157,4 & 123,2 & 109,5 & 178,0 & 184,7 & 136,8 & 143,7 & 102,6 & 123,2 & 138,0 & 40,1 & 20,5 & 54,7 & 41,1 & \begin{tabular}{|l|}
13,7 \\
\end{tabular} & 34,0 \\
\hline Co & 59,1 & 49,8 & 37,1 & 51,9 & 40,4 & 47,7 & 51,0 & 49,3 & 50,0 & 51,3 & 62,8 & 52,9 & 76,9 & 70,1 & 55,1 & 59,1 & 51,1 & 62,5 \\
\hline $\begin{array}{c}\mathrm{La} \\
(\mathrm{ppm})\end{array}$ & 31,3 & 35,5 & 38,2 & 34,4 & 34,5 & 34,8 & 35,7 & 48,8 & 57,8 & 28,8 & 26,9 & 39,6 & 29,2 & 27,0 & 30,1 & 30,7 & 37,1 & 30,8 \\
\hline $\mathrm{Ce}$ & 60,1 & 69,5 & 69,2 & 56,4 & 57,4 & 62,5 & 58,3 & 69,0 & 97,6 & 49,2 & 66,3 & 68,1 & 60,6 & 43,8 & 43,7 & 46,3 & 66,0 & 52,1 \\
\hline $\operatorname{Pr}$ & 7,47 & 7,73 & 8,15 & 6,69 & 6,36 & 7,3 & 7,31 & 8,66 & 11,11 & 5,44 & 6,01 & 7,7 & 6,11 & 4,9 & 4,88 & 5,32 & 6,2 & 5,5 \\
\hline $\mathrm{Nd}$ & 28,2 & 30,2 & 31,2 & 24,9 & 23,1 & 27,5 & 29,9 & 31,4 & 40,6 & 19,7 & 19,5 & 28,2 & 20,8 & 16,2 & 15,5 & 18,2 & 18,0 & 17,7 \\
\hline $\mathrm{Sm}$ & 4,74 & 4,79 & 5,4 & 4,02 & 3,16 & 4,4 & 4,75 & 4,05 & 5,49 & 3,03 & 3,29 & 4,1 & 2,69 & 2,02 & 1,76 & 1,93 & 2,63 & 2,0 \\
\hline
\end{tabular}


Tabela 3.

(Continua)

\begin{tabular}{|c|c|c|c|c|c|c|c|c|c|c|c|c|c|c|c|c|c|c|}
\hline & \multicolumn{18}{|c|}{ Granodiorito Água Limpa } \\
\hline & \multicolumn{6}{|c|}{ Anf-Bt-TnlP } & \multicolumn{6}{|c|}{ Bt-Anf-GrdP } & \multicolumn{6}{|c|}{ Ms-Bt-GrdP } \\
\hline & $\begin{array}{c}\text { ADK } \\
91\end{array}$ & \begin{tabular}{l|l} 
SE & \\
45
\end{tabular} & $\left|\begin{array}{c}\text { SE } \\
20 A(a)\end{array}\right|$ & $\begin{array}{c}\text { ADK } \\
75\end{array}$ & $\begin{array}{l}\text { SE } \\
17 A\end{array}$ & A Méc & \begin{tabular}{c|c} 
ADK & ADK \\
83
\end{tabular} & $\begin{array}{c}\mathrm{ADK} \\
70\end{array}$ & $\begin{array}{c}\text { MRS } \\
41\end{array}$ & $\begin{array}{c}\text { DD } \\
10\end{array}$ & $\begin{array}{c}\text { ADK } \\
39\end{array}$ & Média & $\begin{array}{l}\text { (1) SE } \\
22 \mathrm{a}\end{array}$ & $\begin{array}{l}\text { SE } \\
34\end{array}$ & $\begin{array}{c}\text { EDC } \\
52\end{array}$ & $\begin{array}{c}\text { SE } \\
56 a\end{array}$ & $\begin{array}{l}\text { SE } \\
27\end{array}$ & Média \\
\hline $\mathrm{Eu}$ & 1,1 & 1,15 & 1,02 & 0,97 & 0,8 & 1,0 & 0,99 & \begin{tabular}{l|l}
9 & 0,96
\end{tabular} & 1,45 & 0,75 & 0,7 & 1,0 & \begin{tabular}{|l|l}
0,56 \\
\end{tabular} & 0,64 & 0,62 & 0,63 & 0,67 & 0,6 \\
\hline Gd & 3,18 & 3,37 & 3,97 & 2,95 & 1,9 & 3 & 3,22 & $2 \quad 2,55$ & 3,78 & 2,08 & 2,08 & 2,7 & 1,26 & 1,25 & 0,96 & 1,08 & 1,13 & 1,1 \\
\hline $\mathrm{Tb}$ & 0,44 & 0,45 & 0,54 & 0,4 & 0,2 & 0, & 0,45 & $5 \quad 0,34$ & 0,48 & 0,26 & 0,3 & 0,4 & 0,14 & 0,14 & 0,09 & 0,11 & 0,12 & 0,1 \\
\hline Dy & 2,24 & 2,17 & 2,44 & 1,98 & 1,3 & 2, & 2,27 & \begin{tabular}{l|l}
7 & 1,69
\end{tabular} & 2,38 & 1,23 & 1,37 & 1,8 & 0,57 & 0,6 & 0,38 & 0,44 & 0,49 & 0,5 \\
\hline $\mathrm{Ho}$ & 0,46 & 0,4 & 0,44 & 0,42 & 0,2 & 0, & 0,44 & 0,3 & 0,41 & 0,22 & 0,27 & 0,3 & \begin{tabular}{|l|l}
0,07 \\
\end{tabular} & 0,09 & 0,08 & 0,07 & 0,07 & 0,1 \\
\hline $\mathrm{Er}$ & 1,14 & 1,05 & 1,36 & 0,91 & 0,4 & $1, \mathrm{C}$ & 1,28 & \begin{tabular}{l|l}
3 & 0,79
\end{tabular} & 1,14 & 0,59 & 0,77 & 0,9 & 0,21 & 0,2 & 0,15 & 0,16 & 0,24 & 0,2 \\
\hline $\mathrm{Tm}$ & 0,18 & 0,16 & 0,18 & 0,13 & 0,0 & 0 , & 0,19 & 0,12 & 0,2 & 0,09 & 0,1 & 0,1 & \begin{tabular}{|l|l}
0,04 \\
\end{tabular} & 0,04 & 0,01 & 0,03 & 0,03 & 0,03 \\
\hline $\mathrm{Yb}$ & 1,13 & 0,95 & 1,16 & 0,72 & 0,5 & 1, & 1,03 & 0,7 & 1,2 & 0,53 & 0,74 & 0,8 & 0,25 & 0,26 & 0,12 & 0,16 & 0,2 & 0,2 \\
\hline $\mathrm{Lu}$ & 0,16 & 0,13 & 0,14 & 0,12 & 0,0 & 0 & 0,16 & 0,12 & 0,16 & 0,1 & 0,11 & 0,1 & \begin{tabular}{|l|l}
0,04 \\
\end{tabular} & 0,04 & 0,03 & 0,02 & 0,02 & 0,03 \\
\hline$\Sigma$ ETR & 141,8 & 157,6 & 163,4 & \begin{tabular}{|l|l}
$\mid 135,0$ & 1
\end{tabular} & 130 & \begin{tabular}{l|l}
, 3 & 145
\end{tabular} & \begin{tabular}{l|l}
5,6 & $146, C$
\end{tabular} & \begin{tabular}{l|l}
0 & 169,5
\end{tabular} & 223,8 & 112,0 & 128,4 & 155,9 & $\mid 116,3$ & 97,2 & 98,4 & 105,2 & 132,9 & 110,0 \\
\hline$(\mathrm{La} / \mathrm{Yb})_{\mathrm{N}}$ & 18,7 & \begin{tabular}{|l|l|}
25,22 & 2 \\
\end{tabular} & 22,23 & 32,25 & 40,1 & 15 27, & \begin{tabular}{l|l}
7,7 & 23,39
\end{tabular} & 9477,06 & $6 \quad 32,51$ & 36,68 & 24,54 & $\mid 32,8$ & \begin{tabular}{|l|l|}
78,84 & 7 \\
\end{tabular} & \begin{tabular}{l|l}
70,09 & 1 \\
\end{tabular} & 169,3 & \begin{tabular}{l|l}
3 & 129,5 \\
\end{tabular} & 125,2 & 114,6 \\
\hline Eu/Eu* & 0,82 & 0,83 & 0,65 & 0,82 & 0,9 & $0, \varepsilon$ & 0,73 & \begin{tabular}{l|l}
3 & 0,85
\end{tabular} & 0,92 & 0,87 & 0,76 & 0,8 & 0,82 & 1,15 & 1,33 & 1,22 & 1,02 & 1,1 \\
\hline $\mathrm{Rb} / \mathrm{Sr}$ & 0,12 & 0,08 & 0,14 & 0,12 & 0,1 & 0 & 0,18 & 0,17 & 0,31 & 0,22 & 0,23 & 0,2 & \begin{tabular}{|l|l}
0,23 \\
\end{tabular} & 0,24 & 0,16 & 0,20 & 0,22 & 0,2 \\
\hline $\mathrm{Sr} / \mathrm{Ba}$ & 0,70 & 0,81 & 0,39 & 0,36 & 0,4 & 0, & 0,68 & $8 \quad 0,53$ & 0,52 & 0,58 & 0,65 & 0,6 & \begin{tabular}{|l|l}
0,52 \\
\end{tabular} & 0,60 & 0,41 & 0,44 & 0,42 & 0,5 \\
\hline $\mathrm{K}_{2} \mathrm{O} / \mathrm{Na}_{2} \mathrm{O}$ & 0,76 & 0,49 & 0,81 & 0,74 & 0,9 & 0, & 0,70 & 0,90 & 1,11 & 0,84 & 0,99 & 0,9 & \begin{tabular}{|l|l}
0,75 & $C$ \\
\end{tabular} & $0,48 \quad C$ & 0,73 & 0,81 & 1,06 & 0,8 \\
\hline$\# M g$ & 0,59 & 0,58 & 0,56 & 0,56 & 0,5 & 0, & 0,57 & $7 \quad 0,56$ & 0,54 & 0,55 & 0,54 & 0,6 & $0,47 \quad$ & 0,44 & 0,51 & 0,46 & 0,42 & 0,5 \\
\hline \multirow[t]{4}{*}{$\mathrm{A} / \mathrm{CNK}$} & 0,85 & 0,86 & 0,94 & 0,96 & 0,9 & 0, & 0,89 & \begin{tabular}{l|l}
9 & 0,92
\end{tabular} & 0,92 & 0,95 & 0,94 & 0,9 & \begin{tabular}{l|l}
1,04 \\
\end{tabular} & 1,03 & 1,03 & 1,03 & 1,03 & 1,03 \\
\hline & \multicolumn{18}{|c|}{ Granodiorito Água Azul } \\
\hline & \multicolumn{3}{|c|}{ Ep-Anf-Bt-TnlP } & \multicolumn{6}{|c|}{ Ep-Anf-Bt-GrdP } & \multicolumn{7}{|c|}{ (Anf)-Ep-Bt-MzGP } & \multicolumn{2}{|c|}{ (Ms)Bt-GrdP } \\
\hline & $\begin{array}{c}\text { EDC } \\
76\end{array}$ & $\begin{array}{l}\text { SE } \\
85\end{array}$ & Média & $\begin{array}{l}\text { SE } \\
51\end{array}$ & & $\begin{array}{l}\text { SE } \\
08\end{array}$ & $\begin{array}{l}\text { SE } \\
94\end{array}$ & $\begin{array}{c}\text { EDC } \\
75\end{array}$ & Média & $\begin{array}{c}\text { SDA } \\
01\end{array}$ & $\begin{array}{c}\text { EDC } \\
77\end{array}$ & $\begin{array}{c}\text { EDC } \\
74 a\end{array}$ & $\begin{array}{c}\text { EDC } \\
71\end{array}$ & $\begin{array}{c}\text { EDC } \\
73\end{array}$ & & Média & $\begin{array}{r}\text { EDC } \\
86\end{array}$ & \\
\hline $\begin{array}{l}\mathrm{SiO}_{2} \\
(\%)\end{array}$ & 62,04 & 66,67 & 64,36 & \begin{tabular}{l|l}
6 & 63,44
\end{tabular} & & 65,71 & 65,96 & 66,01 & 65,28 & 66,70 & 67,11 & 67,92 & \begin{tabular}{l|l}
2 & 68,29
\end{tabular} & 69,11 & & 67,83 & 68,9 & \\
\hline $\mathrm{TiO}_{2}$ & 0,45 & 0,35 & 0,40 & 0,36 & & 0,38 & 0,38 & 0,30 & 0,36 & 0,35 & 0,32 & 0,29 & 0,30 & 0,27 & & 0,31 & 0,2 & \\
\hline $\mathrm{Al}_{2} \mathrm{O}_{3}$ & 14,84 & 14,79 & 14,82 & \begin{tabular}{l|l}
2 & 16,69 \\
\end{tabular} & & 14,76 & 14,90 & 15,02 & 15,34 & 15,22 & 15,54 & 15,44 & \begin{tabular}{l|l}
4 & 14,91
\end{tabular} & \begin{tabular}{l|l}
13 & 13,49
\end{tabular} & & 14,92 & 15,2 & \\
\hline $\mathrm{Fe}_{2} \mathrm{O}_{3 \mathrm{t}}$ & 5,28 & 3,96 & 4,62 & 4,13 & & 4,61 & 4,13 & 3,37 & 4,06 & 4,82 & 2,99 & 2,77 & 3,17 & 3,59 & & 3,47 & 3,16 & \\
\hline $\mathrm{MnO}$ & 0,09 & 0,05 & 0,07 & 0,06 & & 0,04 & 0,07 & 0,04 & 0,05 & 0,01 & 0,04 & 0,04 & 0,05 & 0,09 & & 0,05 & 0,0 & \\
\hline $\mathrm{MgO}$ & 4,78 & 2,39 & 3,59 & 2,57 & & 2,75 & 2,70 & 2,95 & 2,74 & 2,38 & 1,81 & 1,59 & 1,80 & 2,41 & & 2,00 & 2,0 & \\
\hline $\mathrm{CaO}$ & 3,28 & 3,11 & 3,20 & 3,03 & & 2,90 & 3,37 & 2,81 & 3,03 & 1,66 & 2,43 & 2,57 & 2,65 & 1,76 & & 2,21 & 1,70 & \\
\hline $\mathrm{Na}_{2} \mathrm{O}$ & 3,82 & 3,85 & 3,84 & 4,55 & & 3,75 & 3,88 & 3,90 & 4,02 & 3,76 & 3,91 & 4,00 & 4,10 & 3,16 & & 3,79 & 4,5 & \\
\hline $\mathrm{K}_{2} \mathrm{O}$ & 2,96 & 3,70 & 3,33 & 3,74 & & 3,61 & 3,57 & 3,84 & 3,69 & 3,81 & 3,98 & 4,01 & 3,34 & 4,32 & & 3,89 & 3,0 & \\
\hline $\mathrm{P}_{2} \mathrm{O}_{5}$ & 0,14 & 0,14 & 0,14 & 0,11 & & 0,15 & 0,15 & 0,11 & 0,13 & 0,13 & 0,11 & 0,11 & 0,11 & 0,10 & & 0,11 & 0,10 & \\
\hline PF & 2,00 & 0,70 & 1,35 & 1,00 & & 1,00 & 0,60 & 1,30 & 0,98 & 0,90 & 1,40 & 0,90 & 1,00 & 1,40 & & 1,12 & 0,7 & \\
\hline Total & 99,68 & 99,71 & 99,70 & \begin{tabular}{l|l}
0 & 99,68
\end{tabular} & & 99,66 & 99,71 & 99,65 & 99,68 & 99,74 & 99,64 & 99,64 & \begin{tabular}{l|l}
4 & 99,72
\end{tabular} & $2 \mid 99,70$ & & 99,69 & 99,7 & \\
\hline
\end{tabular}


Tabela 3.

(Conclusão)

\begin{tabular}{|c|c|c|c|c|c|c|c|c|c|c|c|c|c|c|c|}
\hline & \multicolumn{15}{|c|}{ Granodiorito Água Azul } \\
\hline & \multicolumn{3}{|c|}{ Ep-Anf-Bt-TnlP } & \multicolumn{5}{|c|}{ Ep-Anf-Bt-GrdP } & \multicolumn{6}{|c|}{ (Anf)-Ep-Bt-MzGP } & \multirow{2}{*}{$\begin{array}{c}(\mathrm{Ms}) \mathrm{Bt}-\mathrm{GrdP} \\
\mathrm{EDC} \\
86\end{array}$} \\
\hline & $\begin{array}{c}\text { EDC } \\
76\end{array}$ & $\begin{array}{l}\text { SE } \\
85\end{array}$ & Média & $\begin{array}{l}\text { SE } \\
51\end{array}$ & $\begin{array}{l}\text { SE } \\
08\end{array}$ & $\begin{array}{l}\text { SE } \\
94\end{array}$ & $\begin{array}{c}\text { EDC } \\
75\end{array}$ & Média & $\begin{array}{c}\text { SDA } \\
01\end{array}$ & $\begin{array}{c}\text { EDC } \\
77\end{array}$ & $\begin{array}{l}\text { EDC } \\
74 a\end{array}$ & $\begin{array}{c}\text { EDC } \\
71\end{array}$ & $\begin{array}{c}\text { EDC } \\
73\end{array}$ & Média & \\
\hline $\begin{array}{c}\mathrm{Ba} \\
(\mathrm{ppm})\end{array}$ & 855 & 796 & 825,5 & 1.187 & 824 & 877 & 1.193 & 1.020 & 647 & 1.458 & 1.261 & 1.095 & 1.077 & 1.108 & 634 \\
\hline $\mathrm{Sr}$ & 477,6 & 540,4 & 509,0 & 645,8 & 506,8 & 581,7 & 611,0 & 586 & 301,3 & 577,9 & 657,5 & 656,6 & 355,1 & 510,0 & 432,4 \\
\hline $\mathrm{Rb}$ & 127,9 & 152,1 & 140,0 & 113,7 & 144,5 & 134,7 & 94,9 & 122,0 & 205,7 & 128,3 & 134,5 & 119,0 & 147,8 & 147,0 & 103,1 \\
\hline $\mathrm{Zr}$ & 156,6 & 127,9 & 142,3 & 146,1 & 129,0 & 110,3 & 115,9 & 125,0 & 118,6 & 126,2 & 133,5 & 129,4 & 101,0 & 122,0 & 108,9 \\
\hline Y & 10,1 & 9,3 & 9,7 & 7,3 & 9,1 & 12,8 & 7,0 & 9,05 & 9,2 & 10,5 & 6,1 & 6,1 & 11,2 & 8,6 & 6,5 \\
\hline $\mathrm{Nb}$ & 6,7 & 6,0 & 6,35 & 4,5 & 5,5 & 6,3 & 6,0 & 5,6 & 4,1 & 5,4 & 4,2 & 4,3 & 6,2 & 4,8 & 4,7 \\
\hline $\mathrm{Ga}$ & 17,9 & 16,5 & 17,2 & 19,5 & 17,4 & 17,2 & 16,7 & 17,7 & 18,7 & 17,1 & 17,7 & 18,2 & 17,9 & 17,9 & 17,1 \\
\hline Th & 11,4 & 20,5 & 15,95 & 12,4 & 19,6 & 16,4 & 17,3 & 16,4 & 9,5 & 14,3 & 13,8 & 17,7 & 15,5 & 14,2 & 18,6 \\
\hline $\mathrm{Ni}$ & 117,3 & 37,1 & 77,2 & 45,1 & 46,6 & 39,9 & 65,4 & 49,3 & 31,7 & 33,2 & 26,8 & 32,1 & 38,1 & 32,4 & 30,7 \\
\hline $\mathrm{Cr}$ & 383,2 & 130,0 & 257,0 & 123,2 & 150,5 & 157,4 & 232,6 & 166,0 & 109,5 & 95,8 & 75,3 & 88,9 & 88,9 & 91,7 & 88,9 \\
\hline Co & 56,1 & 53,8 & 54,95 & 46,8 & 59,7 & 52,5 & 55,4 & 53,6 & 51,2 & 49,2 & 57,8 & 50,9 & 51,2 & 52,1 & 53,6 \\
\hline La (ppm) & 31,3 & 47,5 & 39,4 & 25,6 & 38,9 & 35,7 & 28,7 & 32,2 & 43,0 & 39,9 & 32,1 & 32,0 & 44,1 & 38,2 & 27,4 \\
\hline $\mathrm{Ce}$ & 58,8 & 80,5 & 69,65 & 46,4 & 68,6 & 57,9 & 54,5 & 56,9 & 77,2 & 53,0 & 50,2 & 60,7 & 74,5 & 63,1 & 50,5 \\
\hline $\operatorname{Pr}$ & 6,51 & 8,5 & 7,505 & 5,23 & 7,42 & 8,0 & 5,88 & 6,6 & 8,01 & 6,72 & 5,88 & 6,21 & 8,96 & 7,2 & 5,42 \\
\hline $\mathrm{Nd}$ & 23,9 & 28,3 & 26,1 & 19,7 & 26,2 & 27,7 & 19,5 & 23,3 & 27,3 & 23,9 & 22,2 & 21,1 & 33,1 & 25,5 & 19,6 \\
\hline $\mathrm{Sm}$ & 3,77 & 3,8 & 3,785 & 3,18 & 3,82 & 4,83 & 2,97 & 3,7 & 4,11 & 3,46 & 2,81 & 3,04 & 4,8 & 3,6 & 2,79 \\
\hline $\mathrm{Eu}$ & 0,73 & 0,81 & 0,77 & 0,88 & 0,89 & 1,1 & 0,75 & 0,9 & 1,09 & 0,93 & 0,85 & 0,81 & 1,3 & 1,0 & 0,67 \\
\hline Gd & 2,78 & 2,41 & 2,595 & 2,18 & 2,5 & 3,25 & 2,1 & 2,5 & 2,88 & 2,87 & 1,87 & 1,91 & 3,28 & 2,6 & 1,85 \\
\hline $\mathrm{Tb}$ & 0,39 & 0,34 & 0,365 & 0,29 & 0,34 & 0,47 & 0,28 & 0,4 & 0,38 & 0,36 & 0,22 & 0,24 & 0,43 & 0,4 & 0,24 \\
\hline Dy & 2,03 & 1,6 & 1,815 & 1,63 & 1,6 & 2,4 & 1,34 & 1,7 & 1,85 & 1,64 & 1,01 & 1,16 & 2,05 & 1,5 & 1,32 \\
\hline $\mathrm{Ho}$ & 0,38 & 0,3 & 0,34 & 0,27 & 0,33 & 0,46 & 0,24 & 0,3 & 0,27 & 0,29 & 0,2 & 0,21 & 0,36 & 0,3 & 0,25 \\
\hline $\mathrm{Er}$ & 0,99 & 0,89 & 0,94 & 0,73 & 1,0 & 1,37 & 0,76 & 1,0 & 0,76 & 0,72 & 0,49 & 0,56 & 0,93 & 0,7 & 0,57 \\
\hline $\mathrm{Tm}$ & 0,15 & 0,14 & 0,145 & 0,12 & 0,15 & 0,2 & 0,11 & 0,2 & 0,1 & 0,11 & 0,07 & 0,09 & 0,13 & 0,1 & 0,09 \\
\hline $\mathrm{Yb}$ & 0,97 & 0,79 & 0,88 & 0,75 & 1,01 & 1,08 & 0,68 & 0,9 & 0,75 & 0,79 & 0,43 & 0,6 & 0,95 & 0,7 & 0,6 \\
\hline Lu & 0,14 & 0,14 & 0,14 & 0,1 & 0,15 & 0,17 & 0,09 & 0,1 & 0,08 & 0,1 & 0,09 & 0,09 & 0,12 & 0,1 & 0,08 \\
\hline$\sum$ ETR & 132,8 & 176,0 & 154,4 & 107,1 & 152,9 & 144,6 & 117,9 & 130,6 & 167,8 & 134,8 & 118,4 & 128,7 & 175,0 & 144,9 & 111,4 \\
\hline$(\mathrm{La} / \mathrm{Yb})_{\mathrm{N}}$ & 21,78 & 40,58 & 31,18 & 23,04 & 26,0 & 22,31 & 28,49 & 25,0 & 38,7 & 34,09 & 50,39 & 36,0 & 31,33 & 38,1 & 30,82 \\
\hline $\mathrm{Eu} / \mathrm{Eu} *$ & 0,66 & 0,77 & 0,71 & 0,97 & 0,83 & 0,80 & 0,87 & 0,9 & 0,92 & 0,88 & 1,07 & 0,96 & 0,95 & 0,96 & 0,85 \\
\hline $\mathrm{Rb} / \mathrm{Sr}$ & 0,27 & 0,28 & 0,27 & 0,18 & 0,29 & 0,23 & 0,16 & 0,2 & 0,68 & 0,22 & 0,20 & 0,18 & 0,42 & 0,3 & 0,24 \\
\hline $\mathrm{Sr} / \mathrm{Ba}$ & 0,56 & 0,68 & 0,62 & 0,54 & 0,62 & 0,66 & 0,51 & 0,6 & 0,47 & 0,40 & 0,52 & 0,60 & 0,33 & 0,5 & 0,68 \\
\hline $\mathrm{K} / 2 \mathrm{O} / \mathrm{Na}_{2} \mathrm{O}$ & 0,77 & 0,96 & 0,87 & 0,82 & 0,96 & 0,92 & 0,98 & 0,9 & 1,01 & 1,02 & 1,00 & 0,81 & 1,37 & 1,0 & 0,66 \\
\hline \#Mg & 0,64 & 0,54 & 0,59 & 0,55 & 0,54 & 0,56 & 0,63 & 0,6 & 0,49 & 0,55 & 0,53 & 0,53 & 0,57 & 0,5 & 0,56 \\
\hline $\mathrm{A} / \mathrm{CNK}$ & 0,96 & 0,92 & 0,94 & 0,98 & 0,96 & 0,91 & 0,96 & 0,95 & 1,14 & 1,03 & 0,99 & 0,98 & 1,03 & 1,0 & 1,10 \\
\hline
\end{tabular}


Comportamento análogo pode ser observado para o $\mathrm{CaO}$ e $\mathrm{Fe}_{2} \mathrm{O}_{3 \mathrm{t}}$ (Figuras 7E-7F), onde o decréscimo dos teores médios desses óxidos ocorre das rochas menos evoluídas para aquelas mais enriquecidas em $\mathrm{SiO}_{2}$ (Tabela 3): GAL $\left[\mathrm{CaO}(4,1\right.$ a $2,2 \%)$ e $\mathrm{Fe}_{2} \mathrm{O}_{3 \mathrm{t}}(5,0$ a $\left.2,0 \%)\right]$ e $\mathrm{GAA}[\mathrm{CaO}$ $(3,2$ a $2,2 \%)$ e $\mathrm{Fe}_{2} \mathrm{O}_{3 \mathrm{t}}(4,6$ a $\left.3,5 \%)\right]$.

Os valores das somatórias dos teores dos principais óxidos formadores dos minerais ferromagnesianos são elevados nesses corpos, porém com importantes variações entre os tipos petrográficos. No GAL, a somatória dos óxidos $\mathrm{Fe}_{2} \mathrm{O}_{3 \mathrm{t}}+\mathrm{MgO}+\mathrm{TiO}_{2}$ é mais variável do que no GAA, sendo que os valores mais elevados correspondem às fácies portadoras de anfibólio [GAL (5,7 a 12,1\%) e GAA (6,6 a 10,5\%)] e os mais baixos àquelas de caráter mais evoluído [GAL (2,0 a 3,7\%) e GAA $(4,6$ a $7,5 \%)]$.

\section{ELEMENTOS-TRAÇO}

Em séries magmáticas, a variação dos elementos-traço reflete a diferenciação, mistura ou evolução por fusão parcial e pode subsidiar a interpretação dos processos responsáveis pela sua evolução (Wedepohl, 1970; Hanson, 1978), uma vez que a distribuição desses elementos é controlada pelas fases minerais fracionadas durante a gênese e cristalização do magma. O comportamento dos principais elementos-traço nas variedades petrográficas formadoras tanto do GAL quanto do GAA pode ser visualizado nos diagramas da Figura 8. De modo geral, Sr, Y e Zr (Figuras 8A-8C) exibem correlação negativa com a sílica, comportando-se como elementos compatíveis ao longo da história evolutiva dessas rochas, embora o $\mathrm{Zr}$ exiba variações significativas nos tipos mais enriquecidos em $\mathrm{SiO}_{2}$ (Figura 8C). Os teores médios desses elementos diminuem das variedades tonalíticas e granodioríticas portadoras de anfibólio para as rochas onde a biotita é dominante: GAL [Sr (657,5-301,3 ppm), Y (12,8-6,1 ppm), $\operatorname{Zr}$ (156,6-101,0 ppm)]; GAA [Sr (912-310 ppm), Y (13,51,9 ppm), Zr (171,9-97,9 ppm)]. Nesse mesmo sentido,
- Ba (Figura 8D) apresenta variação mais dispersa para as rochas do GAL (1.966-519 ppm), enquanto que, para o GAA, a mesma é mais discreta, observando-se um leve enriquecimento em direção às variedades mais evoluídas (824,0-1.107,6 ppm). Esse comportamento faz com que a razão Sr/Ba (Figura 8E) apresente uma moderada correlação negativa com $\mathrm{SiO}_{2}$.

O Rb (Figura 8F), para as amostras do GAL, apresenta comportamento inicialmente incompatível, com um aumento de seus teores médios da fácies Anf-Bt-TnlP (90,0 ppm) para o Bt-Anf-GrdP (136,7 ppm), e um posterior decréscimo em direção à variedade Ms-Bt-GrdP (97,88ppm), - que pode indicar mudança nas fases fracionadas. Tal comportamento é similar ao descrito para o $\mathrm{K}_{2} \mathrm{O}$ desse corpo (Figura 7A). Para as amostras do GAA, o Rb apresenta variação bastante discreta em seus conteúdos médios, que decrescem da fácies Ep-Anf-Bt-TnlP (140ppm) para o Ep-Anf-Bt-GrdP (121,9 ppm) e aumentam até a variedade (Anf)-Ep-Bt-MzGP (147,1 ppm). Comportamento similar também é observado para a razão Rb/Sr (Figura 8G).

\section{COMPORTAMENTO DOS ELEMENTOS}

\section{TERRAS RARAS (ETR)}

Os conteúdos dos ETR das rochas estudadas, quando normalizados em relação ao condrito (Evensen et al., 1978), fornecem padrões similares para as amostras do GAA e GAL, que são caracterizados pelo enriquecimento acentuado em elementos terras raras leves (ETRL) em relação aos elementos terras raras pesados (ETRP), em resposta a um moderado a forte fracionamento dos ETRP durante a formação de seus magmas (Figuras 9A e 9B). Apesar do padrão de ETR coincidente entre os dois corpos, a variedade Ms-Bt-GrdP pertencente ao GAL mostra um fracionamento mais acentuado de ETRP, como observado nas razões $\mathrm{La}_{N} / \mathrm{Yb}_{N}$ dessas rochas (Tabela 3). No GAL, essa razão varia significativamente, tendo as fácies menos evoluídas (Anf-Bt-TnlP e Bt-Anf-GrdP), razões $\mathrm{La}_{N} / \mathrm{Yb}_{\mathrm{N}}$ $(18,70-47,06)$ inferiores aos Ms-Bt-GrdP (70,09-169,31), que são as mais evoluídas e enriquecidas em $\mathrm{SiO}_{2}$.

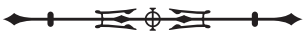



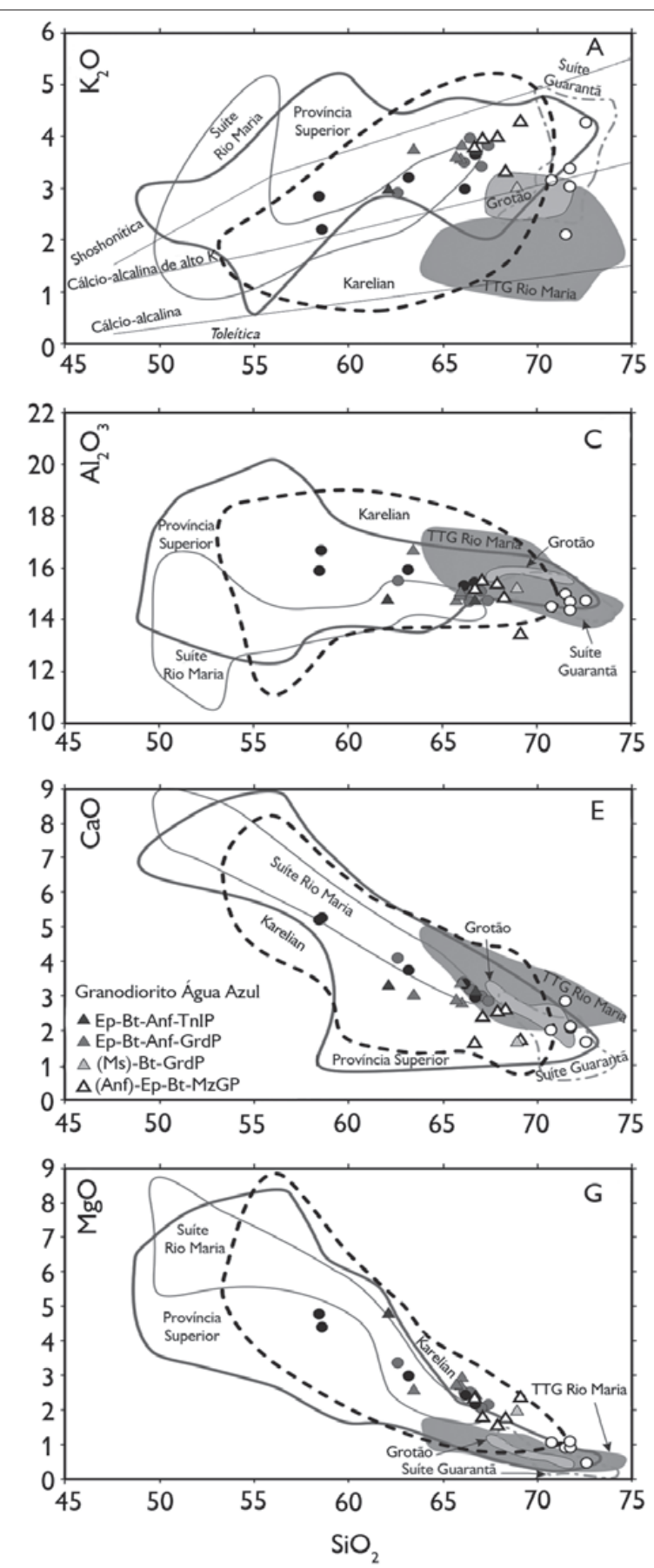
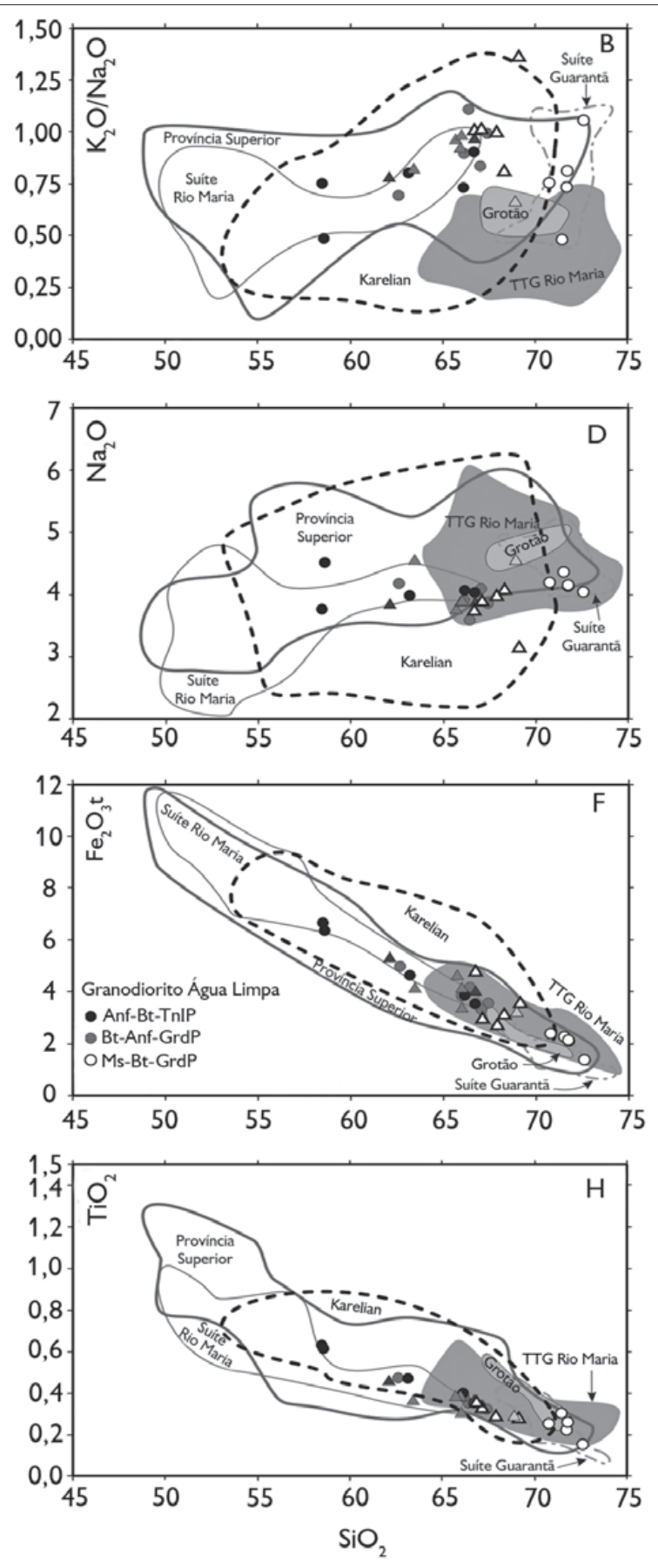

Figura 7. Diagramas de Harker (1965) para os óxidos de elementos maiores e menores das amostras dos granodioritos Água Azul e Água Limpa e das suítes sanukitoides da Província Superior (Stern et al., 1989; Stern \& Hanson, 1991; Stevenson et al., 1999), Província Karelian (Halla, 2005; Heilimo et al., 2010) e Suíte Rio Maria (Oliveira et al., 2009), além dos TTG (Almeida et al., 2011), leucogranodioritos da Suíte Guarantã (granodioritos Azulona e Trairão; Almeida et al., 2008, 2010) e Granodiorito Grotão (Almeida et al., 2010) do Domínio Rio Maria. Diagrama K $O$ versus $\mathrm{SiO}_{2}$ (A) com os campos de Peccerillo \& Taylor (1976). Legendas: Anf = anfibólio; Bt = biotita; Ep = epidoto; Ms = muscovita; Grd = granodiorito; $\mathrm{MzG}=$ monzogranito; $\mathrm{Tnl}=$ tonalito; $\mathrm{P}=$ porfirítico.

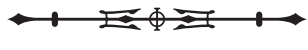




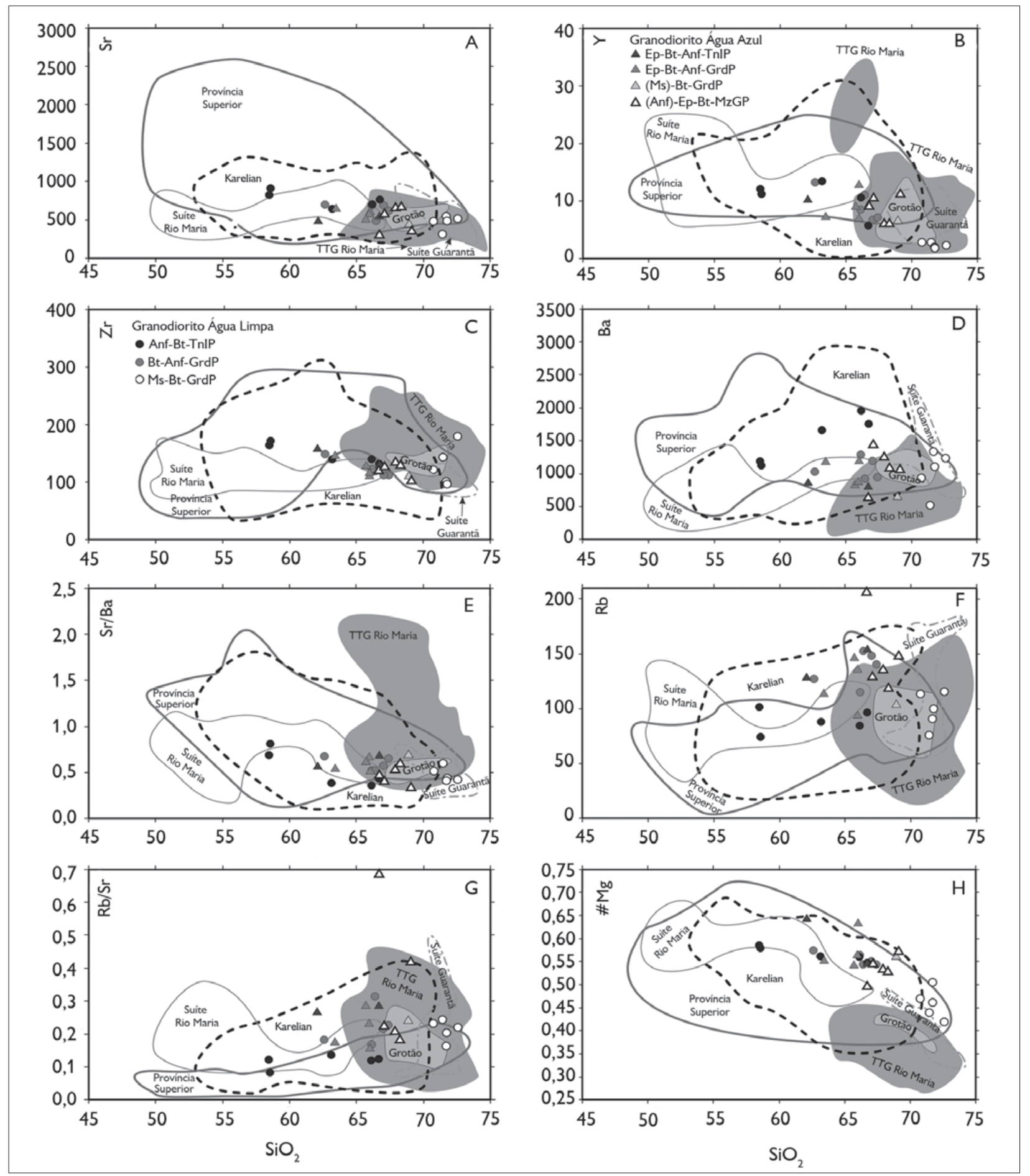

Figura 8. Diagramas de Harker (1965) para os elementos-traço e \#Mg das amostras dos granodioritos Água Azul e Água Limpa e das Suítes Sanukitoides da Província Superior, Província Karelian e Suíte Rio Maria, assim como os TTG e leucogranodioritos do Domínio Rio Maria, conforme a Figura 6. Legendas: Anf = anfibólio; Bt = biotita; Ep = epidoto; Ms = muscovita; Grd = granodiorito; MzG = monzogranito; $\mathrm{Tnl}=$ tonalito; $\mathrm{P}=$ porfirítico. 


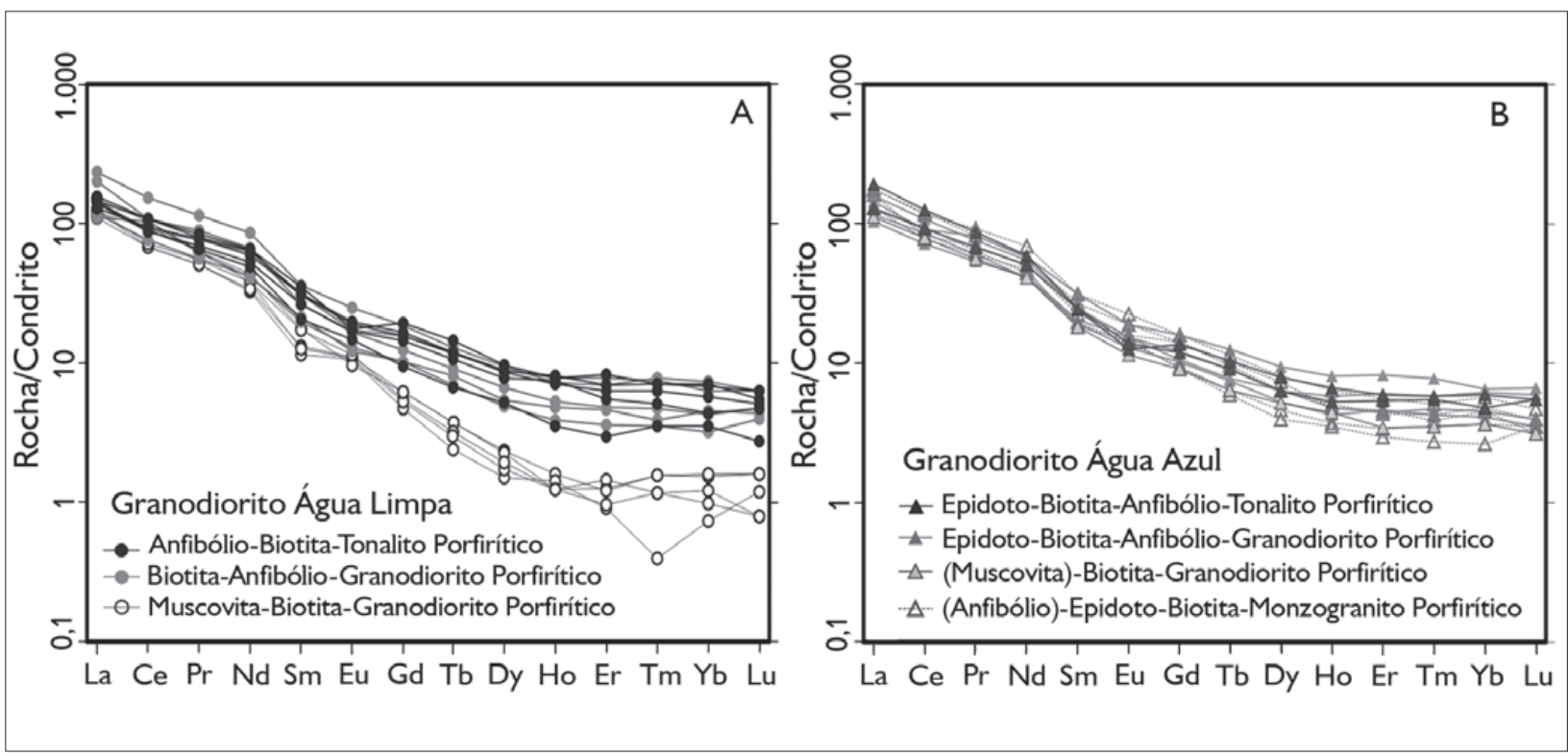

Figura 9. Padrões de distribuição de ETR em amostras dos granodioritos: A) Água Limpa; B) Água Azul. Dados normalizados em relação ao condrito (Evensen et al., 1978).

Algo semelhante ocorre para o GAA, porém com um grau menos acentuado de diferenciação entre as fácies menos evoluídas (Ep-Anf-Bt-TnlP + Ep-Anf-Bt-GrdP: La $_{N} \mathrm{Yb}_{\mathrm{N}}=$ 21,78-40,58) e as mais evoluídas [(Anf)-Ep-Bt-MzGP + (Ms)-Bt-GrdP: $\left.\mathrm{La}_{N} \mathrm{Yb}_{\mathrm{N}}=30,82-50,39\right]$, conferindo assim um comportamento mais homogêneo para os padrões de ETR desse corpo.

As anomalias de Eu, de modo geral, são ausentes, mostrando ou apenas uma pequena anomalia negativa ou positiva nas amostras do GAL (Eu/Eu* $=0,65-1,33)$, assim como naquelas do GAA (Eu/Eu* $=0,66-1,07)$. As altas razões $\operatorname{La}_{N} / \mathrm{Yb}_{N}$ encontradas nas amostras da variedade mais enriquecida em $\mathrm{SiO}_{2}$ do GAL (Ms-BtGrdP) sugerem um grau mais acentuado de diferenciação magmática nos estágios finais de cristalização desse corpo, que poderia ser atribuído ao fracionamento de anfibólio. Os demais padrões de ETR descritos, tanto para o GAA quanto para o GAL, apresentam comportamento semelhante aos padrões observados em algumas suítes sanukitoides, principalmente com aquela do Domínio Rio Maria (Figuras 10A e 10B).

\section{CARACTERIZAÇÃO DA SÉRIE MAGMÁTICA}

No diagrama Ab-An-Or (Figura 11A), amostras do GAA e GAL ocupam o campo dos granodioritos, com a variedade mais evoluída mostrando afinidades com as situadas no campo dos granitos. Comportamento análogo é, de modo geral, também visualizado no diagrama P-Q (Figura 11B; Debon e Le Fort, 1988), porém neste os termos mais pobres em sílica possuem composição quartzo-monzodiorítica e os mais ricos em sílica são dominantemente granodioríticos no GAL e monzograníticos no GAA, em acordo com o observado nas análises modais. $\mathrm{Na}$ relação $\left[\mathrm{Al}_{2} \mathrm{O}_{3} /\right.$ $\left.\left(\mathrm{CaO}+\mathrm{Na}_{2} \mathrm{O}+\mathrm{K}_{2} \mathrm{O}\right)\right]_{\mathrm{mol}}$ versus $\left[\mathrm{Al}_{2} \mathrm{O}_{3} /\left(\mathrm{Na}_{2} \mathrm{O}+\mathrm{K}_{2} \mathrm{O}\right)\right]_{\mathrm{mol}}$, de Shand (1950; Figura 11C), assim como no diagrama B-A (Figura 11D; Debon \& Le Fort, 1988), é nítida a distinção entre as variedades com anfibólio daquelas com biotita e muscovita, que mostram caráter metaluminoso e peraluminoso, respectivamente. As razões $\mathrm{K}_{2} \mathrm{O} / \mathrm{Na}_{2} \mathrm{O}$ variam entre 0,48-1,44 e 0,66-1,37 para as rochas do GAL e GAA, respectivamente, e mostram tendência de aumento das fácies menos evoluídas para as mais evoluídas.

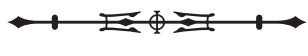




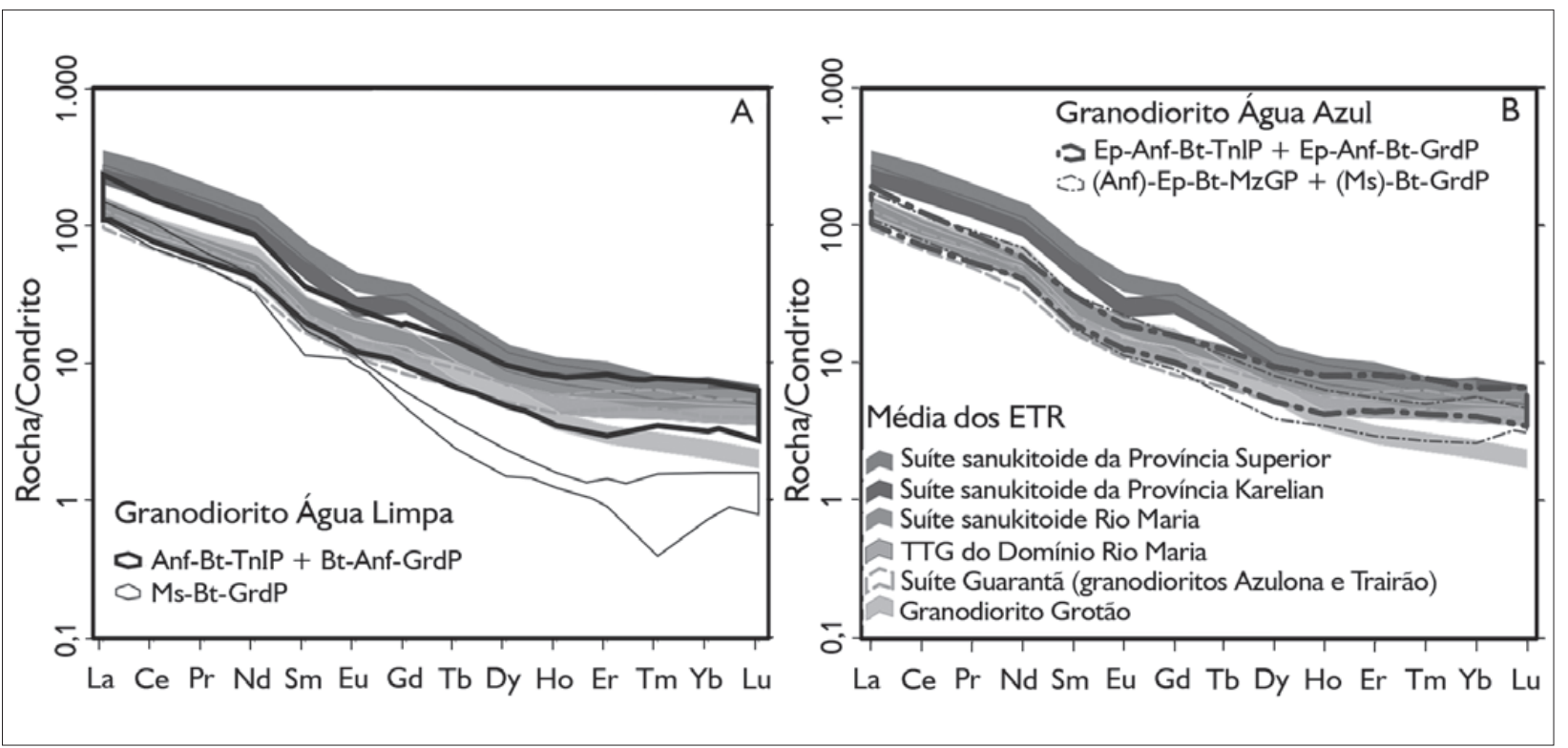

Figura 10. Padrões de distribuição de ETR em amostras dos granodioritos Água Limpa (A) e Água Azul (B), comparados às médias de ETR das Suítes Sanukitoides da Província Superior (Stevenson et al., 1999), Província Karelian (Halla, 2005) e Domínio Rio Maria (Oliveira et al., 2009), assim como TTG (Almeida et al., 2011), leucogranodioritos da Suíte Guarantã (Almeida et al., 2008) e Granodiorito Grotão (Almeida et al., 2010). Dados normalizados em relação ao condrito (Evensen et al., 1978). Legendas: Anf = anfibólio; Bt = biotita; Ep = epidoto; Ms = muscovita; Grd = granodiorito; MzG = monzogranito; Tnl = tonalito; P = porfirítico.

Essas rochas seguem o trend das séries cálcio-alcalinas nos diagramas AFM, K-Na-Ca e P-Q (Figuras 11B, 11E-11F) e ocupam o campo cálcio-alcalino de alto $\mathrm{K}$ no diagrama $\mathrm{K}_{2} \mathrm{O}$ versus $\mathrm{SiO}_{2}$ (Figura 7D). Os dados geoquímicos apresentados neste trabalho, quando comparados com os dos demais granitoides arqueanos do Domínio Rio Maria (Figuras 7 e 8), mostram que os granitoides de Água Azul do Norte possuem, quando comparados com os TTG, leucogranodioritos arqueanos da Suíte Guarantã, de Almeida et al. (2010), e Granodiorito Grotão, de modo geral, além de termos mais pobres em $\mathrm{SiO}_{2}$, valores mais elevados de $\mathrm{MgO}, \mathrm{Cr}$ (Figura 12A) e Ni (Figura 12B), e ligeiramente mais baixos de $\mathrm{Na}_{2} \mathrm{O}$ e $\mathrm{Al}_{2} \mathrm{O}_{3}$. Soma-se a isso o fato de as suítes TTG mostrarem ainda valores mais baixos de $\mathrm{K}_{2} \mathrm{O}$, Ba e $\mathrm{K}_{2} \mathrm{O} / \mathrm{Na}_{2} \mathrm{O}$, mais altos de $\mathrm{Zr}$ e $\mathrm{Sr} / \mathrm{Ba}$ e $\mathrm{Rb} / \mathrm{Sr}$.

Já os leucogranodioritos cálcio-alcalinos são ligeiramente enriquecidos em $\mathrm{K}_{2} \mathrm{O}$, $\mathrm{Rb}$ e $\mathrm{Ba}$, e fortemente empobrecidos em $\mathrm{CaO}$, quando comparados com os granitoides de Água Azul do Norte. Os altos teores de
MgO resultam em \#Mg mais elevado, tanto para amostras do GAL $(0,42-0,59)$ quanto para aquelas do GAA $(0,49-0,64)$, como mostrado na Figura $8 \mathrm{H}$.

O caráter mais evoluído da variedade Ms-Bt-GrdP do GAL faz com que suas composições se sobreponham com as dos leucogranodioritos da Suíte Guarantã em muitos dos diagramas apresentados acima. Porém, os primeiros são notoriamente mais enriquecidos em $\mathrm{MgO}$ (fornecendo \#Mg mais elevados) e Cr (Figura 12A), empobrecidos em Y (Figura 8B), além de mostrar maior fracionamento de ETRP (Figura 10A), refletido em razões $\mathrm{La}_{N} / \mathrm{Yb}_{\mathrm{N}}$ mais altas (Tabela 3). Por outro lado, apesar de não terem sido identificadas até o momento amostras tanto do GAL quanto do GAA com valores abaixo de 58\% de $\mathrm{SiO}_{2}$, as rochas formadoras dos corpos aqui estudados possuem fortes afinidades composicionais com aquelas das suítes sanukitoides do Domínio Rio Maria (Oliveira et al., 2009, 2011), Província Karelian do Escudo Báltico (Halla, 2005; Heilimo et al., 2010) e Província Superior do Canadá

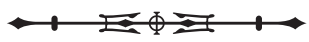



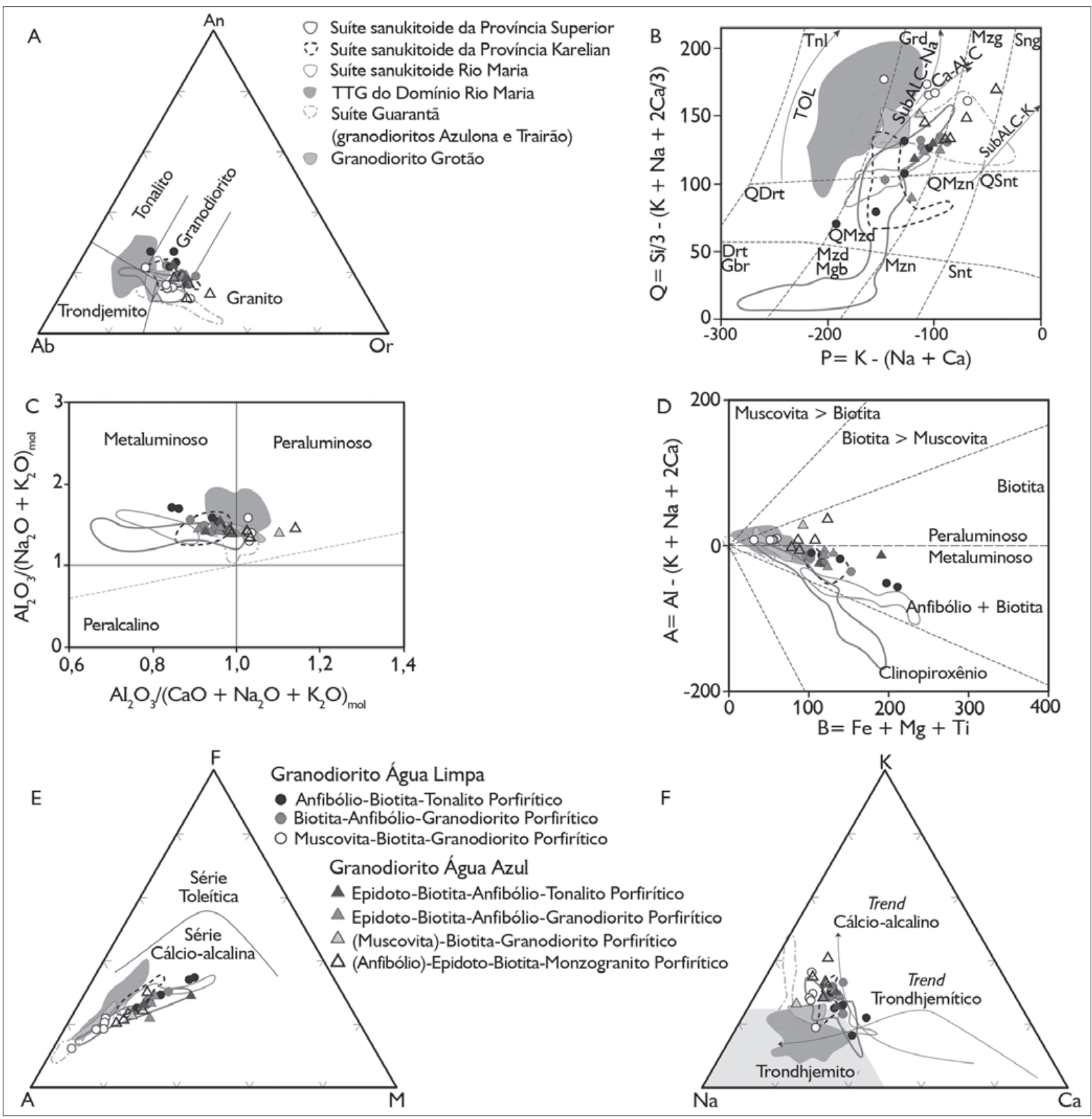

Figura 11. Diagramas geoquímicos mostrando a distribuição de amostras dos granodioritos Água Azul e Água Limpa juntamente com os campos de amostras dos sanukitoides da Província Superior (Stern \& Hanson, 1991; Stevenson et al., 1999), Província Karelian (Halla, 2005) e Suíte Rio Maria (Oliveira et al., 2009), assim como TTG (Almeida et al., 2011), leucogranodioritos da Suíte Guarantã e Granodiorito Grotão (Almeida et al., 2010) do Domínio Rio Maria. A) Diagrama An-Ab-Or normativo (O'Connor, 1965, com campos de Barker, 1979); B) diagrama P-Q (Debon \& Le Fort, 1988). Legendas: Tnl = tonalito; Grd = granodiorito; Mzg = monzogranito; Sng = sienogranito; QDrt = quartzo diorito; QMzd = quartzo monzodiorito; QMzn = quartzo monzonito; QSnt = quartzo sienito; Drt = diorito; Gbr = gabro; Mzd = monzodiorito; Mgb = monzogabro; Mzn = monzonito; Snt = sienito; TOL = tolé́tico; SubALC-Na = subalcalino sódico; Ca-ALC = cálcio-alcalino; SubALC-K = subalcalino potássico; C) diagrama ACNK versus ANK (Shand, 1950); D) diagrama B-A (Debon \& Le Fort, 1988); E) diagrama AFM (Irvine \& Baragar, 1971; $\mathrm{A}=\mathrm{Na}_{2} \mathrm{O}+\mathrm{K}_{2} \mathrm{O} ; \mathrm{F}=\mathrm{FeO}+0,9 * \mathrm{Fe}_{2} \mathrm{O}_{3} ; \mathrm{M}=\mathrm{MgO}$ ); F) diagrama $\mathrm{K}-\mathrm{Na}$ Ca, com os trends cálcio-alcalino e trondhjemítico definidos por Barker \& Arth (1976), campo trondhjemítico conforme Martin (1994).

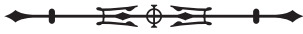




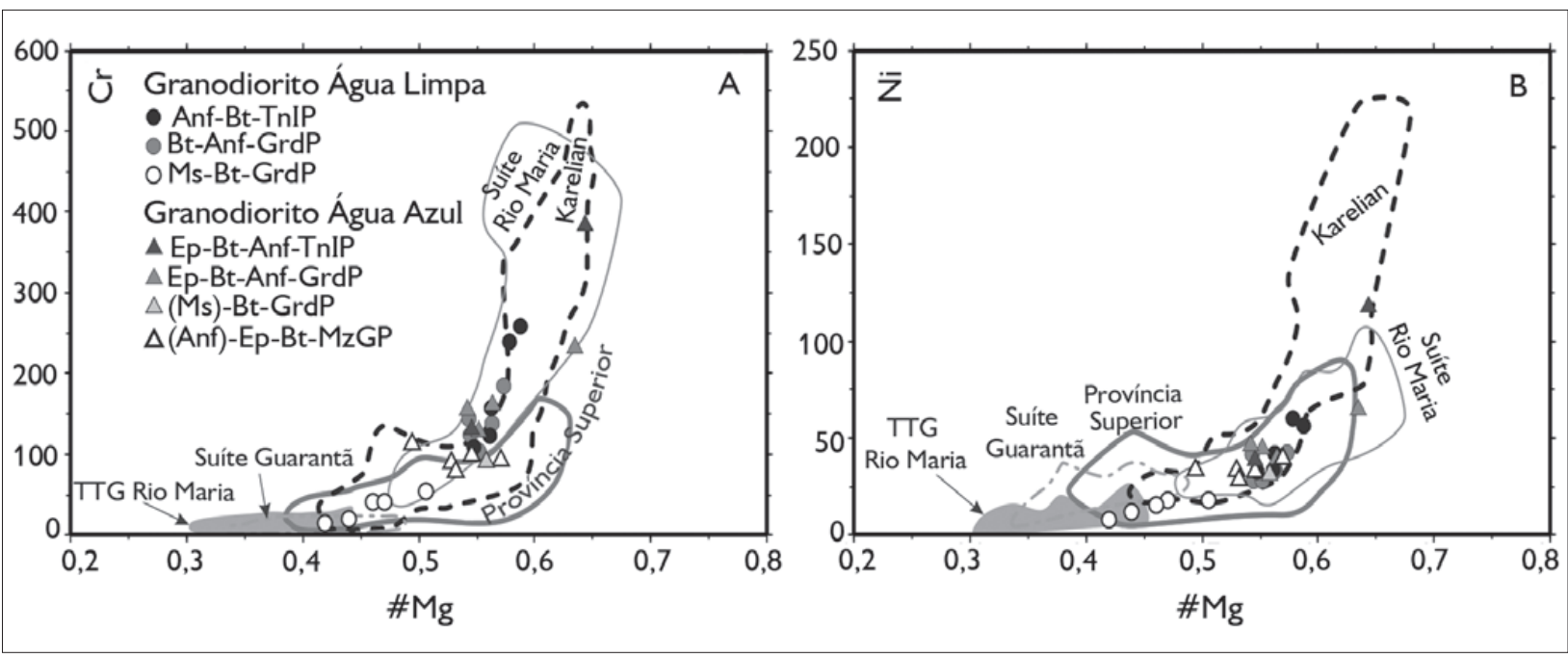

Figura 12. Diagramas Cr (A) e Ni (B) (ppm) versus número de magnésio (\#Mg) para as amostras dos granodioritos Água Azul e Água Limpa, com os campos das composições das suítes sanukitoides da Província Superior (Stern \& Hanson, 1991; Stevenson et al., 1999), Província Karelian (Halla, 2005; Heilimo et al., 2010) e Suíte Rio Maria (Oliveira et al., 2009), assim como TTG (Almeida et al., 2011) e leucogranodioritos (Almeida et al., 2010) do Domínio Rio Maria. Legendas: Anf = anfibólio; Bt = biotita; Ep = epidoto; Ms = muscovita; Grd = granodiorito; $\mathrm{MzG}=$ monzogranito; $\mathrm{Tnl}=$ tonalito; $\mathrm{P}=$ porfirítico.

(Stern \& Hanson, 1991; Stevenson et al., 1999), como pode ser visualizado nos diversos diagramas geoquímicos apresentados (Figuras 7 a 12).

\section{COMPARAÇÕES ENTRE O GAA E GAL}

Apesar das semelhanças na idade de formação (2,88 Ga), aspectos petrográficos e estruturais, além dos comportamentos geoquímicos afins que inicialmente enquadram essas rochas em uma mesma suíte magmática, os dois corpos granitoides de alto magnésio da região de Água Azul do Norte apresentam certas particularidades que justificam a denominação individual para suas ocorrências. Além da separação geográfica, petrograficamente o GAL mostra ser mais enriquecido em minerais máficos e plagioclásio do que o GAA, que, por sua vez, contém teores mais elevados de K-feldspato, biotita e epidoto magmático. Algumas diferenças na composição química dessas rochas refletem acima de tudo as variações mineralógicas encontradas nas mesmas. $\mathrm{O}$ GAL é mais enriquecido em $\mathrm{CaO}$ e $\mathrm{Ba}$, enquanto que no GAA os teores de $\mathrm{K}_{2} \mathrm{O}$ e os valores da razão Rb/Sr são ligeiramente mais elevados. Além disso, nota-se no GAL uma variação mais ampla nos teores de $\mathrm{SiO}_{2}(58,4-72,6 \%)$ em relação às rochas do GAA (62,0-69,1\%), reflexo da ocorrência significativa de rochas mais enriquecidas em quartzo (Ms-Bt-GrdP) e do aspecto mais evoluído do GAL, sugerindo que este possa ter sofrido maior grau de diferenciação magmática, com importante fracionamento de anfibólio e biotita, haja vista o aumento significativo da razão $\mathrm{La}_{N} \mathrm{Yb}_{N}$ e o decréscimo acentuado de $\mathrm{Rb}$ nessas rochas em relação às demais fácies. Tais aspectos podem sugerir que esses corpos são provenientes de magmas similares, porém distintos, que evoluíram sob condições semelhantes de cristalização.

\section{CONSIDERAÇÕES SOBRE OS MECANISMOS DE DEFORMAÇÃO}

Tendo como base as feições microestruturais descritas nas principais fases minerais dos granitoides aqui estudados, foi possível caracterizar os mecanismos de deformação que atuaram durante a instalação das zonas de cisalhamento dúctil que afetaram essas rochas.

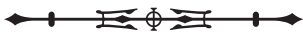


A evolução microestrutural desses granitoides pode ser caracterizada pelo estabelecimento da seguinte sequência de estágios: 1) extinção ondulante; 2) bandas de deformação; 3) subgrãos; 4) novos grãos (neoblastos); e 5) extinção ondulante em novos grãos. Essa sequência é mais evidente em cristais de quartzo, que apresentam deformação dúctil, enquanto feldspatos e anfibólios apresentam-se aparentemente menos afetados.

Os estágios 1, 2 e 3 associam-se à recuperação no sentido de diminuir a quantidade de dislocamentos (dislocations). Os novos grãos foram formados principalmente por rotação dos subgrãos ou por migração de limites de grãos. No estágio 4, a recristalização toma forma. As feições do estágio 5 são indicativas de que a deformação foi progressiva e cíclica. Em muitas amostras estudadas, é possível encontrar neoblastos poligonais em junções tríplices formando pequenos agregados, ocupando principalmente os espaços entre porfiroclastos de variada granulação. Tais feições indicam que a recristalização estática foi, talvez, importante com o término da recristalização dinâmica, pelo menos em alguns pontos desses corpos. Genericamente, a recristalização estática pode estar relacionada a eventos pós-cinemáticos. A foliação do GAA e GAL mostra ser um elemento estrutural importante na escala dos dois corpos. Seu aspecto penetrativo e o maior desenvolvimento estão diretamente relacionados às proximidades das zonas de cisalhamento que cortam essas rochas, fazendo com que as mesmas ganhem caráter milonítico típico com uma matriz de granulação fina, que engloba porfiroclastos médios a grossos (cristais que variam entre 1 e $11 \mathrm{~mm}$ ).

Os dados disponíveis para os corpos estudados são ainda insuficientes para uma discussão mais precisa sobre os cenários de suas colocações. Mesmo assim, as feições deformacionais discutidas acima, aliadas às feições estruturais em escala de afloramento dos dois corpos, permitiram definir pelo menos duas fases principais de deformação: (i) a primeira é marcada pelo desenvolvimento da foliação com variados graus de recristalização e que chega a ser milonítica nas proximidades das zonas de cisalhamento, sendo, assim, similar, sobretudo no GAA, àquela dos xistos do Grupo Sapucaia, juntamente com o desenvolvimento de lineações de estiramento de minerais como o quartzo (quartzo ribbon). Essas estruturas são associadas a movimentos transcorrentes sinistrais com inversão local da cinemática, marcada por estruturas de contração (arrasto) e rotação de porfiroclastos/enclaves; (ii) a segunda fase de deformação foi responsável pela transposição das estruturas geradas na primeira fase (em especial a foliação) e pela geração de clivagem de crenulação associada com bandas de cisalhamento e boudinage, relacionada a um evento compressivo de cinemática dextral. Tais aspectos divergem claramente do que é descrito para os sanukitoides mesoarqueanos do Domínio Rio Maria, o que implicaria diferenças significativas em termos deformacionais entre estes e os sanukitoides mesoarqueanos do Domínio Carajás aqui estudados.

\section{CONCLUSÕES}

Os granitoides de alto magnésio da região de Água Azul do Norte são intrusivos nas sequências supracrustais do Grupo Sapucaia. Seu posicionamento estratigráfico em relação aos trondhjemitos que separam as duas ocorrências não foi definido, admitindo-se que tenham idades similares. Em relação aos leucogranodioritos, as evidências de campo apontam que essas rochas sejam intrusivas nos sanukitoides. Os granodioritos estudados ocorrem como dois corpos deformados e alongados em padrão estrutural E-W. Os mecanismos de deformação atuantes sobre as mesmas foram o de recuperação e recristalização, os quais deram origem a uma foliação penetrativa realçada nas zonas de cisalhamento dúctil, gerando rochas tipicamente miloníticas. A relação espacial entre estes corpos e as principais zonas de cisalhamento da área, juntamente com a forma alongadas dos corpos graníticos, bem como o quadro cinemático similar observado nos granitoides estudados e nos xistos encaixantes (Grupo Sapucaia), são indicativos de que tanto o GAA quanto o GAL são 
corpos pré-tectônicos à primeira fase de deformação. Sua colocação/deformação foi controlada por zonas de cisalhamento transpressivas sinistrais.

Os corpos estudados são, em geral, formados por sucessivas intrusões que variam composicionalmente desde tonalitos até granodioritos, e mais restritamente monzogranitos. Os granodioritos são mais expressivos, frequentemente apresentam típica textura porfirítica com fenocristais de feldspatos e possuem anfibólio, biotita e epidoto magmático como principais fases ferromagnesianas. De modo geral, esses granitoides delineiam trend de evolução marcado pelo decréscimo de $\mathrm{CaO}, \mathrm{Fe}_{2} \mathrm{O}_{3}, \mathrm{MgO}, \mathrm{TiO}_{2}$ e $\mathrm{Al}_{2} \mathrm{O}_{3}$, paralelamente ao aumento de $\mathrm{SiO}_{2}$, que, por sua vez, é acompanhado pelo aumento de $\mathrm{K}_{2} \mathrm{O}$ e da razão $\mathrm{K}_{2} \mathrm{O} / \mathrm{Na}_{2} \mathrm{O}$ a partir das variedades tonalíticas, passando pelos granodioritos ricos em anfibólio, em direção às fácies em que a biotita é o principal mineral ferromagnesiano (mais evoluídas). Sr, Y, Zr, \#Mg, Ni, Cre a razão Sr/Ba decrescem, enquanto que $\mathrm{Rb}$, Ba e a razão Rb/Sr aumentam no sentido da evolução dessas rochas. Os padrões de ETR são muito similares entre as diversas variedades, porém as altas razões $\mathrm{La}_{N} \mathrm{Yb}_{\mathrm{N}}$ encontradas nas rochas mais enriquecidas em $\mathrm{SiO}_{2}$ do GAL (Ms-Bt-GrdP) sugerem um grau mais acentuado de diferenciação magmática nos estágios finais de cristalização desse corpo, que poderia ser atribuído ao fracionamento de anfibólio, assim como de biotita, haja vista o decréscimo acentuado de Rb e K nessas rochas. Por outro lado, para as demais variedades petrográficas desses corpos, o anfibólio não deve ter sido uma fase fracionada importante, como é indicado pelo fracionamento menos acentuado de ETR, levando à ausência da concavidade nos padrões de ETR.

As rochas estudadas são predominantemente metaluminosas e plotam em sua maioria no campo dos granodioritos no diagrama Ab-An-Or, mostrando comportamento distinto dos TTG e leucogranodioritos do Domínio Rio Maria. No diagrama K-Na-Ca, tanto o GAL quanto o GAA fogem ao trend trondhjemítico, com enriquecimento em K em relação aos TTG e alinhamento conforme o trend das séries cálcio-alcalinas, porém com conteúdos mais baixos de $\mathrm{CaO}$. Entretanto, o GAA e o GAL apresentam altos valores de \#Mg, $\mathrm{Cr}$ e $\mathrm{Ni}$, que os distinguem das séries cálcio-alcalinas de margens continentais, e os aproximam dos granodioritos arqueanos ricos em Mg de outros crátons. Tais aspectos também diferenciam claramente essas rochas daquelas relacionadas aos TTG e leucogranodioritos arqueanos do Domínio Rio Maria, embora seus padrões de ETR sejam similares, com altos conteúdos de ETRL e um forte a moderado fracionamento de ETRP (alta razão $\mathrm{La}_{N}\left(\mathrm{Yb}_{\mathrm{N}}\right.$ ), associado a baixas anomalias de Eu. As afinidades petrográficas e geoquímicas existentes entre as rochas estudadas neste trabalho e as principais ocorrências de granitoides de alto-Mg, em especial aquelas de Rio Maria, sugerem que tanto o GAA quanto o GAL possam fazer parte de uma suíte magmática análoga, até então não identificada nesta parte da Província Carajás, mais especificamente na porção sul do Domínio Carajás.

\section{AGRADECIMENTOS}

Ao Conselho Nacional de Desenvolvimento Científico e Tecnológico (CNPq), por concessão de bolsa de mestrado ao primeiro autor e de produtividade em pesquisa ao segundo autor, e pelo apoio financeiro (Processo no 476444/2008-0); ao Instituto de Geociências da Universidade Federal do Pará (IG-UFPA), pelo suporte técnico; ao professor C. M. D. Fernandes, do IG-UFPA, pelo apoio na etapa de campo; aos pesquisadores do Grupo de Pesquisa Petrologia de Granitoides (GPPG-IGUFPA), pelo apoio nas diversas etapas deste trabalho; aos revisores, pelas críticas que levaram ao aperfeiçoamento do artigo; à Fundação Amazônia Paraense de Amparo à Pesquisa (FAPESPA) (Processo no 133/2008-0), ao convênio Vale-FAPESPA (Edital 001/2010 - Instrumento de Concessão e Aceitação de Apoio Financeiro - ICAAF 053/2011) e Instituto Nacional de Ciência e Tecnologia de Geociências da Amazônia (INCT/GEOCIAM) (Processo $\left.n^{\circ} 573733 / 2008-2\right)$, pelo apoio financeiro.

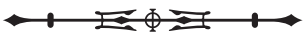




\section{REFERÊNCIAS}

ACMELABS, s.d. AcmeLabs ${ }^{\mathrm{TM}}$ : a bureau veritas group company. Disponível em: <www.acmelab.com>. Acesso em: 19 junho 2012.

ALMEIDA, F. F. M., Y. HASUI, B. B. BRITO NEVES \& R. A. FUCK, 1981. Brazilian structural provinces: an introduction. Earth-Science Reviews 17(1-2): 1-29.

ALMEIDA, J. A. C., M. A. OLIVEIRA, R. DALL'AGNOL, F. J. ALTHOFF \& R. M. K. BORGES, 2008. Relatório de mapeamento geológico na escala 1:100.000 da Folha Marajoara (SB-22-Z-C-V): 1-147. Serviço Geológico do Brasil - CPRM, Belém.

ALMEIDA, J. A. C., R. DALL'AGNOL, S. B. DIAS \& F. J. ALTHOFF, 2010. Origin of the Archean leucogranodiorite-granite suites: evidence from the Rio Maria terrane and implications for granite magmatism in the Archean. Lithos 120(3-4): 235-257.

ALMEIDA, J. A. C., R. DALL'AGNOL, M. A. OLIVEIRA, M. J. B. MACAMBIRA, M. M. PIMENTEL, O. T. RÄMÖ, F. V. GUIMARÃES \& A. A. S. LEITE, 2011. Zircon geochronology, geochemistry and origin of the TTG suites of the Rio Maria granite-greenstone terrane: implications for the growth of the Archean crust of the Carajás Province, Brazil. Precambrian Research 187(1-2): 201-221.

ARAÚJO, O. J. B., R. G. N. MAIA, X. S. JORGE JOÃO \& J. B. S. COSTA, 1988. A megaestrutura arqueana da Folha Serra dos Carajás. Anais do Congresso Latino-Americano de Geologia 7: 324-338.

AVELAR, V. G., J. M. LAFON, F. C. CORREIA JR. \& E. M. B. MACAMBIRA, 1999. O magmatismo arqueano da região de Tucumã - Província Mineral de Carajás: novos resultados geocronológicos. Revista Brasileira de Geociências 29(4): 453-460.

BARKER, F., 1979. Trondhjemites: definition, environment and hypotheses of origin. In: F. BARKER (Ed.): Trondhjemites, dacites and related rocks: 1-12. Elsevier, Amsterdam.

BARKER, F. \& J. G. ARTH, 1976. Generation of trondhiemitic-tonalitic liquids and Archaean bimodal trondhjemite-basalt suites. Geology 4(10): 596-600.

CASSIDY, K. F., M. E. BARLEY, D. I. GROVES, C. S. PERRING \& J. A. HALLBERG, 1991. An overview of the nature, distribution and inferred tectonic setting of granitoids in the late- Archaean NorsemanWiluna Belt. Precambrian Research 51(1-4): 51-83.

DALL'AGNOL, R., Z. S. SOUZA, F. J. ALTHOFF, C. E. M. BARROS, A. A. S. LEITE \& X. S. JORGE JOÃO, 1997. General aspects of the granitogenesis of the Carajás metallogenic province. Extended Abstracts of the International Symposium on Granites and Associated Mineralizations 2: 135-161.

DALL'AGNOL, R., N. P. TEIXEIRA, O. T. RÄMÖ, C. A. V. MOURA, M. J. B. MACAMBIRA \& D. C. OLIVEIRA, 2005. Petrogenesis of the Paleoproterozoic rapakivi A-type granites of the Archean Carajás metallogenic province, Brazil. Lithos 80(1-4): 101-129.
DALl'AGNOL, R., D. C. OLIVEIRA \& C. N. LAMARÃO, 2013. Magmatismo granitoide arqueano e evolução geológica do Subdomínio de Transição da Província Carajás, sudeste do Cráton Amazônico, Brasil. Boletim do Museu Paraense Emílio Goeldi. Ciências Naturais 8(3): 251-256.

DEBON, F. \& P. LE FORT, 1988. A cationic classification of common plutonic rocks and their magmatic associations: principles, method, applications. Bulletin de Minéralogie 111: 493-510.

EVANS, O. C. \& G. N. HANSON, 1997. Late- to post-kinematic Archean granitoids of the S.W. Superior Province: derivation through direct mantle melting. In: M. J. DE WIT \& L. D. ASHWAL (Eds.): Greenstone belts: 280-295. Oxford University Press, Oxford.

EVENSEN, N. M., P. T. HAMILTON \& R. K. O'NIONS, 1978. Rare earth abundances in chondritic meteorites. Geochimica et Cosmochimica Acta 42(8): 1199-1212.

FEIO, G. R. L., R. DALL'AGNOL, E. L. DANTAS, M. J. B. MACAMBIRA, A. C. B. GOMES, A. S. SARDINHA, D. C. OLIVEIRA, R. D. SANTOS \& P. A. SANTOS, 2012. Geochemistry, geochronology, and origin of the Neoarchean Planalto Granite suite, Carajás, Amazonian craton: A-type or hydrated charnockitic granites? Lithos 151: 57-73.

FEIO, G. R. L., R. DALL'AGNOL, E. L. DANTAS, M. J. B. MACAMBIRA, J. O. S. SANTOS, F. J. ALTHOFF \& J. E. B. SOARES, 2013. Archean granitoid magmatism in the Canaã dos Carajás area: implications for crustal evolution of the Carajás province, Amazonian craton, Brazil. Precambrian Research 227: 157-185.

GABRIEL, E. O., D. C. OliVEIRA \& M. A. GALARZA, 2010. Petrografia e geocronologia de granitoides do Complexo Xingu da região nordeste de Água Azul do Norte, Província Mineral de Carajás. Anais do Congresso Brasileiro de Geologia 45: 1 CD-ROM

GOMES, A. C. B. \& R. DALL'AGNOL, 2007. Nova associação tonalítica-trondhjemítica neoarqueana na região de Canaã dos Carajás: TTGs com altos conteúdos de Ti, Zr e Y. Revista Brasileira de Geociências 37(1): 182-193.

HALLA, J., 2005. Late Archean high-Mg granitoids (sanukitoids) in the southern Karelian domain, eastern Finland: $\mathrm{Pb}$ and $\mathrm{Nd}$ isotopic constraints on crust-mantle interactions. Lithos 79(1-2): 161-178.

HANSON, G. N., 1978. The application of trace elements to the petrogenesis of igneous rocks of granitic composition. Earth and Planetary Science Letters 38(1): 26-43.

HARKER, A., 1965. The natural history of igneous rocks: 1-384. The Macmillan Company, New York.

HEILIMO, E., J. HALLA \& P. HÖLTTÄ, 2010. Discrimination and origin of the sanukitoid series: geochemical constraints from the Neoarchean western Karelian Province (Finland). Lithos 115(1-4): 27-39.

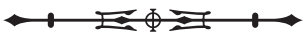


HIRATA, W. K., J. C. RIGON, A. A. C. CORDEIRO \& E. M. MEIRELES, 1982. Geologia regional da Província Mineral de Carajás. Anais do Simpósio de Geologia da Amazônia 1: 100-110.

HUHN, S. B., M. J. B. MACAMBIRA \& R. DALL'AGNOL, 1999. Geologia e geocronologia Pb-Pb do Granito Alcalino Arqueano Planalto, região da Serra do Rabo, Carajás - PA. Boletim de Resumos Expandidos do Simpósio de Geologia da Amazônia 6(1): 463-466.

IRVINE, T. N. \& W. R. A. BARAGAR, 1971. A guide to the chemical classification of the common volcanic rocks. Canadian Journal of Earth Sciences 8(5): 523-548.

KAMPUNZU, A. B., A. R. TOMBALE, M. ZHAI, Z. BAGAI, T. MAJAULE \& M. P. MODISI, 2003. Major and trace element geochemistry of plutonic rocks from Francistown, NE Botswana: evidence for a Neoarchaean continental active margin in the Zimbabwe craton. Lithos 71(2-4): 431-460.

KOTO, B., 1916. On the volcanoes of Japan (V). The Journal of the Geological Society of Tokyo 23: 95-127.

KOVALENKO, A. V., J. D. CLEMENS \& V. M. SAVATENKOV, 2005. Petrogenetic constraints for the genesis of Archaean sanukitoid suites: geochemistry and isotopic evidence from Karelia, Baltic Shield. Lithos 79(1-2): 147-160.

LAFON, J. M., M. J. B. MACAMBIRA \& R. T. PIDGEON, 2000. Zircon U-Pb SHRIMP dating of Neoarchean magmatism in the southwestern part of the Carajás Province (eastern Amazonian Craton, Brazil). Abstracts of the International Geological Congress 31: 1 CD-ROM.

LE MAITRE, R. W. (Ed.), 2002. Igneous rocks: a classification and glossary of terms: 1-193. Cambridge University Press, London.

LOBACH-ZHUCHENKO, S. B., V. P. CHEKULAEV, V. V. IVANIKOV, A. V. KOVALENKO \& E. S. BOGOMOLOV, 2000. Late Archean high-Mg and subalkaline granitoids and lamprophyres as indicators of gold mineralization in Karelia (Baltic Shield), Russia. In: A. A. KREMENETSKY, B. LEHMANN \& R. SELTMANN (Eds.): Orebearing granites of Russia and adjacent countries: 193-211. Institut of Mineralogy, Geochemistry and Crystal Chemistry of Rare Elements, Moscow.

MACAMBIRA, E. M. B. \& A. G. VALE, 1997. Programa Levantamentos Geológicos Básicos do Brasil. São Félix do Xingu, Folha SB.22-Y-B. Estado do Pará: 1-384. DNPM/CPRM, Brasília.

MACHADO, N., Z. LINDENMAYER, T. E. KROGH \& D. LINDENMAYER, 1991. U-Pb geochronology of Archean magmatism and basement reactivation in the Carajás area, Amazon shield, Brazil. Precambrian Research 49(3-4): 329-354.

MARTIN, H., 1994. The Archean grey gneisses and the gneisses of continental crust. In: K. C. CONDIE (Ed.): Archean crustal evolution: 205-259. Elservier (Developments in Precambriam Geology, 11), Amsterdam.
MORETO, C. P. N., L. V. S. MONTEIRO, R. P. XAVIER, W. S. AMARAL, T. J. S. SANTOS, C. JULIANI \& C. R. SOUZA FILHO, 2011. Mesoarchean $(3.0$ and $2.86 \mathrm{Ga}$ ) host rocks of the iron oxide- $\mathrm{Cu}-\mathrm{Au}$ Bacaba deposit, Carajás Mineral Province: U-Pb geochronology and metallogenetic implications. Mineralium Deposita 46(7): 789-811.

MOYEN, J.-F., H. MARTIN, M. JAYANANDA \& J.-J. PEUCAT, 2003. Magmatism during the accretion of the late Archaean Dharwar Craton (South India): sanukitoids and related rocks in their geological context. Abstracts of the European Geophysical Society American Geophysical Union - European Union of Geociences Joint Assembly 5: 6-11.

O'CONNOR, J. T., 1965. A classification for quartz-rich igneous rocks based on feldspar ratios. United States Geological Survey Profissional Paper 525B: 79-84.

OliveIRA, D. C., P. J. L. SANTOS, E. O. GABRIEL, D. S. RODRIGUES, A. C. FARESIN, M. L. T. SILVA, S. D. SOUSA, R. V. SANTOS, A. C. SILVA, M. C. SOUZA, R. D. SANTOS \& M. J. B. MACAMBIRA, 2010. Aspectos geológicos e geocronológicos das rochas magmáticas e metamórficas da região entre os municípios de Água Azul do Norte e Canaã dos Carajás - Província Mineral de Carajás. Anais do Congresso Brasileiro de Geologia 45: 1 CD-ROM.

OLIVEIRA, M. A., R. DALL'AGNOL, F. J. ALTHOFF \& A. A. S. LEITE, 2009. Mesoarchean sanukitoid rocks of the Rio Maria GraniteGreenstone Terrane, Amazonian craton, Brazil. Journal of South American Earth Sciences 27(2-3): 146-160.

OLIVEIRA, M. A., R. DALL'AGNOL \& B. SCAILLET, 2010. Petrological constraints on crystallization conditions of Mesoarchean Sanukitoid Rocks, southeastern Amazonian Craton, Brazil. Journal of Petrology 51(10): 2121-2148.

OLIVEIRA, M. A., R. DALL'AGNOL \& J. A. C. ALMEIDA, 2011. Petrology of the Mesoarchean Rio Maria suite and the discrimination of sanukitoide series. Lithos 127(1-2): 192-209.

PASSCHIER, C. W. \& R. A. J. TROUW, 1996. Microtectonics: 1-289. Springer-Verlag, Berlin.

PECCERILLO, A. \& S. R. TAYLOR, 1976. Geochemistry of eocene calc-alkaline volcanic rocks from the Kastamoru area, Northern Turkey. Contributions to Mineralogy and Petrology 58(1): 63-81.

PIDGEON, R. T., M. J. B. MACAMBIRA \& J. M. LAFON, 2000. Th- $U-\mathrm{Pb}$ isotopic systems and internal structures of complex zircons from an enderbite from the Pium Complex, Carajás Province, Brazil: evidence for the ages of granulite facies metamorphism and the protolith of the enderbite. Chemical Geology 166(1-2): 159-171.

RICCI, P. S. F. \& M. A. CARVALHO, 2006. Rocks of the PiumArea, Carajás Block, Brazil - a deep seated high-T gabbroic pluton (charnockitoid-like) with xenoliths of enderbitic gneisses dated at $3002 \mathrm{Ma}$ - the basement problem revisited. Resumos Expandidos do Simpósio de Geologia da Amazônia 8(1): 1 CD-ROM.

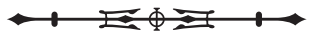


RIO DOCE GEOLOGIA E MINERAÇÃOS. A. (DOCEGEO), 1988. Revisão litoestratigráfica da Província Mineral de Carajás. Anais do Congresso Brasileiro de Geologia 35: 10-54.

RODRIGUES, D. S., D. C. OLIVEIRA \& M. J. B. MACAMBIRA, 2010. Geologia, geoquímica e geocronologia do magmatismo granítico da porção SW de vila Sedere III, município de Agua Azul do Norte Província Mineral de Carajás. Anais do Congresso Brasileiro de Geologia 45: 1 CD-ROM.

SANTOS, J. O. S., L. A. HARTMANN, H. E. GAUDETTE, D. I. GROVES, N. J. MCNAUGHTON \& I. R. FLETCHER, 2000. A new understanding of the provinces of the Amazon craton based on integration of field mapping and $\mathrm{U}-\mathrm{Pb}$ and $\mathrm{Sm}-\mathrm{Nd}$ geochronology. Gondwana Research 3(4): 453-488.

SANTOS, P. A., G. R. L. FEIO, R. DALL'AGNOL, H. T. COSTI, C. L. LAMARÃO \& M. A. GALARZA, 2013. Petrography, magnetic susceptibility and geochemistry of the Rio Branco Granite, Carajás Province, southeast of Pará, Brazil. Brazilian Journal of Geology 43(1): 2-15

SANTOS, R. D., M. A. GALARZA \& D. C. OLIVEIRA, 2013 Geologia, geoquímica e geocronologia do Diopsídio-Norito Pium, Província Carajás. Boletim do Museu Paraense Emílio Goeldi. Ciências Naturais 8(3): 355-382.

SARDINHA, A. S., R. DALL'AGNOL, A. C. B. GOMES, M. J. B. MACAMBIRA \& M. A. GALARZA, 2004. Geocronologia Pb-Pb e U-Pb em zircão de granitoides arqueanos da região de Canaã dos Carajás, Província Mineral de Carajás. Anais do Congresso Brasileiro de Geologia 42: 1 CD-ROM.

SARVOTHAMAN, H., 2001. Archaean high-Mg granitoids of mantle origin in the Eastern Dharwar craton of Andhra Pradesh. Journal of the Geological Society of India 58: 261-268.

SHAND, S. J., 1950. Eruptive rocks, their genesis, composition, classification and their relation to ore-deposits: 1-488. Thomas Murby, London.

SHIREY, S. B. \& G. N. HANSON, 1984. Mantle-derived Archaean monzodiorites and trachyandesites. Nature 310: 222-224.

SILVA, G. G., M. I. C. LIMA, A. R. F. ANDRADE, R. S. ISSLER \& G. GUIMARÃES, 1974. Geologia. In: BRASIL. Projeto RADAMBRASIL: Folha SB.22 Araguaia e parte de SC.22 Tocantins; geologia, geomorfologia, pedologia, vegetação e uso potencial da Terra: 1: 1-143. Programa de Integração Nacional (Levantamento de Recursos Naturais, 4), Rio de Janeiro.

SMITHIES, R. H. \& D. C. CHAMPION, 2000. The Archaean high-Mg diorite suite: links to tonalite-trondhjemite-granodiorite magmatism and implications for early Archaean crustal growth. Journal of Petrology 41(12): 1653-1671.
SOUSA, S. D., D. C. OliveIRA, E. O. GABRIEL \& M. J. B. MACAMBIRA, 2010. Geologia, petrografia e geocronologia das rochas granitoides do Complexo Xingu da porção a leste da cidade de Água Azul do Norte (PA) - Província Mineral de Carajás. Anais do Congresso Brasileiro de Geologia 45: 1 CD-ROM.

STEENFELT, A., A. A. GARDE \&J. F. MOYEN, 2005. Mantle wedge involvement in the petrogenesis of Archaean gray gneisses in West Greenland. Lithos 79(1-2): 207-228.

STERN, R. A., G. N. HANSON \& S. B. SHIREY, 1989. Petrogenesis of mantle-derived, LILE-enriched Archean monzodiorites and trachyandesites (sanukitoids) in southwestern Superior Province. Canadian Journal of Earth Sciences 26(9): 1688-1712.

STERN, R. A. \& G. N. HANSON, 1991. Archean high-Mg granodiorite: a derivative of light rare earth element-enriched monzodiorite of mantle origin. Journal of Petrology 32(1): 201-238.

STEVENSON, R., P. HENRY \& C. GARIÉPY, 1999. Assimilationfractional crystallization origin of Archean sanukitoid suites: Western Superior Province, Canada. Precambrian Research 96(1-2): 83-99.

TASSINARI, C. C. G. \& M. J. B. MACAMBIRA, 1999. Geochronological provinces of the Amazonian Craton. Episodes 22(3): 174-182.

TATSUMI, Y. \& K. ISHIZAKA, 1982. Origin of high-magnesian andesites in the Setouchi volcanic belt, southwest Japan, I. Petrographical and chemical characteristics. Earth and Planetary Science Letters 60(2): 293-304.

TROUW, R. A. J., C. W. PASSCHIER \& D. J. WIERSMA, 2010. Atlas of mylonites and related microstructures: 1-322. SpringerVerlag, Berlin.

VASQUEZ, M. L., L. R. ROSA-COSTA, C. G. SILVA, P. F. RICCI, J. O. BARBOSA, E. L. KLEIN, E. S. LOPES, E. B. MACAMBIRA, C. L. CHAVES, J. M. CARVALHO, J. G. OLIVEIRA, G. C. ANJOS \& H. R. SILVA, 2008. Geologia e recursos minerais do estado do Pará: Sistema de Informações Geográficas - SIG: texto explicativo dos mapas geológico e tectônico e de recursos minerais do estado do Pará. In: M. L. VASQUEZ \& L. T. ROSA-COSTA (Orgs.): Escala 1:1.000.000: 118-121. CPRM, Belém.

WEDEPOHL, K. H., 1970. Rubidium. In: K. H. WEDEPOHL (Ed.): Handbook of Geochemistry: 37B-37N. Springer-Verlag, Berlin.

WIEDENBECK, M. \& K. P. WATKINS, 1993. A time scale for granitoid emplacement in the Archean Murchison Province, Western Australia, by single zircon geochronology. Precambrian Research 61(1-2): 1-26. 